\title{
Hollow cathode discharge ionization mass spectrometry: detection, quantification and gas phase ion-molecule reactions of explosives and related compounds
}

\author{
Huanhuan Hong ${ }^{\mathrm{a}, \mathrm{b}}$, Ahsan Habib ${ }^{\mathrm{a}, \mathrm{c} *}$, Lei Bi ${ }^{\mathrm{a}, \mathrm{b}}$, Deepro Sanjid Qais ${ }^{\mathrm{c}}$ and Luhong Wen ${ }^{\mathrm{a}, \mathrm{b} *}$

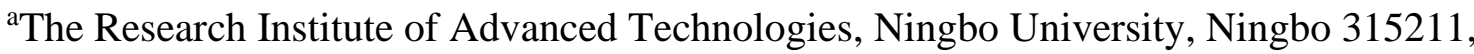 \\ Zhejiang, China \\ ${ }^{\mathrm{b}}$ China Innovation Instrument Co., Ltd, Ningbo 315000, Zhejiang, China \\ cDepartment of Chemistry, University of Dhaka, Dhaka 1000, Bangladesh \\ *Corresponding author's e-mail: habibchem@du.ac.bd (A. Habib); \\ wenluhong@nbu.edu.cn (L. Wen)
}

\begin{abstract}
Mass spectrometry (MS) has become an essential analytical method in every sector of science and technology. Because of its unique ability to provide direct molecular structure information on analytes, an extra method is rarely required. This review describes fabrication of a variable-pressure hollow cathode discharge (HCD) ion source for MS in detection, quantification and investigation of gas-phase ion molecule reactions of explosives and related compounds using air as a carrier gas. The HCD ion source has been designed in such a way that by altering the ion source pressures, the system can generate both HCD and conventional GD. This design enables for the selective detection and quantification of explosives at trace to ultra-trace levels. The pressure-dependent HCD ion source has also been used to investigate ion-molecule reactions in the gas phase of explosives and related compounds. The mechanism of ion formation in explosive reactions is also discussed.
\end{abstract}

Keywords: Hollow cathode discharge (HCD) ion source; explosives and related-compounds; simultaneous detection; oxidation; adduct ions; Birch type reduction; hydride-adduct ions; miniature-MS system; real time analysis. 


\section{Introduction}

Mass spectrometry (MS) is essentially a 'weighing' technique for molecules and/or elements. This is obviously not done using a conventional balance. MS, on the other hand, is based on the motion of a charged particle, called an ion, in an electric or magnetic field. This motion is influenced by the ion's mass to charge ratio $(\mathrm{m} / \mathrm{z})$. Because the charge of an electron is known, the mass to charge ratio can be used to calculate the mass of an ion. For a long time, organic chemists employed MS to elucidate the structure of unknown compounds [1-6]. Later, this novel technique became an essential analytical tool in analytical science for detecting and quantifying the analytes of interest at trace to ultra-trace levels [7-32]. The MS has proven to be a useful analytical tool for analyzing the kinetics of organic dye degradation $[33,34]$.

The MS technique has been widely used in biological science, such as proteomics, metabolomics, and lipidomics, due to its remarkable ability to characterize any molecules [3544]. Recent applications of MS in the development of environmental monitoring systems such as single particle aerosol-MS (SPA-MS), single photon ionization-MS (SPI-MS), volatile organic compounds (VOCs) analyzers, and so on, have demonstrated its multipurpose uses $[45,46]$. The development of the MS-imaging system is a turning point in the scientific world since it allows for precise medical diagnosis of tumors, cancer, and other diseases by analyzing complex biomolecules [47-50]. Because the MS approach allows for the direct identification and quantification of analytes of interest, space scientists and technologists are employing MSbased analytical techniques [51,52]. The National Aeronautics and Space Administration (NASA) employed the MS technique to investigate the Space Shuttles' air quality and propellant leaking as well [53].

Despite the fact that the periodic table restricts the number of elements to 118 , these 118 elements can form thousands of compounds. As a result, substantial effort has gone into developing new analytical methods capable of analyzing the compounds as required. Because MS techniques provide direct molecular structure information on the analytes of interest, they stood out among the many analytical methods as promising instruments in science and technology. It is worth noting that analyte molecules should first be in a gaseous state before being ionized efficiently with the help of an appropriate ionization source.

Almost all compounds, with the exception of proteins, peptides, and nucleic acids, exist in a neutral state. Because it is required to ionize neutral molecules, the ion source is referred to be the MS's heart in MS. When it comes to quantification, the effectiveness of the ionization source determines the performance of MS. As a result, developing effective ion sources is essential. Traditional ion sources including electron ionization (EI) [54,55], chemical 
ionization (CI) [56-58], fast atom bombardment (FAB) ionization [59-61], Penning ionization [62-64] and electrospray ionization (ESI) [65-68] require a vacuum system, which makes the MS heavier and bulkier, whereas miniaturized-MS system is required for practical applications. The development of ambient ion sources is the only approach to fabricate miniaturized-MS systems that can analyze relevant analytes at trace to ultra-trace levels. Accordingly, many efforts have been made to develop ambient ion sources for mass spectrometer, such as desorption electrospray ionization (DESI) [69-73], probe electrospray ionization (PESI) [7476], atmospheric pressure chemical ionization (APCI) [17,18,77-79], direct analysis in real time (DART) [80-82], matrix-assisted laser desorption/ionization (MALDI) [83-90] and desorption atmospheric pressure chemical ionization (DAPCI) [91], electrospray-assisted laser desorption/ionization (ELDI) [92], dielectric barrier discharge ionization (DBDI) [21,2830,93-99].

As stated previously, MS-based techniques' excellent analytical performance has expanded their applications beyond chemistry to proteomics, lipidomics, metabolomics, genomics, environmental monitoring systems, and even space shuttles. In analytical science, the main goals of MS are to identify and quantify relevant analytes at trace to ultra-trace levels, but in fundamental organic chemistry, structural elucidation is the ultimate goal. In organic chemistry, for structural elucidation of unknown compounds, analyte molecules are targeted to break down into fragments either using hard ionization or collision induced dissociation (CID). Ion sources such as CI, FAB, APCI etc have been widely used as hard ionization sources. However, soft ionization methods, such as ESI, nano-ESI, PESI, DESI, MALDI etc have been used to ionize analytes of interest in order to improve sensitivity in analytical science. Because of the significant fragmentation of the neutral analyte molecules caused by hard ionization, the sensitivity is reduced.

On the other hand, fragmentation may improve the sensitivity of particular analytes. For example, when 1,3,5-trinitroperhydro-1,3,5-triazine (RDX) was fragmented to ([M-NO${ }_{2-}$ $\left.\mathrm{HNO}_{2}\right]^{-}, m / z, 129$ ), the limit of detection (LOD) was found to be $10.33 \pm 0.45 \mathrm{pg}$, whereas the LOD for its adduct ion, $\left(\left[\mathrm{RDX}+\mathrm{NO}_{3}\right]^{-}, m / z 284\right)$ was $30.75 \pm 0.95 \mathrm{pg}[21,23,29-31]$. According to McLuckey et al. (1996), RDX's sensitivity has increased as it has fragmented to ([RDX$\left.\mathrm{NO}_{2}\right]^{-}, m / z$ 176) [7]. The better sensitivity for RDX was also found as RDX fragmented to $\left[\mathrm{RDX}-\mathrm{NO}_{2}\right]^{-}$that appeared at $\mathrm{m} / \mathrm{z} 176$ under 0.8 Torr of air pressure using glow discharge ion source [7]. They also reported that fragmentation of the parent ion, ([RDX-NO $\left.]^{-}, m / z 176\right)$, to $\left(\left[\mathrm{CH}_{2} \mathrm{NCH}_{2} \mathrm{NNO}_{2}\right]^{-}, m / z, 102\right)$ in MS/MS mode can detect only $0.5 \mathrm{pg}$ of RDX [7]. The results revealed that under the negative mode of operation, some of the fragmented molecules have a 
stronger electron affinity than the parent molecules. The ESI, nano-ESI, PESI, DESI, MALDI etc systems serve as both an ion source and a desorption process for semi-volatile and nonvolatile compounds. The essential step in the MS analysis is gasification of the analytes of interest. We recently developed an ultrasonic cutter-based desorption method for gasification of highly nonvolatile compounds such as explosives, drugs of abuse, herbicides, steroids, ionic liquids, rhodamine $\mathrm{B}$, sugars etc, which were ionized using a homemade He-DBDI and analyzed using an ion trap MS [21,29,30].

The focus of this review is on the development of a variable-pressure hollow cathode discharge (HCD), a quasi-ambient, ion source for mass spectrometry that uses air as the carrier gas for practical applications. The designed HCD ion source (Fig. 1) has been employed successfully in conjunction with a linear ion trap MS for explosive detection and quantification at trace to ultra-trace levels. The HCD ion has also been used to investigate gas phase ionmolecule reactions involving explosives and related compounds. The use of air as a carrier gas in the HCD ion source eliminates the need for reagent gas changes (e.g., He or Ar). An ambient ion source like this could enable the development of a miniature-MS system capable of quickly analyzing illicit substances in the real world. The HCDI-MS system's versatility in analyzing explosives in both negative and positive modes of operation at trace to ultra-trace levels is demonstrated in Scheme 1.

\begin{tabular}{|c|c|c|c|}
\hline \multicolumn{4}{|c|}{ Abbreviations } \\
\hline ac & Alternating current & i.d. & Inner diameter \\
\hline ADNT & Amino-dinitrotoluene & kcal & Kilocalorie \\
\hline AN & Ammonium nitrate & $\mathrm{kV}$ & kilo volt \\
\hline $\mathrm{Ar}$ & Argon & LOD & Limit of detection \\
\hline APCI & Atmospheric pressure chemical ionization & LTQ & Linear ion trap quadrupole \\
\hline ac-APCI & $\begin{array}{l}\text { Alternating current- atmospheric pressure } \\
\text { chemical ionization }\end{array}$ & LC-MS & $\begin{array}{l}\text { Liquid chromatography-mass } \\
\text { spectrometry }\end{array}$ \\
\hline APPI & Atmospheric pressure photon ionization & $m / z$ & Mass-to-charge \\
\hline AAS & Atomic absorption spectrophotometer & MS & Mass spectrometry \\
\hline AES & Atomic emission spectrophotometer & MS/MS & Mass spectrometry/mass spectrometry \\
\hline $\mathrm{CA}$ & California & MALDI & $\begin{array}{ll}\text { Matrix-assisted } & \text { laser } \\
\text { desorption/ionization } & \end{array}$ \\
\hline $\mathrm{CI}$ & Chemical ionization & $\begin{array}{l}\text { MALDI- } \\
\text { ToF }\end{array}$ & $\begin{array}{l}\text { Matrix-assisted laser } \\
\text { desorption/ionization-time of flight }\end{array}$ \\
\hline CID & Collision induced dissociation & $\mathrm{mA}$ & Milli ampere \\
\hline DFT & Density functional theory & $\begin{array}{l}\text { mol } \\
\text { nano-ESI }\end{array}$ & $\begin{array}{l}\text { Mole } \\
\text { Nano-electrospray ionization }\end{array}$ \\
\hline DAPCI & $\begin{array}{l}\text { Desorption atmospheric pressure } \\
\text { chemical ionization }\end{array}$ & ng & Nanogram $\left(=10^{-9} \mathrm{~g}\right)$ \\
\hline DESI & Desorption electrospray ionization & NASA & $\begin{array}{l}\text { National Aeronautics and Space } \\
\text { Administration }\end{array}$ \\
\hline DBDI & Dielectric barrier discharge ionization & NG & Nitroglycerine \\
\hline DNT & Dinitrotoluene & PETN & Pentaerythritol tetranitrate \\
\hline DART & Direct analysis in real time & $\mathrm{pg}$ & Picogram $\left(=10^{-12} \mathrm{~g}\right)$ \\
\hline
\end{tabular}




\begin{tabular}{|c|c|c|c|c|}
\hline $\mathrm{dc}$ & Direct current & PESI & \multirow{2}{*}{\multicolumn{2}{|c|}{$\begin{array}{l}\text { Probe electrospray ionization } \\
\text { Radiofrequency }\end{array}$}} \\
\hline dc-APCI & $\begin{array}{l}\text { Direct current-atmospheric pressure } \\
\text { chemical ionization }\end{array}$ & $\mathrm{Rf}$ & & \\
\hline $\mathrm{eV}$ & Electron-volt & SPA-MS & $\begin{array}{l}\text { single particle } \\
\text { spectrometry }\end{array}$ & aerosol-mass \\
\hline ELDI & $\begin{array}{l}\text { Electrospray-assisted } \\
\text { desorption/ionization }\end{array}$ & SPI-MS & $\begin{array}{l}\text { Single photon } \\
\text { spectrometry }\end{array}$ & ionization-mass \\
\hline ESI & Electrospray ionization & SMC & Sintered Metal Corp & ation \\
\hline EIC & Extracted ion current & $\mathrm{MS}^{2}$ & Tandem mass spectr & netry \\
\hline EESI & Extractive electrospray ionization & HMX & $1,3,5,7$-tetranitro- 1,3 & ,7-tetrazoctane \\
\hline EESI-MS & $\begin{array}{l}\text { Extractive electrospray ionization-mass } \\
\text { spectrometry }\end{array}$ & $\mathrm{TIC}$ & Total ion current & \\
\hline FAB & Fast atom bombardment & TATP & Triacetone triperoxic & \\
\hline fg & Femtogram $\left(=10^{-15} \mathrm{~g}\right)$ & TNB & Trinitrobenzene & \\
\hline GD & Glow discharge & RDX & 1,3,5-Trinitroperhyd & -1,3,5-triazine \\
\hline $\mathrm{He}$ & Helium & TNT & Trinitrotoluene & \\
\hline HMTD & Hexamethylene triperoxide diamine & UV & Ultraviolet & \\
\hline HCD & Hollow cathode discharge & USA & United States of Am & ica \\
\hline HCDI & Hollow cathode discharge ionization & VOCs & Volatile organic con & ounds \\
\hline $\begin{array}{l}\text { HCDI- } \\
\text { MS }\end{array}$ & $\begin{array}{l}\text { Hollow cathode discharge ionization- } \\
\text { mass spectrometry }\end{array}$ & & & \\
\hline
\end{tabular}

\section{HCD ion source}

The developed variable pressure HCD ion source and its image are depicted in Figures 1(a) and (b), respectively. Instead of He or Ar, air has been used as a carrier gas in the HCD ion source to generate the glow discharge. This design may make the HCDI-MS system appropriate for application in public places such as airports, train stations, cultural centers, and other locations for the detection of prohibited chemicals such as explosives, drugs of abuse etc. The use of air as a carrier gas in the HCD ion source eliminates the requirement for reagent gas changes on a regular basis. The HCD ion source was kept running at 5 Torr for a month using air as the carrier gas to test its resilience, and no substantial corrosion inside the electrodes or insulators was visible to the naked eye.

The ion source was fabricated with two inlets for introducing samples in ambient conditions (Fig. 1a). The length and inner diameter (i.d.) of the stainless-steel capillary inlets are 10 and $0.25 \mathrm{~mm}$, respectively. The HCD ion source is made up of two stainless steel metallic electrodes. An insulator composed of ceramic with a thickness of 5-6 mm separates the two electrodes. Inlet- 1 is connected to the cathode, whereas inlet- 2 is connected to the flange of the ion source that acts as an anode (Fig. 1a). Throughout the experiment, inlet-1 was used for ambient sampling while inlet-2 was closed. The cathode (length: $2 \mathrm{~mm}$; i.d.: $2 \mathrm{~mm}$ ) was connected to a high-voltage power supply (Pulse Electronic Engineering Co. Ltd, Chiba, Japan), while the anode (flange) was held at ground potential.

The pressure of the HCD ion source can be varied by inserting a $1 \mathrm{~mm}$ diameter aperture between the flange and the transfer tube (Fig. 1a). Installing a pressure gauge (SMC, Tokyo, 
Japan) at the port of inlet-2 allowed the gas pressure in the HCD ion source to be measured. After the aperture was placed between the flange and the transfer tube, the pressure gauge showed a gas pressure of 28-30 Torr, whereas it was 5 Torr when the aperture was removed. In order to determine an empirical flow rate of the analyte of interest, the flow rate of air through inlet-1 was calculated, and the calculated flow rate was found to be $360 \mathrm{~mL} / \mathrm{min}$ [23,30-32]. The ions generated in the HCD ion source were transmitted to the S-lens of a linear ion trap mass spectrometer (LTQ XL, Thermo Scientific, San Jose, CA, USA) using a stainlesssteel transfer tube. In the MS's initial pumping stage, a rotary vane pump was employed to keep the pressure at 1 Torr. It should be noted that running an ion trap mass spectrometer properly necessitates a high vacuum environment.

To generate HCD plasma, high-voltage power was supplied to the cathode. To keep the HCD glow stable, the potential was just above the gaseous breakdown voltage threshold. For the ion source pressures of 5 and 28 Torr, the potential and current were kept constant at -1.30 $\mathrm{kV}(0.3 \mathrm{~mA})$ and $-1.62 \mathrm{kV}(0.3 \mathrm{~mA})$, respectively. The discharge current was kept relatively low in this study to allow soft ionization of the labile explosives, but Ganeev et al. (2007) claimed that the HCD ion source may be operated over a wide range of currents, ranging from a few $\mathrm{mA}$ to several hundreds of $\mathrm{mA}$ [100].In order to investigate the ionization mechanism of the relevant explosives with ion source pressure of 1 Torr, a dc plasma was generated between the transfer tube and the S-lens by applying $+0.85 \mathrm{kV}(0.12 \mathrm{~mA})$ and $-0.85 \mathrm{kV}(0.15 \mathrm{~mA})$ to the transfer tube in the positive and negative ion modes, respectively (Fig. 1a).

The ions generated by the HCD ion source for the explosives of interest were monitored using a linear ion trap mass spectrometer by altering the experimental settings as follows: 150$200{ }^{\circ} \mathrm{C}$ for ion transport tube; $80 \%$ for S-lens and $600-800 \mathrm{~V}$ for RF ion guide voltage. With a maximum ion injection time of $2 \mathrm{~ms}$ and a number of micro scans of 1 , auto gain control was enabled. The ions produced by the explosive compounds were characterized using tandem mass spectrometry (MS/MS). When helium was employed for collision, the collision-induced dissociation (CID) mode was used, with the collision energy ranging from 20 to 50\% [23,3032].

Exactly, $2 \mu \mathrm{L}$ solution of the relevant explosive was deposited on a microscopic glass slide and allowed to air dry. The sample spot had a diameter of around $2 \mathrm{~mm}$. The solid compounds were vaporized by heating from the backside of the sample spot with an air heater (varying from 150 to $225^{\circ} \mathrm{C}$ ) linked to a quartz nozzle (i.d. $2 \mathrm{~mm}$ ). The temperature of the heater was measured using a thermocouple. The solid explosives were gasified with hot air except for TATP, benzene, deuterated benzene, and toluene. These analytes were kept in a separate glass 
vial as a headspace because to their high vapor pressures at room temperature, and then fed into the ion source through inlet-1 for ionization (Fig. 1a).

The HCD ion source was designed for the purpose of analyzing explosive compounds [23,30-32]. TATP and HMTD mass spectra were measured in the positive mode, and RDX, PETN, TNT, NG, TNB, DNT isomers, 2A-DNT, and 4A-DNT mass spectra were measured in the negative mode by setting the ion source pressures to 1,5 and 28 Torr. The temperatures of ion sources used in explosives analysis can be found elsewhere [23,30-32].

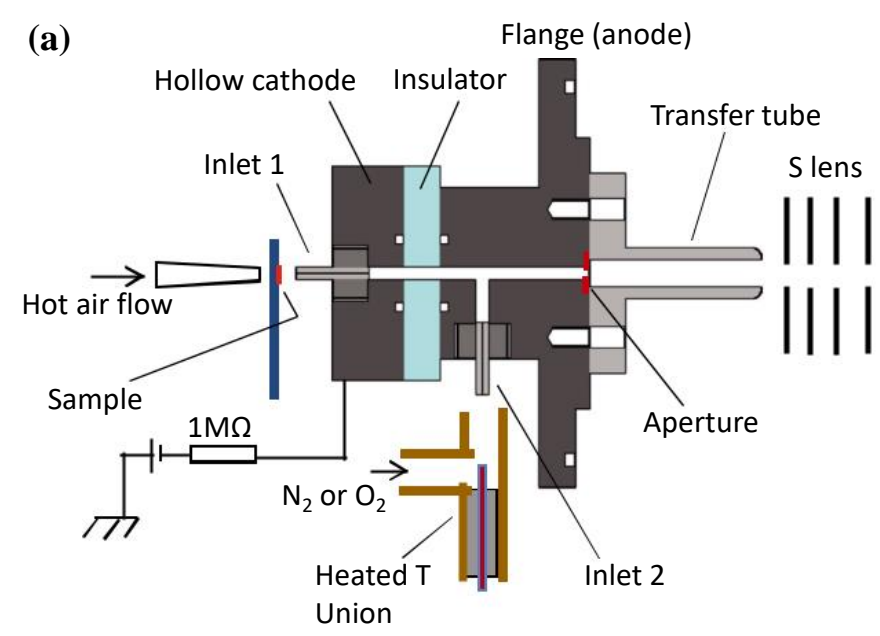

(b)

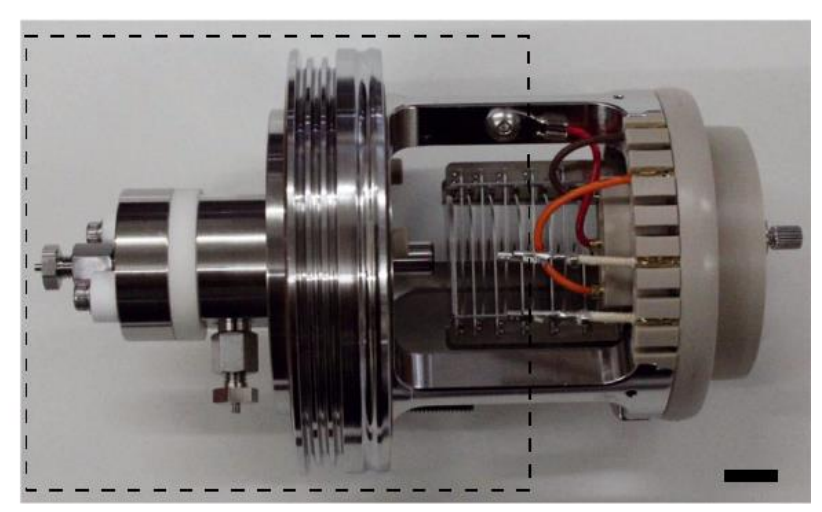

Figure 1. The HCD ion source is depicted in Figure 1(a). The cathode electrode has about 5-6 $\mathrm{mm}$ length and a $2 \mathrm{~mm}$ inner diameter. The cathode and anode are separated by a $5 \mathrm{~mm}$ thick insulator made of aluminum oxide. A $1 \mathrm{~mm}$ diameter aperture is used to introduce ions into the 1 Torr vacuum stage. To transmit ions from the ion source to the S-lens, a stainless-steel capillary (ion transfer tube) with an i.d. of $4 \mathrm{~mm}$ is used. The distance between the transfer tube's aperture and its exit is $24 \mathrm{~mm}$. The transfer tube's border and the first electrode of the S-lens are separated by about $3 \mathrm{~mm}$. A photograph of the HCD ion source is shown in Figure 
1(b). The dotted-line box surrounding the portion of the photograph represents part of (a). Wiley and Frontiers Media S.A. have granted permission for this reprint [23,30].

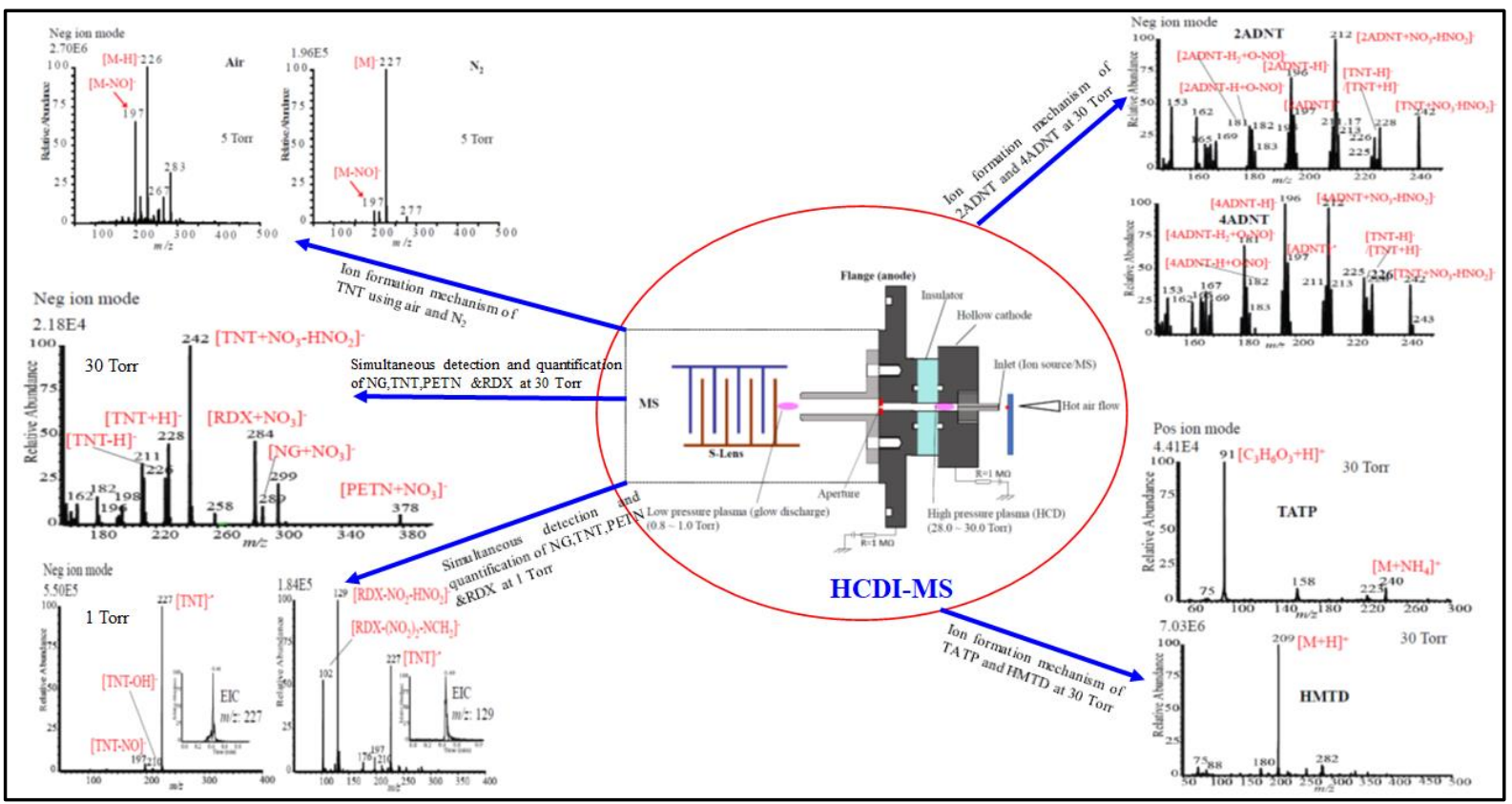

Scheme 1. The HCDI-MS system's versatility in analyzing explosives in both negative and positive modes of operation.

Figure 2(a) and (b) show the background positive and negative mass spectra of the HCD ion source obtained at 5 Torr, respectively. The primary ion signals in the positive ion mode (Fig. 2a) came from oxygen molecular ions, $\left(\mathrm{O}_{2}{ }^{+}, \mathrm{m} / \mathrm{z}, 32\right)$, and protonated acetone, $\left.\left[\left(\mathrm{CH}_{3}\right)_{2} \mathrm{CO}+\mathrm{H}\right]^{+}, \mathrm{m} / \mathrm{z}, 59\right)$; whereas, the major ions in the negative ion mode were $\left(\mathrm{NO}_{2}^{-}, \mathrm{m} / z\right.$ 46), $\left(\mathrm{CO}_{3}{ }^{-}, m / z 60\right)$, and $\left(\mathrm{NO}_{3}{ }^{-}, m / z\right.$ 62). Protonated acetone, $\left[\left(\mathrm{CH}_{3}\right)_{2} \mathrm{CO}+\mathrm{H}\right]^{+}, \mathrm{m} / z$ 59), is a reasonable base peak in the positive ion mode. This is due to the presence of organic solvents such as acetone, ethanol, methanol, ammonia etc in laboratory air. In the positive ion mode, the formation of the protonated acetone, $\left[\left(\mathrm{CH}_{3}\right)_{2} \mathrm{CO}+\mathrm{H}\right]^{+}$, ion functions as the primary regent ion for the protonation of TATP and HMTD. The HCD plasma energized the ambient air molecules, resulting in the creation of $\mathrm{NO}_{2}{ }^{-}, \mathrm{CO}_{3}{ }^{-}$, and $\mathrm{NO}_{3}{ }^{-}$ions, and they appeared in the negative ion mode, as shown in Fig. 2. (b). The mechanism of generation of $\mathrm{NO}_{2}^{-}, \mathrm{CO}_{3}^{-}$, and $\mathrm{NO}_{3}{ }^{-}$ions in plasma-excited air was also explained by Sekimoto and Takayama (2010) [123]. Other background signals in Fig. 2 were unidentified. 

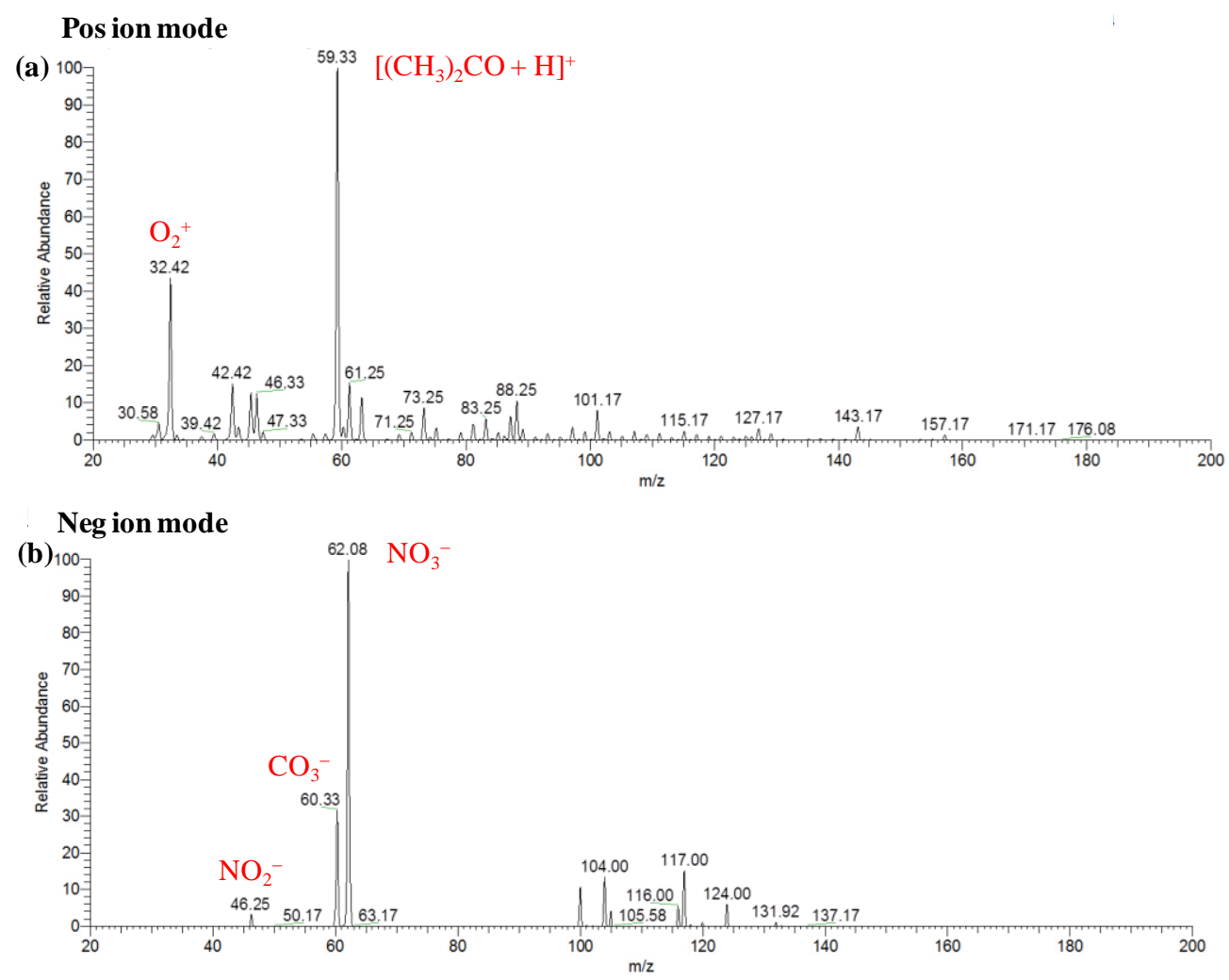

Figure 2. Background mass spectra for hollow cathode discharge (HCD) ion source measured at 5 Torr: (a) positive ion mode and (b) negative ion mode. Wiley, Frontiers Media S.A. and Elsevier have granted permission for this reprint [29-32].

In order to explore ion generation mechanisms, the fabricated HCD ion source was used to analyze explosives such as TATP, HMTD, RDX, PETN, TNT, and NG at various ion source pressures. In the positive ion mode, the formation of protonated acetone, $\left[\left(\mathrm{CH}_{3}\right)_{2} \mathrm{CO}+\mathrm{H}\right]^{+}$, as a reagent ion facilitates the formation of protonated compounds of interest such as $[\mathrm{HMTD}+\mathrm{H}]^{+}$, $[\mathrm{TATP}+\mathrm{H}]^{+}$and protonated fragment ion of TATP, $\left[\mathrm{C}_{3} \mathrm{H}_{6} \mathrm{O}_{3}+\mathrm{H}\right]^{+}, m / z$ 91)while in the negative ion mode, the formation of $\mathrm{NO}_{2}^{-}, \mathrm{NO}_{3}^{-}$leads to the formation of cluster ions of $\mathrm{RDX}$ $\left(\left[\mathrm{RDX}+\mathrm{NO}_{2}\right]^{-}, m / z \text { 268; [RDX+NO}\right]^{-}, m / z$ 284), PETN ([PETN+NO $]^{-}, m / z$ 378) and also $\left.\left([\mathrm{TNT}]+\mathrm{NO}_{2}{ }^{-} / \mathrm{NO}_{3}{ }^{-} \rightarrow[\mathrm{TNT}-\mathrm{H}]^{-}, m / z, 226\right)+\mathrm{HNO}_{2} / \mathrm{HNO}_{3}\right)[23,29-32]$.

\subsection{Importance of developing new ion sources for MS}

Only MS gives direct molecular structure information of the analyte of interest among the analytical tools, making it a vital analytical method in the detection and quantification of a wide range of compounds in all fields of science and technology. The ion source, mass analyzer, and detector are the three major components of MS. Although all three components contribute to an MS's performance, coupling and/or decoupling the new ion sources with the 
MS appears to be a simple operation. As a result, substantial effort has gone into developing new ion sources; yet, a single ion source may not be suitable for all kinds of compounds. The ESI, for example, is very successful for ionization of polar molecules, whereas glow discharge (GD) techniques such as APCI, DBDI, APPI etc are suited for non-polar compounds.

The ultimate goal of analytical chemistry is to identify and quantify analytes with a wide range of polarity at trace to ultra-trace levels. MS has two goals: (i) detection and measurement of the analyte of interest at trace to ultra-trace levels, and (ii) structural elucidation of unknown analyte molecules via fragmentation. The first fragmentation process reduces the population of neutral analyte molecules, leading to fewer effective ions. So, sensitivity is expected to be reduced; yet, fragment ions can demonstrate superior sensitivity [23,30-32]. Therefore, developing efficient ion sources that are softer, more resilient, compact, and capable of higher sensitivity is very desirable.

\subsection{HCD versus conventional GD}

Many attempts have been made to understand the processes occurring in the HCD since Friedrich Paschen's pioneering work in 1916 [29-32,101-118]. Despite the fact that the hollow cathode effect and conventional glow discharge (GD) are two distinct electrical processes, some of their properties were assumed to be the same. In fact, the nature of the processes that occur in the HCD and conventional GC was poorly understood. For the first time, Little and von Engel (1954) demonstrated that HCD causes photoelectric effect while conventional GD emits UV light $[102,119,120]$. Eichhorn et al. (1993) used experimental evidence to clarify the problematic assumptions about HCD and conventional GD [107]. For equivalent size and gas characteristics, the breakdown voltage of gaseous substances in the HCD is lower than in a conventional GD. Furthermore, the current created in the HCD is several orders of magnitude greater than that produced in the glow discharge. The HCD is an extremely effective electron generator. One of the most significant advantages of the HCD is that electrons emitted from the emitter surface can accelerate to the opposing emitter surface, which is in the shape of a hollow cylinder, and ionize gas. The energetic electron reaches the opposing surface in the $\mathrm{HCD}$, causing the electric field to slow and the electrons to return to their original position. The pendulum effect, which is present in the HCD system, allows an electron to bounce back and forth between the emitter inner surface [102]. The pendulum effect is critical for discharging insulating gaseous species at lower voltages and maintaining stable HCD conditions. Stepwise ionization, the presence of sputtered particles, and the pendulum effect all contribute to the increased ionization in the HCD [107]. The HCD system's ability to emit 
spectral lines and ionize has sparked interest in its use as a spectral emitter in atomic absorption/emission spectroscopy (AAS/AES) $[107,112,117,121,122]$ and as an ion source in MS [23,30-32].

\section{HCD ion source for explosives}

\subsection{Positive HCD mass spectra of explosives}

Positive HCD mass spectra for TATP at 5 and 28 Torr ion source pressures are shown in Figures 3(a) and $\left(\mathrm{a}_{1}\right)$, respectively. TATP had the protonated fragment ion $\left[\mathrm{C}_{3} \mathrm{H}_{6} \mathrm{O}_{3}+\mathrm{H}\right]^{+}, \mathrm{m} / 2$ 91) as the major ion, with another protonated fragment ion $\left.\left[\mathrm{C}_{3} \mathrm{H}_{6} \mathrm{O}_{2}+\mathrm{H}\right]^{+}, \mathrm{m} / z, 75\right)$ and protonated molecular ion $\left.[\mathrm{TATP}+\mathrm{H}]^{+}, m / z, 223\right)$ as minor ions, as shown in Figs. 3(a) and (a 1 , however, when the ion source pressure was held at 28 Torr, a new peak for ammoniated TATP, $\left[\mathrm{TATP}+\mathrm{NH}_{4}\right]^{+}$, was found at $\mathrm{m} / \mathrm{z} 240$. However, no ions at $\mathrm{m} / \mathrm{z} 91$ and 75 were found in a blank experiment involving the addition of methanol to the ion source. In our previous study, we also found the ammoniated TATP ion $\left(\left[\mathrm{TATP}+\mathrm{NH}_{4}\right]^{+}, \mathrm{m} / z, 240\right)$ in the positive mode of operation using the ac/dc-APCI [18]. This is due to the ammonia used in chemical laboratories for various purposes contaminating laboratory air. The adduct ion of TATP with ammonia, $\left[\mathrm{TATP}+\mathrm{NH}_{4}\right]^{+}$, $m / z$ 240), is formed when ammonia is present in the laboratory air. The formation of the $\left(\left[\mathrm{TATP}+\mathrm{NH}_{4}\right]^{+}, \mathrm{m} / \mathrm{z} 240\right)$ ion is facilitated by the presence of a sufficient amount of ammonia at high ion source pressures, such as 28 Torr. The adduct ion is formed by passing through its transition state complex, [TATP $\left.\bullet \bullet \mathrm{NH}_{4}\right]^{+*}$, and according to transition state theory, a third-body collusion is required to stabilize the intermediate transition state in order to obtain the product ion, $\left[\mathrm{TATP}+\mathrm{NH}_{4}\right]^{+}$, which can be ascribed by the equation $[18,23,30]$ :

$\mathrm{TATP}+\mathrm{NH}_{4}^{+} \rightleftarrows\left[\mathrm{TATP} \bullet \bullet \mathrm{NH}_{4}\right]^{+*} \longrightarrow\left[\mathrm{TATP}+\mathrm{NH}_{4}\right]^{+}$

where TB represents the third body.

In the upper left-hand corner of the spectra, peak intensities of the relevant ion signals are shown. The intensities of the ions at $m / z$ 91, 223 were increased by a factor 2 in Fig. 3(a $\left.a_{1}\right)$ compared to Fig. 3 (a). The formation of protonated acetone, $\left[\left(\mathrm{CH}_{3}\right)_{2} \mathrm{CO}+\mathrm{H}\right]^{+}, m / z$ 59), and/or hydronium ions, $\left(\left[\mathrm{H}_{3} \mathrm{O}\right]^{+}, \mathrm{m} / z\right.$ 19) as reagent ions in the positive ion mode is aided by high ion source pressure. The formation of the protonated ion of the relevant compounds is enhanced by the comparatively high level of reagent ions $\left[\left(\mathrm{CH}_{3}\right)_{2} \mathrm{CO}+\mathrm{H}\right]^{+} /\left[\mathrm{H}_{3} \mathrm{O}\right]^{+}$at high ion source pressure. As a result, plasma-based ionization methods appear to accelerate the formation of the protonated fragment ion $\left(\left[\mathrm{C}_{3} \mathrm{H}_{6} \mathrm{O}_{3}+\mathrm{H}\right]^{+}, m / z\right.$ 91) of TATP, which emerged at $m / z 91$. Takada et al. (2012b) used counter-flow dc corona APCI to find the protonated fragment ion for TATP, $\left[\mathrm{C}_{3} \mathrm{H}_{6} \mathrm{O}_{3}+\mathrm{H}\right]^{+}, \mathrm{m} / z$ 91) [124], whereas electrospray-based ionization methods like DESI [12] 
and extractive electrospray ionization (EESI) [125] produce protonated, sodiated and ammoniated TATP. Sigman et al. (2006) investigated the fragmentation process of the $\left([\mathrm{TATP}+\mathrm{H}]^{+}, m / z, 223\right)$ ion using chemical ionization and a theoretical calculation using density functional theory (DFT) [126]. They also detected the protonated fragment ion $\left(\left[\mathrm{C}_{3} \mathrm{H}_{6} \mathrm{O}_{3}+\mathrm{H}\right]^{+}\right.$, $m / z$ 91) for TATP.
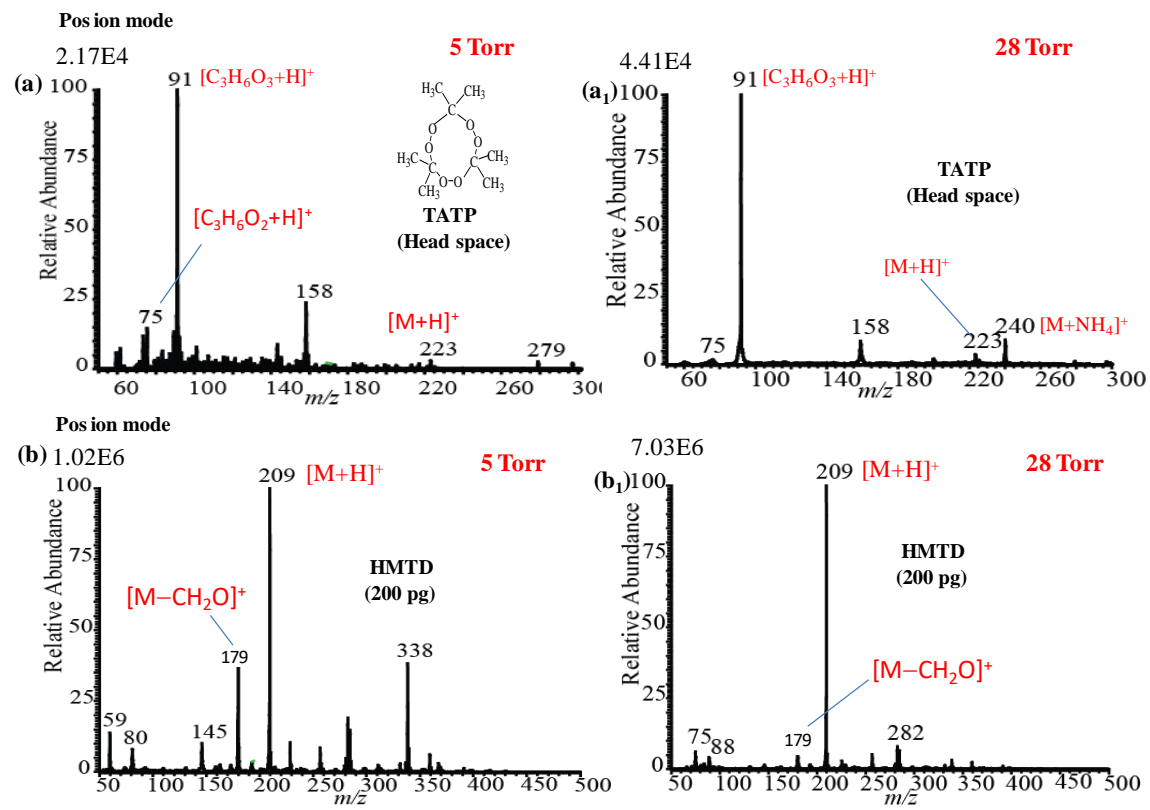

Figure 3. Positive HCD mass spectra for (a) TATP (headspace) measured at 5 Torr, (a $)$ TATP (headspace) measured at 28 Torr, (b) HMTD (200 pg) measured at 5 Torr, and ( $\left.b_{1}\right)$ HMTD (200 pg) measured at 28 Torr. Wiley and Frontiers Media S.A. have granted permission for this reprint $[23,30]$.

The mass spectra of HMTD measured by the HCD ion source at 5 and 28 Torr in the positive ion mode are shown in Figures $3(b)$ and $\left(b_{1}\right)$, respectively. The major ion was $([\mathrm{HMTD}+\mathrm{H}]+, m / z, 209)$ with a protonated fragment ion, ([HMTD $\left.\left.+\mathrm{H}-\mathrm{CH}_{2} \mathrm{O}\right]^{+}, m / z, 179\right)$, as a minor ion $[23,30]$. The protonated form of HMTD, $\left([\mathrm{HMTD}+\mathrm{H}]^{+}, m / z 209\right)$, has also been identified utilizing discharge-based ion sources $[18,21,30,127]$.As the ion source pressure increased from 5 to 28 Torr, the intensity of the protonated molecular ion [HMTD+H] ${ }^{+}$ increased by a factor of 7 and the ratio of $\left[\mathrm{HMTD}-\mathrm{CH}_{2} \mathrm{O}\right]^{+} /[\mathrm{HMTD}+\mathrm{H}]^{+}$declined (Fig. $3 b_{1}$ ). A third-body collision stabilizes a nascent protonated molecular ion when the ion source pressure is increased [128]. Under high gas pressure, electrons generated in the HCD plasma gain relatively little kinetic energy [23,30,116]. As a result, it's concluded that a high ion source pressure makes it easier to identify HMTD in its protonated form. The remaining peaks in Figures 3(b) and $\left(b_{1}\right)$ were not assigned. 
In the positive ion mode, the HCD plasma's high ion source pressure favors the formation of protonated molecular and/or protonated fragment ions. For HMTD and TATP, this is the explanation for the increased intensity of protonated ions at increasing ion source pressure. Finally, in order to identify explosive substances at trace levels, a high gas pressure in the positive HCD ion source is desirable.

\subsection{Negative HCD mass spectra of explosives}

The negative mass spectra for $1 \mathrm{ng}$ RDX measured by the HCD ion source at 5 and 28 Torr ion source pressure are shown in Figures $4(a)$ and $\left(a_{1}\right)$, respectively. At 5 Torr, RDX fragmented severely, so its fragment ion, ([RDX- $\left.-\mathrm{NO}_{2}-\mathrm{HNO}_{2}\right]^{-}, m / z$ 129), appeared as a base peak, while its adduct ions, $\left(\left[\mathrm{RDX}+\mathrm{NO}_{2}\right]^{-}, m / z, 268\right)$ and $\left(\left[\mathrm{RDX}+\mathrm{NO}_{3}\right]^{-}, m / z, 284\right)$, appeared as minor ion signals [23,29-31]. Despite the higher ion source pressure (28 Torr), the adduct ion of $\mathrm{RDX}$ with the reagent ion $\mathrm{NO}_{3}{ }^{-},\left(\left[\mathrm{RDX}+\mathrm{NO}_{3}\right]^{-}, \mathrm{m} / z, 284\right)$, showed as a significant ion, with an ion intensity 8 times that of the 5 Torr ion. The formation of the RDX adduct ion, $\left(\left[\mathrm{RDX}+\mathrm{NO}_{3}\right]^{-}, m / z 284\right)$, should be aided by a higher ion source pressure. This is because in the negative ion mode, the rate of generation of the reagent ions, $\mathrm{NO}_{2}{ }^{-}$and $\mathrm{NO}_{3}{ }^{-}$, increases as the ion source pressure rises. The presence of more reagent ions at increased gas pressure functions as a third body, increasing the collisional probability between $\mathrm{RDX}$ and $\mathrm{NO}_{3}^{-}$, allowing the transition state complex of RDX and $\mathrm{NO}_{3}{ }^{-},\left[\mathrm{RDX} \cdot \cdots \mathrm{NO}_{3}\right]^{-*}$, to achieve sufficient stabilizing energy. Under 0.8 Torr of air pressure, RDX gave mostly fragment ions by dc glow discharge ionization [7], while adduct ions of $\mathrm{RDX},\left[\mathrm{RDX}+\mathrm{NO}_{2}\right]^{-}$and $\left[\mathrm{RDX}+\mathrm{NO}_{3}\right]^{-}$, were observed as major ions using an atmospheric-pressure DBD ion source $[10,11,21,29,30,98]$.

The negative HCD mass spectra of $10 \mathrm{ng}$ of PETN recorded at 5 and 28 Torr of ion source pressures are shown in Figures $4(b)$ and $\left(b_{1}\right)$, respectively. At 5 Torr, the intensity of the fragment ion ([PETN-CH$\left.{ }_{2} \mathrm{ONO}_{2}\right]^{-}, m / z$ 240) for PETN is higher than that of the adduct ion ([PETN $\left.+\mathrm{NO}_{3}\right]^{-}, m / z$ 378) for PETN, as shown in Fig. 4(b). With increasing ion source pressure, the strength of the adduct ion $\left[\mathrm{PETN}+\mathrm{NO}_{3}\right]^{-}$rises, eventually becoming the dominant ion at 28 Torr. McLuckey et al. (1996) used a dc glow discharge in the negative ion mode to find only the fragment ion for PETN, ([PETN-CH$\left.\left.{ }_{2} \mathrm{ONO}_{2}\right]^{-}, m / z 240\right)$, by setting the ion source pressure to 0.8 Torr with air [7]. PETN, on the other hand, provided the adduct ion $\left(\left[\mathrm{PETN}+\mathrm{NO}_{3}\right]^{-}, \mathrm{m} / \mathrm{z}\right.$ 378 ) as the major ion when ionized at atmospheric pressure [10,11,21,29,30,98], which was similarly seen for RDX (Fig. 4a 1 ).

TNT has been extensively investigated among explosives, with several ion sources for mass spectrometry, including the $\mathrm{MS}^{\mathrm{n}}$ system $[18,23,30-32,95,96,98,99]$. The negative mass spectra 
for $2 \mathrm{ng}$ TNT measured by the HCD ion source at 5 and 28 Torr are shown in Figures 4(c) and $\left(\mathrm{c}_{1}\right)$, respectively. At 5 Torr, the fragment ion $\left([\mathrm{TNT}-\mathrm{H}]^{-}, \mathrm{m} / \mathrm{z}, 226\right)$ is the major ion, followed

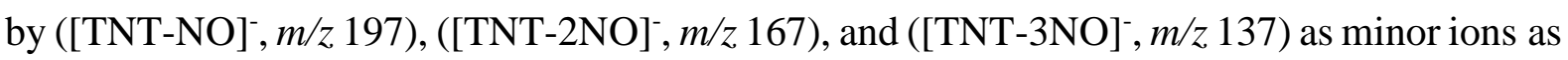
shown in Fig. 4(c). However, even at ambient conditions, TNT usually yields its molecular ion, ([TNT] $]^{-} m / z$ 227), as the major ion [18]. At 5 Torr, TNT produced an adduct, ([TNT-H+O]', $m / z 242$ ), as a minor ion. At 28 Torr (Fig. $4 \mathrm{c}_{1}$ ), the adduct ion ([TNT-H+O]', $m / z$ 242) became the major ion. It is reasonable to conclude from the mass spectra of TNT at 5 and 28 Torr that the TNT molecules were subjected to complex ion-molecule reactions in the HCD ion source [23,30-32].

Tandem mass spectrometry $\left(\mathrm{MS}^{2}\right)$ was used to monitor the collision induced dissociation (CID) products in order to analyze the generation of fragment and adduct ions from TNT molecules utilizing the HCD ion source. To monitor the $\mathrm{MS}^{2} \mathrm{CID}$ product ions, the adduct ion ([TNT-H+O $]^{-}, m / z, 242$ ) was used as a precursor ion. The MS/MS product ion spectrum for the precursor ion ([TNT-H+O $\left.]^{-}, m / z 242\right)$ is shown in the inset of Figure 4( $\left.\mathrm{c}_{1}\right)$ [23,30-32]. The first product ion, $m / z 225$, is due to the elimination of $\mathrm{OH}$ from the precursor ion, ([TNT-H+O $]^{-}$, $m / z 242$ ), the ion at $m / z 210$ is due to the elimination of NO from ([TNT]', $m / z 227$ ), the ion at $m / z 167$ is for the elimination of NO from ([TNT-NO] ${ }^{-}, \mathrm{m} / z, 197$ ), the ion at 137 is for the elimination of NO from ([TNT-2NO] $]^{-} \mathrm{m} / z, 167$ ) and the ion at $m / z, 107$ is for the elimination of NO from ([TNT-3NO] $\left.]^{-}, m / z, 137\right)$ (inset in Fig. 4c 1 ) [23,30-32].

The HCD ion source was used to investigate nitroglycerine (NG), an explosive substance, in the negative mode of operation at 1, 5, and 28 Torr of ion source pressures (data is not displayed). Unlike RDX and PETN, NG did not produce any ion signal at low ion source pressures such as 1 and 5 Torr, despite increasing the amount of NG to $10 \mathrm{ng}$; nevertheless, at 28 Torr, the adduct ion for $\mathrm{NG}$ with $\mathrm{NO}_{3}{ }^{-},\left(\left[\mathrm{NG}+\mathrm{NO}_{3}\right]^{-}, m / z, 289\right)$, was seen [23,30-32]. In the negative ion mode, $\mathrm{NG}$ can produce $\mathrm{NO}_{3}{ }^{-}$as a fragment ion, which makes it difficult to analyze $\mathrm{NG}$ at low ion source pressures $[23,29,30,127]$. This is because $\mathrm{NO}_{3}{ }^{-}$is one of the HCD ion source's reagent ions (see Fig. 2b). As adduct ions with the $\mathrm{NO}_{3}{ }^{-},\left(\left[\mathrm{NG}+\mathrm{NO}_{3}\right]^{-}, m / 2,289\right)$, the thermal instability of NG causes poor detection sensitivity. Yinon et al. (1997) also reported the formation of the $\left(\left[\mathrm{NG}+\mathrm{NO}_{3}\right]^{-}, m / z, 289\right)$ adduct ion of $\mathrm{NG}$ with $\mathrm{NO}_{3}{ }^{-}$reagent ion [129]. A preliminary experiment was carried out to evaluate the stability of NG by placing a significant amount on a metal substrate, and it was revealed that it decomposed above $100{ }^{\circ} \mathrm{C}$. 

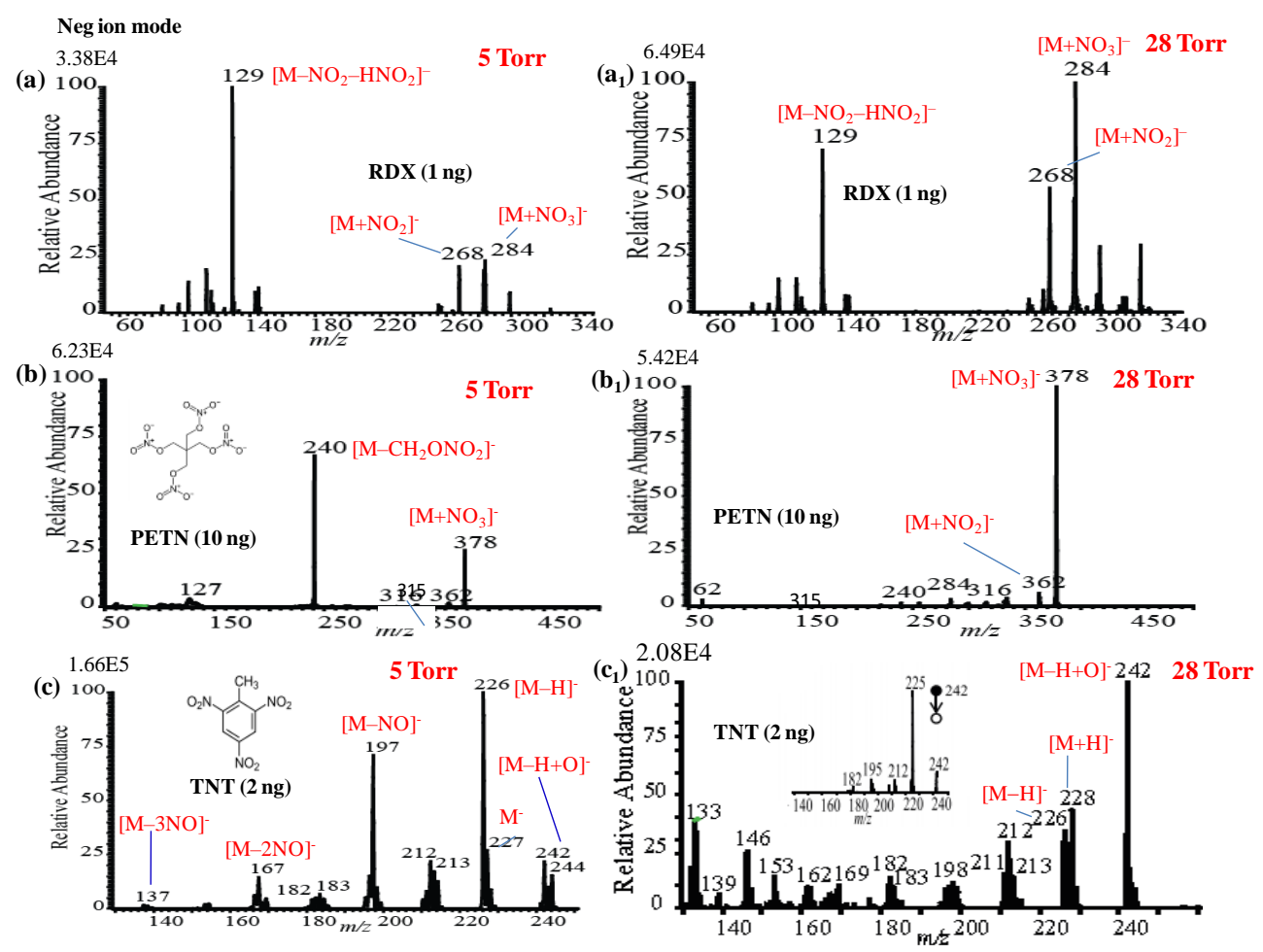

Figure 4. Mass spectra for (a) RDX (5 Torr), (a 1 ) RDX (28 Torr), (b) PETN (5 Torr), (b 1 ) PETN (28 Torr), (c) TNT (5 Torr) and ( $\left.\mathrm{c}_{1}\right)$ TNT (28 Torr) measured by the HCD ion source in the negative ion mode. The MS/MS spectrum of ([TNT-H+O $]^{-}, \mathrm{m} / z$ 242) is shown in the inset (CID: 25\%). Wiley and Frontiers Media S.A. have granted permission for this reprint [23,30].

The ion source pressures have a significant impact on the negative mass spectra of explosive chemicals (Figs. 3 and 4). In order to explore the ionization mechanism of the explosives with the ion source pressures, additional experiments for the explosives were done at a lower ion source pressure (1 Torr). By applying $+0.85 \mathrm{kV}$ and $-0.85 \mathrm{kV}$ in the positive and negative ion modes, respectively, at 1 Torr, a dc plasma was created between the transfer tube and S-lens. TATP and HMTD did not produce any ion signals in both positive and negative ion modes at 1 Torr ion source pressure, whereas RDX, PETN, and TNT produced strong ion signals in the negative mode (see Figs. 5a-c).

At 1 Torr, RDX produced the fragment ion ([RDX-NO $\left.-\mathrm{NNO}_{2}\right]^{-}, m / z$ 129) as the major ion,

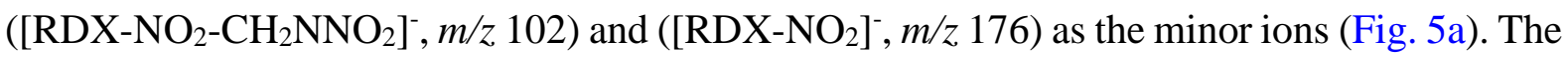
results were quite similar to those of McLuckey et al. (1996), who applied a low-pressure glow discharge ion source ( 0.8 Torr of air pressure) [7]. The mass spectrum for $10 \mathrm{ng}$ of PETN in the negative ion mode is shown in Figure 5(b). PETN only produced the fragment ion ([PETN$\left.\mathrm{CH}_{2} \mathrm{ONO}_{2}\right]^{-}, m / 2,240$ ) in the negative mode in this experiment. At 0.8 Torr of air pressure, the 
major ion was recognized as $\left[\mathrm{PETN}-\mathrm{CH}_{2} \mathrm{ONO}_{2}\right]^{-}, \mathrm{m} / z$ 240) by McLuckey et al. (1996) [7]. When the ion source pressure was kept at 1 Torr, RDX and/or PETN did not yield adduct ions such as $\left[\mathrm{M}+\mathrm{NO}_{2}\right]^{-}$or $\left[\mathrm{M}+\mathrm{NO}_{3}\right]^{-}$, but these adduct ions were formed in abundance at 5 and/or 28 Torr $[23,30,31]$.

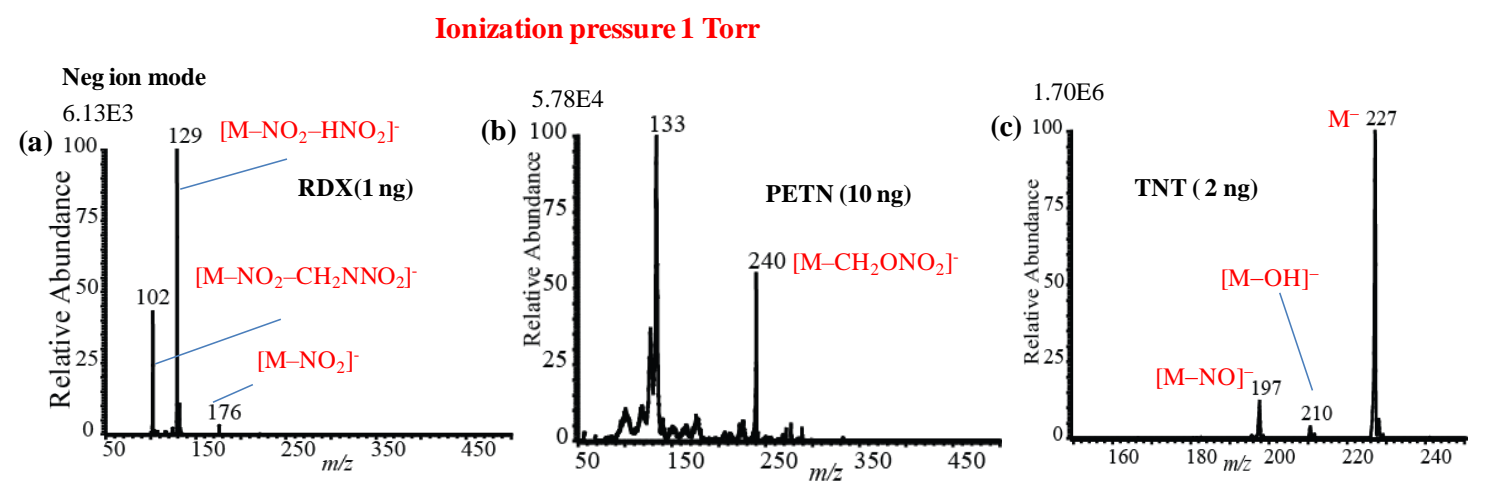

Figure 5. Mass spectra for (a) RDX (1 ng), (b) PETN (10 ng) and (c) TNT (2 ng) at 1 Torr using the HCD ion source in the negative ion mode. Wiley and Frontiers Media S.A. have granted permission for this reprint $[23,30]$.

The mass spectrum of TNT ( $2 \mathrm{ng}$ ) in the negative ion mode at 1 Torr is shown in Figure 5(c). TNT produced the molecular ion $\left(\left[\mathrm{TNT}^{-}, \mathrm{m} / \mathrm{z} 227\right)\right.$ as the major ion with a very high ion intensity (1.70E6) under 1 Torr ion source pressure, together with the minor ions ([M-NO]', $m / z$ 197) and ([M-OH] $\left.]^{-}, m / z 210\right)$ as shown in Fig. 5(c). At 1 Torr, the additional fragment ions ([M-H] $\left.]^{-}, m / z, 226\right),\left([\mathrm{M}-2 \mathrm{NO}]^{-}, m / z, 167\right)$, and the adduct ion $\left([\mathrm{M}-\mathrm{H}+\mathrm{O}]^{-}, m / z, 242\right)$ all were completely absent (see Fig. 5c). Using the fabricated HCD ion source, the explosive substances did not produce any dimer ions.

At 1 Torr, the LOD values of HMTD, RDX, PETN, and TNT are 20, 40, 800, and 2 pg, respectively. These explosive compounds' LOD values at 5 and 30 Torr can be found elsewhere [23]. The DESI [8,89], DBDI [21,29,30,93-99], and ac-APCI [18,30] all produced similar results. The HCD recorded a LOD value of $800 \mathrm{pg}$ for PETN [23], but Zhang et al. (2009) found only $500 \mathrm{fg}$ using the DBD ion source, which is 16 times lower than the HCD ion source [14]. This is reasonable because the DESI and DBDI generate ions in ambient conditions and introduce them directly into the mass spectrometer, avoiding thermal degradation of the compounds of interest and their ions. The generated ions in the HCD ion source, on the other hand, may be subject to thermal breakdown due to the high temperature $\left(150{ }^{\circ} \mathrm{C}\right)$ of the ion source observed in this work [23,30]. The HCD ion source's small size also permits the generated ions to be neutralized by hitting the ion source's walls under lower pressure. 
Except for TNT at 1 Torr, where TNT was observed as its molecular ion, ([TNT] ${ }^{-}, m / z$ 227) with the strongest ion signal, the intensities (digits at the top in each spectrum) of the observed ions rose with increased ion source pressure (ion intensity 1.70E6) (Figs. 4 and 5). Because TNT molecules have a positive electron affinity, the electron capturing mechanism became more advantageous when the ion source pressure was low [23,30-32]. In the negative ion mode, a lower ion source pressure is appropriate for detecting TNT with better sensitivity; however, RDX, PETN, and NG in the negative ion mode, and TATP and HMTD in the positive ion mode, displayed better sensitivity with low LOD under higher ion source pressures. The ion generation mechanism for explosive compounds employing the HCD ion source was extensively described in this review paper [23,30-32].

Compounds containing nitro and nitro-groups have a positive electron affinity; for example, the electron affinity of $\mathrm{NO}_{3}$ is $3.92 \mathrm{eV}$ [130], while that of TNT is only $2.50 \mathrm{eV}$ [23,30-32,130]. Cooper et al. (2012) applied ab initio calculations to determine the values of the electron affinities for RDX, HMX, TNT, and PETN, and they revealed that these explosive chemicals have positive electron affinities [131]. Except for TNT in the negative mode of operation, none of these explosive compounds formed the molecular ion $[\mathrm{M}]^{-*}$. The findings imply that RDX, PETN, and NG prefer adduct/cluster ion production with reagent ions, such as $\mathrm{NO}_{2}{ }^{-} / \mathrm{NO}_{3}{ }^{-}$, over electron capture in the $\mathrm{HCD}$ ion source. Other groups that employed plasma-based ionization methods found similar results $[10,11,14,16,21,30]$. The $\mathrm{NO}_{\mathrm{x}}$ is one of the major products in plasma-excited air [23,30-32,132,133]. Because of their higher electron affinity than the relevant explosives, the nitro-species $\left(\mathrm{NO}_{\mathrm{x}}\right)$ generated in plasma-excited air preferentially capture electrons, resulting in a decrease in the signal strength of the $[\mathrm{TNT}]^{-\bullet}$ ion with pressure [23,30-32].

Among the explosive compounds, TNT ionization is strongly dependent on the ion source pressure (see Figs. 4(c), (c1), and 5(c)). Additional experiments were carried out using air and nitrogen as carrier gases to examine the ion generation mechanism of TNT molecules with ion source pressure. Figure 6(a) illustrates a schematic of the manufactured HCD ion source, which has two inlets: inlet-1 was used to introduce the analytes into the ion chamber with air while inlet-2 was closed (see Fig. 6). A sample was introduced through inlet-2 while inlet-1 was closed to confirm the ionization of TNT with varying ion source pressures, as illustrated in Fig. 6(a). The negative HCD mass spectra of TNT for air and $\mathrm{N}_{2}$ as carrier gas are shown in Figures 6(b) and (c), respectively. Because air was the carrier gas, there was no molecular ion of TNT,

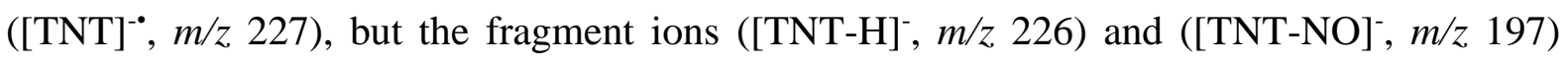
occurred with considerable intensities, with $\left(\left[\mathrm{TNT}^{-\mathrm{H}}\right]^{-}, \mathrm{m} / z\right.$ 226) being the major ion (Fig. 
6(b)). Using $\mathrm{N}_{2}$ as a carrier gas, on the other hand, the molecular ion for TNT, ([TNT] ${ }^{-*}, \mathrm{~m} / \mathrm{z}$ 227), appeared as the major ion with a strong intensity, while the fragment ion, ([TNT-H] $]^{-}, m / z$ 226), disappeared completely (Fig. 6(c)). TNT also produced another fragment ion, ([TNT$\mathrm{NO}^{-}, m / z$ 197), however it had a low intensity. The ionization mechanism of TNT was investigated using ambient ion sources such as DBDI [10,11,13,14,97,135], dc-corona APCI [134], electrospray-based methods [8,125,129], and ac-corona APCI [18]. TNT produced its molecular ion, ([TNT] $\left.]^{-*}, m / z, 227\right)$, using electrospray-based ionization methods, while the fragment ion, ([TNT-H] $\left.]^{-}, m / z, 226\right)$, was rarely observed $[8,125,129]$.

Using discharged-based ionization methods, TNT yielded both the fragment ion, ([TNT$\mathrm{H}]^{-}, m / z, 226$ ), and the molecular ion, ([TNT $\left.]^{-}, m / z, 227\right)$, with high ion intensities [911,14,23,30-32,135]. Using the desorption atmospheric pressure chemical ionization (DAPCI), Song and Cooks (2006) found that TNT gave strong ion signals of the ([TNT-H $\left.]^{-}, m / z 226\right)$ and $[\mathrm{TNT}]^{-}, m / z$ 227) [9]. The strong signals of the ([TNT-H $]^{-}, m / z$ 226) and ([TNT] $\left.]^{\bullet}, m / z 227\right)$ were also obtained by dielectric barrier discharge ionization (DBDI) [10,11,14,135]. As a result, the relative ratio of $[\mathrm{TNT}]^{-\bullet}$ and $[\mathrm{TNT}-\mathrm{H}]^{-}$is found to be influenced by the ionization methods. The relative ratios of the $[\mathrm{TNT}]^{-\bullet}$ and $[\mathrm{TNT}-\mathrm{H}]^{-}$ions are affected by the presence of air in the plasma as well [23,30-32,135]. Because of the use of helium plasma in DART, there was a high signal of the $[\mathrm{TNT}]^{-}$ion $[77,79]$. The relative abundances of $[\mathrm{TNT}]^{-}$and $[\mathrm{TNT}-\mathrm{H}]^{-}$ are determined by the presence or absence of air in the plasma/glow. As a result, it can be stated that analyzing explosives at the trace-level is a challenging task from an analytical standpoint.

In conclusion, the developed HCD ion source had better sensitivity for analyzing explosives such as HMTD, TATP, RDX, PETN etc in both positive and negative ion modes under high ion source pressures, e.g., 5 and 28 Torr, but the low ion source pressure HCD (1 Torr) gave ultra-trace level detection for TNT (LOD 2 pg) in the negative ion mode $[23,30]$. Through ionmolecule reactions, no cluster ions were seen from RDX and PETN at 1 Torr, however these two explosives generated fragment ions with improved sensitivity, especially RDX at lower ion source pressures (1 Torr). Under low ion source pressure (e.g., 1 Torr) in the HCD plasma, electron density reaches maximum levels, allowing compounds with positive electron affinity to participate in electron attachment processes. Accordingly, electron attachment processes revealed TNT's molecular ion, ([TNT]', $m / z$ 227), as the main ion, whereas electron capture dissociation in the negative ion mode revealed RDX and PETN at 1 Torr [23,30]. Electron affinity of TNT was calculated to be between 0.6 and $0.7 \mathrm{eV}$ [136]. At low ion source pressure, the electron capture dissociation processes of RDX and PETN yielded their fragment ions as the major ions ( 1 Torr). At higher ion source pressures such as 5 and 28 Torr, RDX and PETN 
generated cluster ions with the reagent ions, namely $\mathrm{NO}_{2}{ }^{-}, \mathrm{NO}_{3}{ }^{-}$, whereas $\mathrm{AN}$ produced cluster ions of $\mathrm{HNO}_{3}$ with $\mathrm{NO}_{3}{ }^{-},\left(\left[\mathrm{HNO}_{3}+\mathrm{NO}_{3}\right]^{-}, \mathrm{m} / z, 125\right)[23,30]$. This is because in plasma-excited air, $\mathrm{AN}$ decomposes to $\mathrm{HNO}_{3}$, and the resulting $\mathrm{HNO}_{3}$ forms a cluster ion with the majority $\mathrm{NO}_{3}{ }^{-}$ion in the HCD ion source. TNT had the most pressure-dependent mass spectra of all the explosive chemicals. The predominant ion signal for TNT at 1 Torr was its molecular ion, ([TNT] $\left.]^{-*}, m / z 227\right)$; however, as the ion source pressure increased from 1 to 28 Torr, fragment ions such as [TNT-H $]^{-}$, [TNT-nNO $^{-}(\mathrm{n}=1-3)$, and $\left([\mathrm{TNT}-\mathrm{H}+\mathrm{O}]^{-}, m / z\right.$ 242) became prominent ions. The formation of these fragment ions is thought to be caused by the presence of $\mathrm{NO}_{2}^{-}$, $\mathrm{NO}_{3}{ }^{-}$, and $\mathrm{O}_{3}$ in the $\mathrm{HCD}$ ion source. The detection limits for the explosives studied were slightly greater than those reported by DESI, DBDI, and/or DAPCI, but the current HCD ion source proved to be reliable, compact, and simple to use. Furthermore, the HCD ion source's use of air as a carrier gas makes it suitable for usage in practical applications.
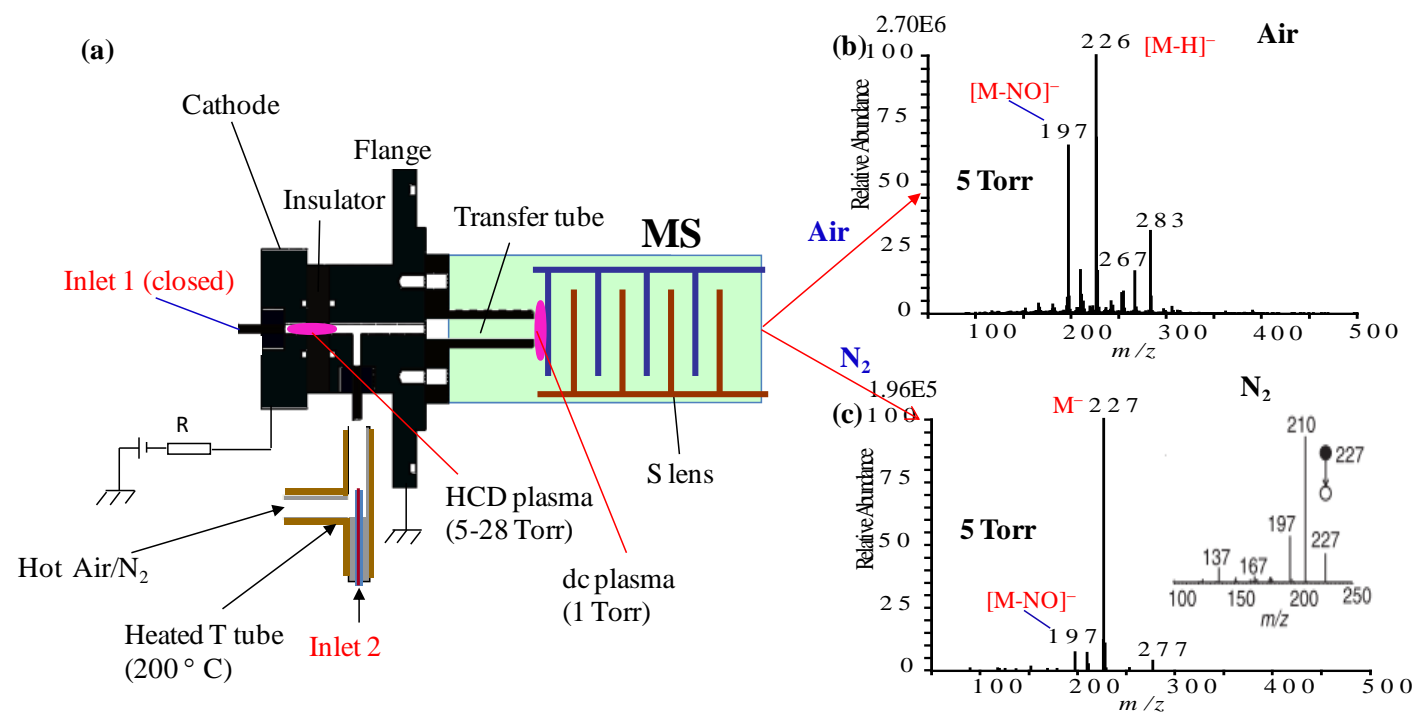

Figure 6. A diagram of the HCD ion source (a) (details are shown in Fig. 10). Mass spectra of TNT using air (b) and $\mathrm{N}_{2}$ (c) as carrier gas in the negative ion mode under ion source pressure 5 Torr. The inset depicts the MS/MS mass spectrum for the TNT molecular ion, $\left([\mathrm{TNT}]^{-}, \mathrm{m} / \mathrm{z}\right.$ 227), with $25 \%$ of CID. Wiley and Frontiers Media S.A. have granted permission for this reprint $[23,30]$.

\subsection{Explosives analysis in real time using HCD at $\sim 28.0-30.0$ Torr}

Real-time explosive assessment is essential for public safety and security. This is because terrorists are developing new explosive chemicals to deploy in public places. As a result, for a practical monitoring system, a fast, easy, and reliable analytical method for simultaneous detection of explosives from their mixture is highly desirable. Figure 7(a) depicts the real-time 
analysis of NG, TNT, PETN, and RDX utilizing the modified HCD ion source in negative mode at 28.0-30.0 Torr of air pressure, whereas Figure 7(b) depicts the modified HCD ion source in schematic form. Details are shown in Figure 1.

Negative HCD mass spectra of $1 \mathrm{ng}$ of each NG, TNT, PETN and RDX at the higher ion source pressure ( 28.0-30.0 Torr) using air as a carrier gas are shown in Figures 8(a), (b), (c) and (d), respectively, whereas Figure 8(e) depicts the total ion current (TIC). NG, PETN, and RDX displayed adduct ions with predominantly $\mathrm{NO}_{3}{ }^{-}$ions, $\left[\mathrm{M}+\mathrm{NO}_{3}\right]^{-}$(Fig. 8a, c and d), while TNT showed a strong ion signal of $\left[\mathrm{TNT}+\mathrm{NO}_{3}-\mathrm{HNO}_{2}\right]^{-}, \mathrm{m} / z, 242$ ) with weak fragment ions (Fig. 8b). The extracted ion current (EIC) of the relevant ions is shown in the insets of Figures 8(a)-(d). The values of EIC for ions of $m / z 289$ (NG), 242 (TNT), 378 (PETN), and 284 (RDX) are $0.40,0.40,0.41$, and $0.42 \mathrm{~min}$, respectively. NG, TNT, PETN, and RDX have vapor pressures of about $\sim 10^{-4}, 10^{-7}$, and $\sim 10^{-9}$ Torr $\left(20^{\circ} \mathrm{C}\right)$, respectively (insets in Figs. 8a-d). The appearance of varied EIC values is due to variations in the vapor pressures of the explosives.

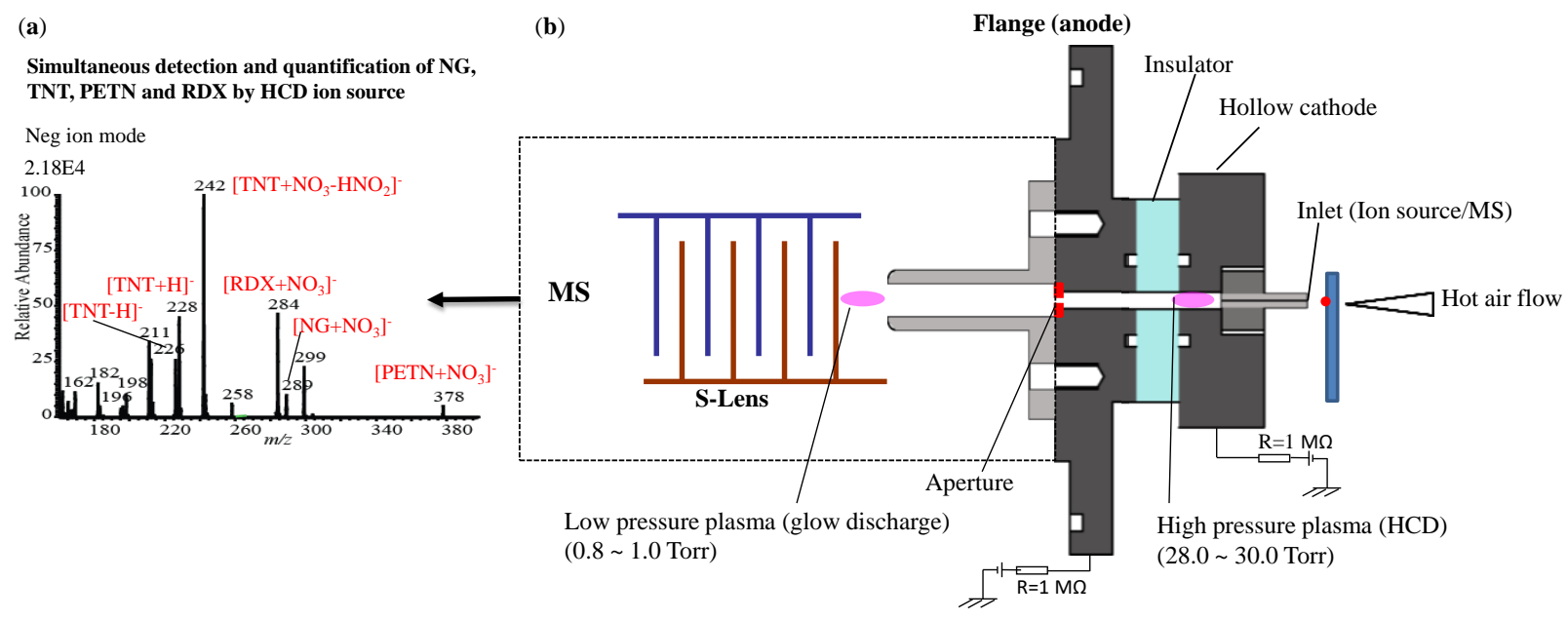

Figure 7. Real time analysis of NG, TNT, PETN and RDX under 28.0-30.0 Torr of air pressure by the modified HCD ion source (a) and a diagram of the modified HCD ion source (b) (details are shown in Fig. 1). This reprint has been approved by Elsevier [31].

A weak ion signal of the adduct ion for $\mathrm{NG}$ with $\mathrm{NO}_{3}{ }^{-},\left(\left[\mathrm{NG}+\mathrm{NO}_{3}\right]^{-}, m / z, 289\right)$, was detected based on the EIC for the $m / z 289$ (NG) ion, whereas TNT gave the adduct ion $\left[\mathrm{TNT}+\mathrm{NO}_{3}-\right.$ $\left.\mathrm{HNO}_{2}\right]^{-}, m / z, 242$ ), which emerged as a major ion (Fig. 8a). A very weak ion signal of the adduct ion for $\mathrm{RDX}$ with $\mathrm{NO}_{3}{ }^{-}$, ([RDX+NO 3$]^{-}, m / z, 284$ ), was also identified for EIC $m / z, 289$ (Fig. 8a). Using an ESI ion source, Yinon et al. (1997) found the formation of the adduct ion for NG with $\mathrm{NO}_{3}{ }^{-},\left(\left[\mathrm{NG}+\mathrm{NO}_{3}\right]^{-}, m / z 289\right)$, as a major ion and fragment ion signals as minor ions [129]. The ESI ion source should be able to detect the adduct ion for $\mathrm{NG}$ with the $\mathrm{NO}_{3}{ }^{-}$ion as a major ion. 
This is due to the fact that the ESI is a soft ion source, therefore thermally labile molecules like $\mathrm{NG}$ are not severely fragmented [129]. The generation of a large amount of $\mathrm{NO}_{3}{ }^{-}$as reagent ions is also aided by the ambient conditions for ESI. The synergistic effect of the soft ESI ion source and the abundance of the $\mathrm{NO}_{3}{ }^{-}$ion under ambient conditions aided the formation of the adduct ion for $\mathrm{NG},\left(\left[\mathrm{NG}+\mathrm{NO}_{3}\right]^{-}, m / z 289\right)$, resulting in it gaining prominence as a major ion with improved sensitivity. Using ac-APCI, Usmanov et al. (2015) detected the adduct ion of $\mathrm{NG}$ with the $\mathrm{NO}_{3}{ }^{-},\left(\left[\mathrm{NG}+\mathrm{NO}_{3}\right]^{-}, m / z, 289\right)$, as a minor ion signal with $\mathrm{NO}_{3}{ }^{-}(\mathrm{m} / z, 62)$ as a major background ion [135]. Because of the abundance of $\mathrm{NO}_{3}{ }^{-}$ions formed by APCI under ambient conditions, it is expected that it will provide the adduct ion $\left(\left[\mathrm{NG}+\mathrm{NO}_{3}\right]^{-}, m / z, 289\right)$ as a major ion. Because the ESI, APCI, and/or DBDI have different ionization methods, the mass spectra may show differences in ion signals. Due to the fragile nature of NG molecules, even temperatures as low as $60-70{ }^{\circ} \mathrm{C}$ might trigger thermal degradation. The deposited NG on a metal substrate was almost degraded at $100{ }^{\circ} \mathrm{C}$ in our preliminary experiment $[23,30,31]$.

It is worth noting that for the EIC of $m / z 242\left(\left[\mathrm{TNT}+\mathrm{NO}_{3}-\mathrm{HNO}_{2}\right]^{-}\right)$, all of the explosives yielded ion signals of varying intensities (Fig. 8b). TNT yielded a very strong ([TNT+NO $3^{-}$ $\left.\mathrm{HNO}_{2}\right]^{-}, m / z, 242$ ) ion signal, which included the adduct ions for RDX, NG, and PETN with the $\mathrm{NO}_{3}{ }^{-}$ion (Fig. 8b). The modified HCD ion source, as shown in Figure 8(b), has the potential to be used as a versatile ion source for real-time analysis of explosives at trace levels. The ion at $m / z 228$ is the result of TNT forming an adduct ion with the hydride ion $\left(\mathrm{H}^{-}\right),\left([\mathrm{TNT}+\mathrm{H}]^{-}\right.$, $m / z$ 228). The surfaces of the metals adsorb molecular hydrogen, making the surface-assisted reduction reaction (Birch reduction type reaction) easier [23,30-32,137,138]. TNT reduction may be aided by the presence of photons and a high electron density in the HCD plasma. The mass spectrum for the EIC of the $m / z, 378$ ion, [PETN+NO$]^{-}$, is shown in Figure 8(c), while RDX's adduct ion with the $\mathrm{NO}_{3}{ }^{-},\left(\left[\mathrm{RDX}+\mathrm{NO}_{3}\right]^{-}, m / z, 284\right)[23,30,31]$, revealed a very strong ion signal. TNT also produced the adduct ion ([TNT $\left.\left.+\mathrm{NO}_{3}-\mathrm{HNO}_{2}\right]^{-}, m / z, 242\right)$, which included ions, for example, $\left([\mathrm{TNT}+\mathrm{H}]^{-}, m / z, 228\right)$ and $\left([\mathrm{TNT}-\mathrm{H}]^{-}, m / z, 226\right)$. The EIC of the $m / z, 378$ ion, however, detected no ion signal from NG (Fig. 8c).

For the EIC of $m / z 284\left(\left[\mathrm{RDX}+\mathrm{NO}_{3}\right]^{-}\right), \mathrm{RDX}$ showed a very strong ion signal for the adduct ion with the $\mathrm{NO}_{3}{ }^{-},\left(\left[\mathrm{RDX}+\mathrm{NO}_{3}\right]^{-}\right.$which included very weak ion signals of $\left([\mathrm{TNT}+\mathrm{H}]^{-}, \mathrm{m} / z, 228\right)$, $\left(\left[\mathrm{PETN}+\mathrm{NO}_{3}\right]^{-}, m / z, 378\right)$, and $\left(\left[\mathrm{TNT}+\mathrm{NO}_{3}-\mathrm{HNO}_{2}\right]^{-}, m / z, 24\right)$ (Fig. 8d). TNT should not provide strong ion signals at this stage of the TIC. TNT has a vapor pressure of $10^{-4}$ Torr $\left(20^{\circ} \mathrm{C}\right)$, whereas RDX has a vapor pressure of just $10^{-9}$ Torr $\left(20^{\circ} \mathrm{C}\right)$, hence the TNT molecules exit the ion source before the RDX molecules. The $\left([\mathrm{TNT}+\mathrm{H}]^{-}, \mathrm{m} / z, 228\right)$ ion has a higher relative intensity than the $\left[\mathrm{TNT}+\mathrm{NO}_{3}-\mathrm{HNO}_{2}\right]^{-}, m / z$ 242) ion (Fig. 8d). 
Neg ion mode
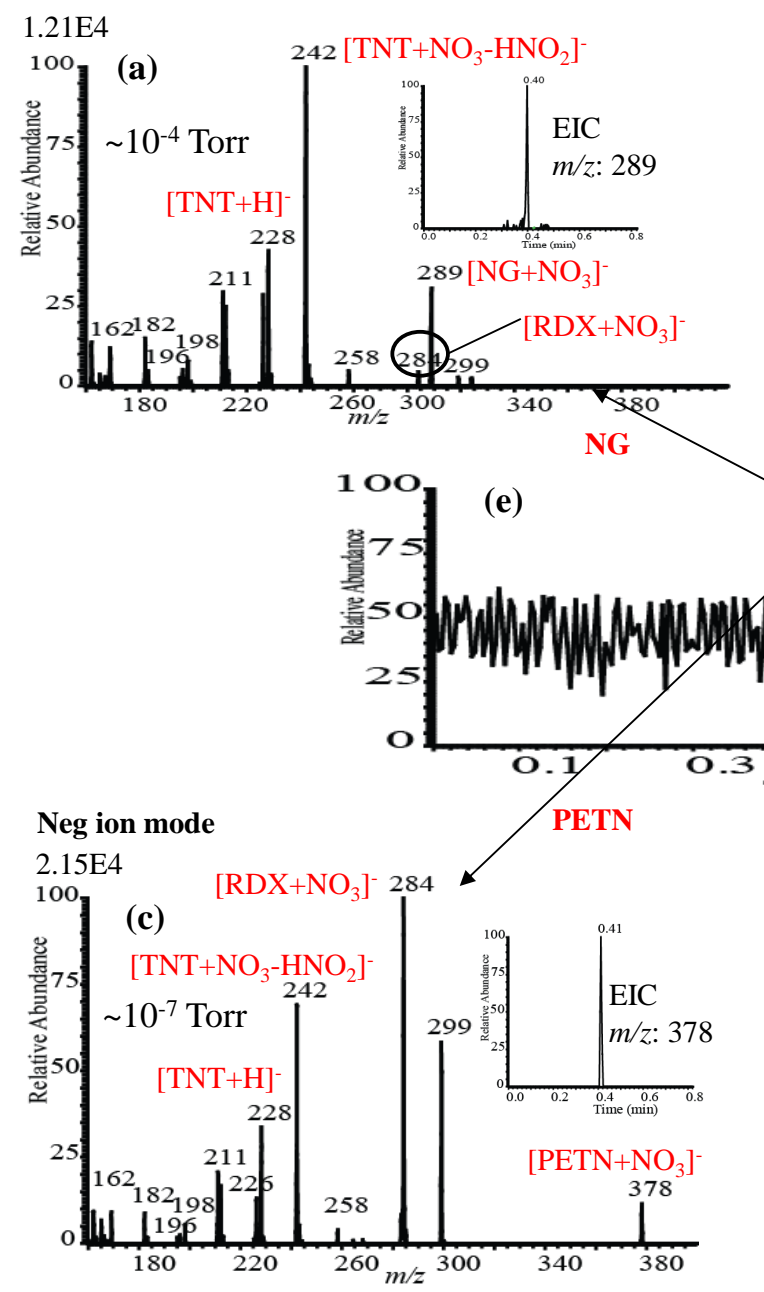

Neg ion mode

$2.18 \mathrm{E} 4 \quad\left[\mathrm{TNT}+\mathrm{NO}_{3}-\mathrm{HNO}_{2}\right]$

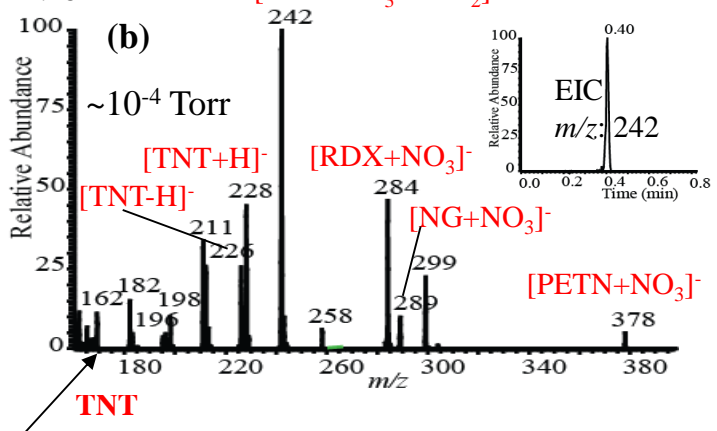

TIC

Figure 8. Negative mass spectra of mixed explosives employing the dual pressure HCD ion source (a) $1 \mathrm{ng} \mathrm{NG}$, (b) $1 \mathrm{ng}$ TNT, (c) $1 \mathrm{ng}$ PETN, and (d) $1 \mathrm{ng}$ RDX, where (e) stands for total ion current (TIC). Insets represent respective extracted ion current (EIC) of each explosive. This reprint has been approved by Elsevier [31].

The $\left([\mathrm{TNT}+\mathrm{H}]^{-}, m / z 228\right)$ ion is formed through mainly surface-assisted reduction process $[23,31,32,137,138]$, whereas the $\left(\left[\mathrm{TNT}+\mathrm{NO}_{3}-\mathrm{HNO}_{2}\right]^{-}, \mathrm{m} / \mathrm{z} 242\right)$ ion is formed in the gas phase. As a result, the intensity of $\left([\mathrm{TNT}+\mathrm{H}]^{-}, m / z 228\right)$, the hydride adduct ion for TNT, is somewhat higher than that of $\left(\left[\mathrm{TNT}+\mathrm{NO}_{3}-\mathrm{HNO}_{2}\right]^{-}, m / z 242\right)$. Although the vapor pressure of TNT is fairly high $\left(\sim 10^{-4}\right.$ Torr at $\left.20^{\circ} \mathrm{C}\right)$, the surface-assisted reduction reaction may also cause a tiny fraction of TNT molecules to have a longer relaxation period, resulting in the hydride ion, $\left([\mathrm{TNT}+\mathrm{H}]^{-}\right.$, $\mathrm{m} / \mathrm{z}$ 228), appearing later in the TIC.

TNT produced a strong ion signal of the adduct ion, $\left(\left[\mathrm{TNT}+\mathrm{NO}_{3}-\mathrm{HNO}_{2}\right]^{-}, m / z 242\right)$, when mixed with NG, PETN, and RDX at 28.0-30.0 Torr of air pressure using a modified HCD ion 
source with each explosive sample weighing $1 \mathrm{ng}$ (Fig. 8b). Using the EIC for $m / z$ 242, NG, PETN, and RDX also revealed their appropriate adduct ions with the $\mathrm{NO}_{3}{ }^{-}$ion as minor ion signals (Fig. 8b). As a result, the modified HCD ion source can be used in combination with an MS system to detect explosives at trace to ultra-trace levels while employing air as a carrier gas.
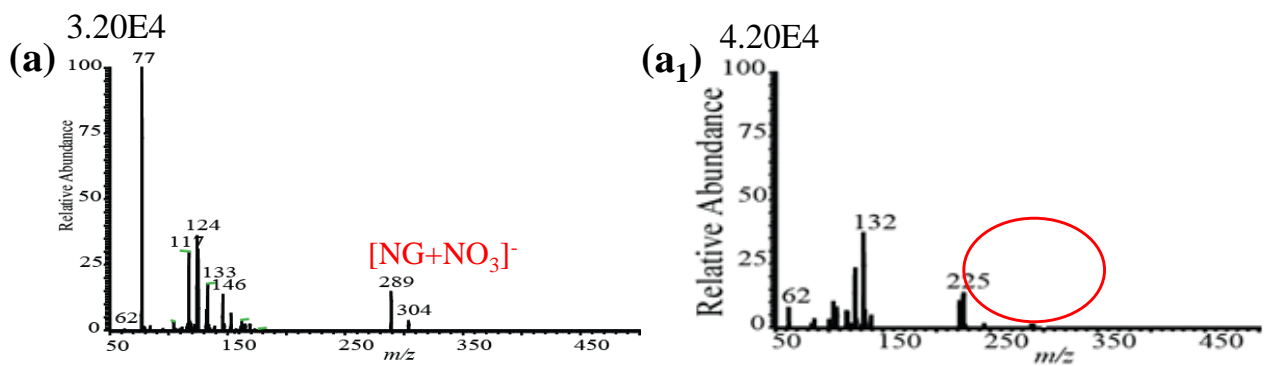

(b) $2.60 \mathrm{E} 4$

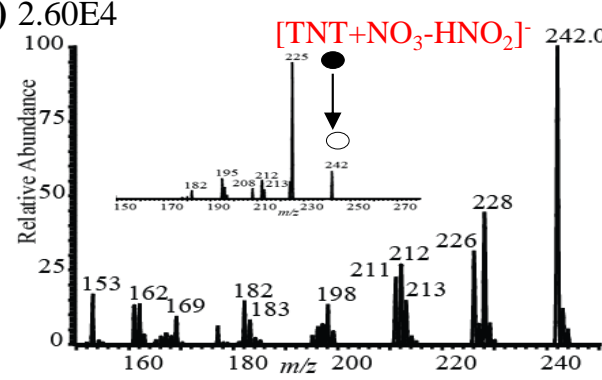

$\left(\mathbf{b}_{1}\right) 1.15 \mathrm{E} 5$

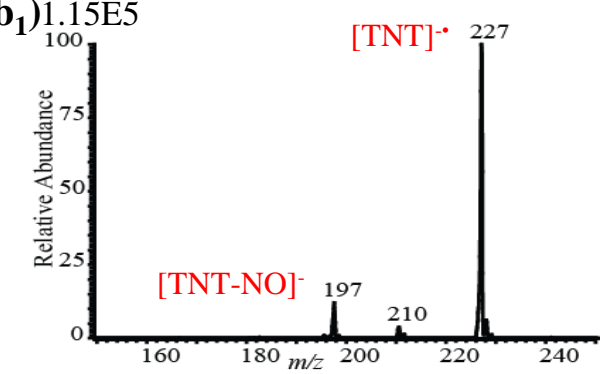

(c) $5.25 \mathrm{E} 3$
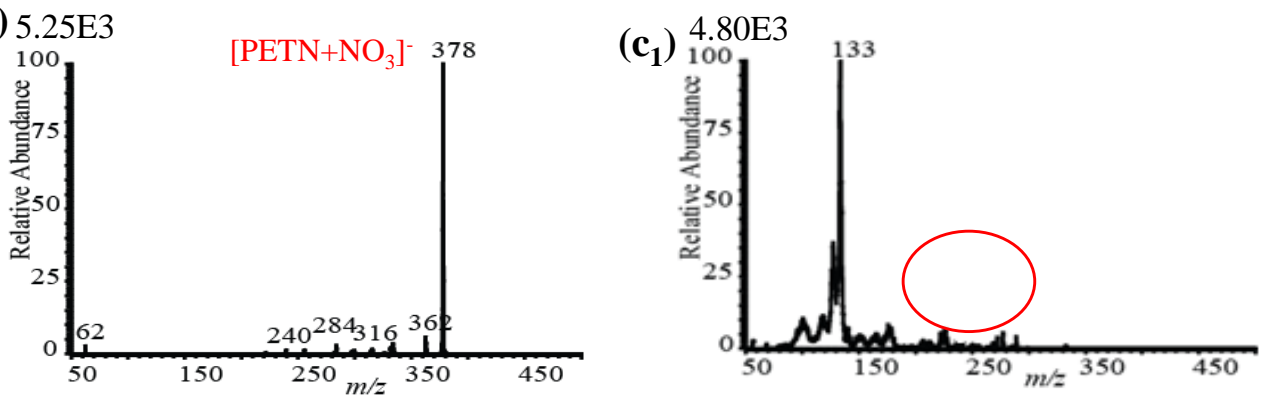

(d) $3.85 \mathrm{E} 4$
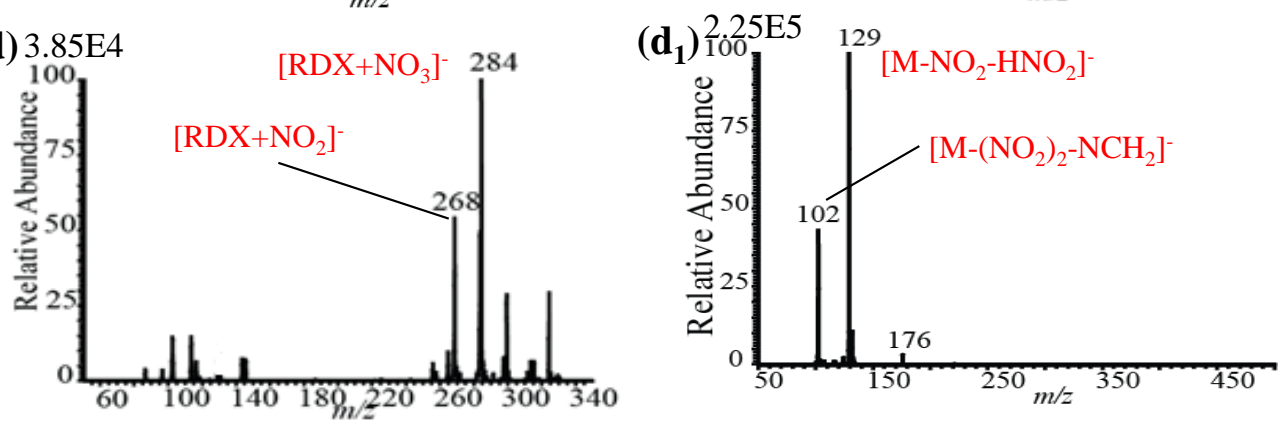

Figure 9. Negative HCD mass spectra for (a) $1 \mathrm{ng}$ NG measured at 0.8-1.0 Torr; ( $\left.\mathrm{a}_{1}\right) 1 \mathrm{ng}$ NG measured at $\sim 28.0-30.0$ Torr; (b) $1 \mathrm{ng}$ TNT measured at $\sim 0.8-1.0$ Torr; (b $\left.{ }_{1}\right) 1 \mathrm{ng}$ TNT at $\sim 28.0$ 30.0 Torr; (c) $1 \mathrm{ng}$ PETN measured at $\sim 0.8-1.0$ Torr; $\left(\mathrm{c}_{1}\right) 1 \mathrm{ng}$ PETN measured at $\sim 28.0-30.0$ Torr; (d) 1 ng RDX measured at 0.8-1.0 Torr; and ( $\left.\mathrm{d}_{1}\right) 1 \mathrm{ng}$ RDX measured at $~ 28.0-30.0$ Torr. The MS/MS spectrum of ([TNT-H+O $\left.]^{-}, m / z 242\right)$ is shown in the inset (CID: $\left.30 \%\right)$. This reprint has been approved by Elsevier [31]. 
The negative mass spectra of NG, TNT, PETN and RDX at the higher ion source pressure are shown in Figures 9(a), (b), (c) and (d), respectively, while Figures 9(a $\left.a_{1}\right),\left(b_{1}\right),\left(c_{1}\right)$, and $\left(d_{1}\right)$ show the mass spectra of the explosive compounds at the lower ion source pressures. The spectral pattern for the explosives examined separately for both higher and lower ion source pressures is identical with a little change with that recorded concurrently, as shown in Figure 9. The spectral pattern for $1 \mathrm{ng}$ RDX examined separately revealed adduct ions with both $\mathrm{NO}_{3}{ }^{-}$ and $\mathrm{NO}_{2}{ }^{-}$ions, $\left(\left[\mathrm{RDX}+\mathrm{NO}_{3}\right]^{-}, m / z 284\right)$ and $\left(\left[\mathrm{RDX}+\mathrm{NO}_{2}\right]^{-}, m / z, 268\right)($ Fig. 8d), whereas the simultaneous measurement for $1 \mathrm{ng} \mathrm{RDX}$ revealed only the ([RDX $\left.\left.+\mathrm{NO}_{3}\right]^{-}, m / z, 284\right)$ ion signal (Fig. 7d). Both the $\mathrm{NO}_{3}{ }^{-}$and $\mathrm{NO}_{2}{ }^{-}$ions have a trigonal planar shape, with the oxygen atoms of each ion being extremely negatively charged. RDX has three nitro groups $\left(\mathrm{NO}_{2}\right)$, each of which has a very positive charge on its nitrogen atoms [21,23,29-31]. With RDX and its homologue, 1,3,5,7-tetranitro-1,3,5,7-tetrazoctane (HMX), both the $\mathrm{NO}_{3}{ }^{-}$and $\mathrm{NO}_{2}{ }^{-}$ions should form adduct ions [21,23,29-31]. However, during simultaneous measurement, the other explosives and their fragments may scavenge most of the $\mathrm{NO}_{2}{ }^{-}$ion, preventing the formation of the $\left(\left[\mathrm{RDX}+\mathrm{NO}_{2}\right]^{-}\right.$, $m / z$ 268) ion. The MS/MS spectrum for the $m / z 242$ ion is shown in the inset of Figure 8(b). These findings revealed that under the hard HCD plasma environment at the higher ion source pressure, the majority of the ions that occurred at lower $m / z$ values originated from the $m / z 242$.

\subsubsection{EIC dependence mass spectral pattern of the explosives}

In MS, the analyte molecules must be desorbed into the gas phase and then ionized using a suitable ion source for detection and quantification. The volatility of condensed substances affects their desorption. Because different explosive compounds have varying vapor pressures, their desorption processes are likewise variable. On the basis of their EICs, we investigated the desorption process of various explosives from their mixture (EICs). On a glass slide, $2 \mu \mathrm{L}$ of acetonitrile solution containing $1 \mathrm{ng}$ of each explosive compound was poured and air dried. To desorb the condensed explosive compounds for ionization by the HCD ion source, hot air blowing between 140 and $200{ }^{\circ} \mathrm{C}$ was applied opposite the sample spot. The EICs for NG, TNT, PETN, and RDX are shown in Figures 10(a), (b), (c), and (d), respectively. Signals in the EICs rise and decline swiftly, as seen in Figs. 10(a)-(c), while signals in the EIC for RDX rise quickly but fall slowly (Fig. 10d). The EICs for NG and TNT peak at 0.40 min, while PETN and RDX peak at 0.41 and 0.42 min, respectively (Fig. 10). The low EIC value is due to the high vapor pressure of NG $\left(\sim 10^{-4}\right.$ Torr at $\left.20^{\circ} \mathrm{C}\right)$ and TNT $\left(\sim 10^{-4}\right.$ Torr at $\left.20{ }^{\circ} \mathrm{C}\right)(0.40$ min). The high EIC values are due to the non-volatility of PETN $\left(\sim 10^{-7}\right.$ Torr at $\left.20{ }^{\circ} \mathrm{C}\right)$ and 
RDX $\left(\sim 10^{-9}\right.$ Torr $)$. Because of its non-volatility $\left(\sim 10^{-9}\right.$ Torr at $\left.20^{\circ} \mathrm{C}\right)$, the delay signal decline in the EIC for RDX seems logical; nevertheless, the fast rise and fall for PETN is unclear.
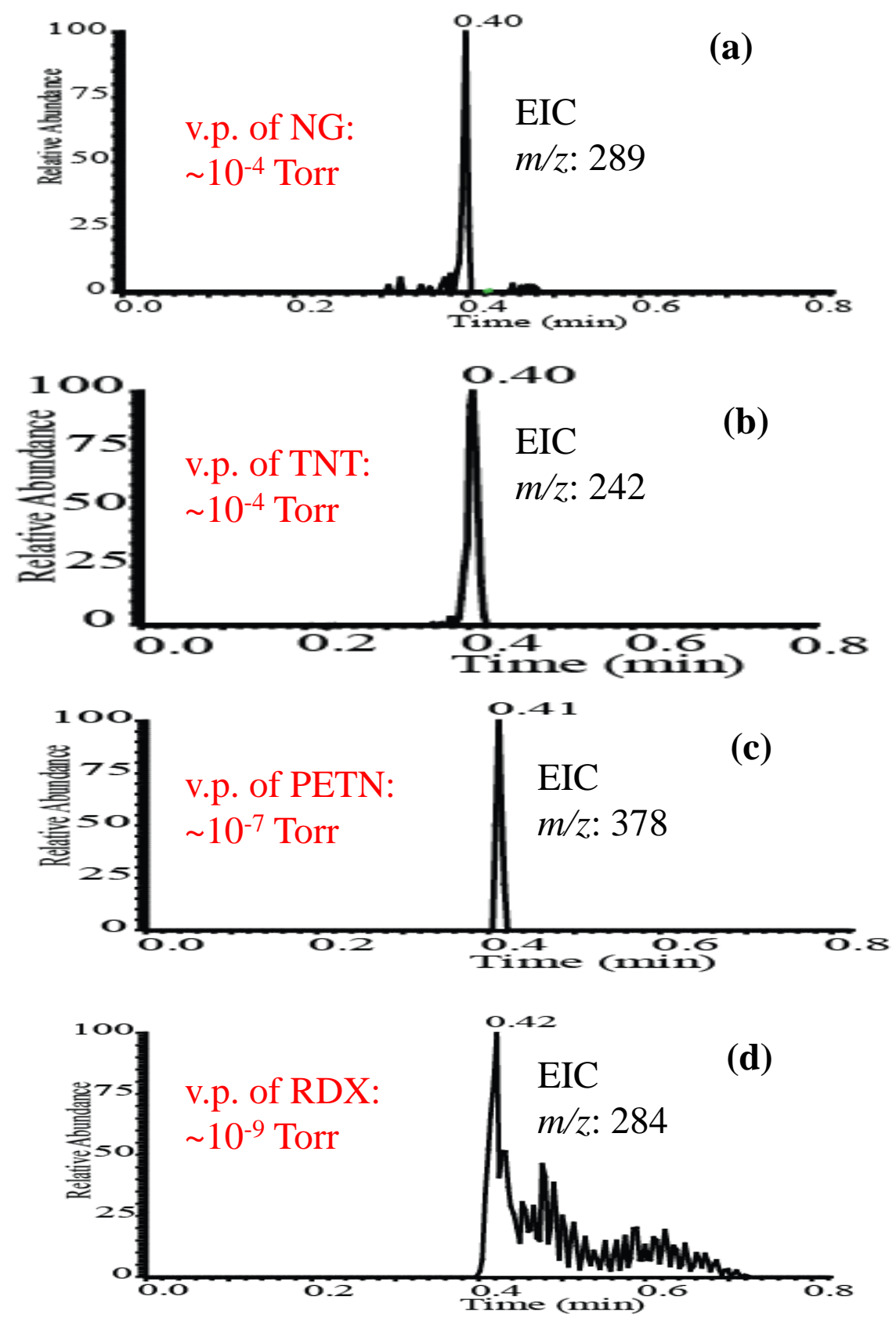

Figure 10. EIC of (a) $\left[\mathrm{NG}+\mathrm{NO}_{3}\right]^{-}$at $\mathrm{m} / \mathrm{z} 289$, (b) $\left[\mathrm{TNT}+\mathrm{NO}_{3}-\mathrm{HNO}_{2}\right]^{-}$at $\mathrm{m} / z$ 242, (c) $\left[\mathrm{PETN}+\mathrm{NO}_{3}\right]^{-}$at $m / z, 378$ and (d) $\left[\mathrm{RDX}+\mathrm{NO}_{3}\right]^{-}$at $m / z, 284$. Each explosive compound is exactly $1 \mathrm{ng}$ in the mixture. This reprint has been approved by Elsevier [31].

The adduct ion for RDX, ([RDX+NO $\left.]^{-}, m / z, 284\right)$ appeared as a major ion in Fig. 10(c) using the EIC for $\left[\mathrm{PETN}+\mathrm{NO}_{3}\right]^{-}$at $\mathrm{m} / \mathrm{z} 378$, but the adduct ion for PETN, $\left(\left[\mathrm{PETN}+\mathrm{NO}_{3}\right]^{-}, \mathrm{m} / \mathrm{z}\right.$ 
378) appeared as a minor ion. For the $\left(\left[\mathrm{PETN}+\mathrm{NO}_{3}\right]^{-}, \mathrm{m} / \mathrm{z} 378\right)$ ion, the concordance between the fast increase and fall and the very low intensity is reasonable. There could be two reasons for this. To begin with, PETN molecules may be thermally labile, hence the majority of PETN molecules were fragmented prior to ionization. Second, the PETN molecules' ion production efficiency with the $\mathrm{NO}_{3}{ }^{-}$ion is not as good as $\mathrm{RDX}^{\prime}$ 's with the $\mathrm{NO}_{3}{ }^{-}$. In the mass spectrum, a fraction of the PETN molecules formed adduct ions with the $\mathrm{NO}_{3}{ }^{-}$(Fig. 8c). The PETN adduct ion $\left(\left[\mathrm{PETN}+\mathrm{NO}_{3}\right]^{-}, \mathrm{m} / \mathrm{z}, 378\right)$ was detected using the EICs for $\left(\left[\mathrm{TNT}+\mathrm{NO}_{3}-\right.\right.$ $\left.\mathrm{HNO}_{2}\right]^{-}, m / z$ 242) (Fig. 8b) and $\left[\mathrm{RDX}+\mathrm{NO}_{3}\right]^{-}, m / z$ 284) (Fig. 8d). The fact that the $\left(\left[\mathrm{PETN}+\mathrm{NO}_{3}\right]^{-}, \mathrm{m} / \mathrm{z} 378\right)$ appears in the RDX spectrum with a relatively low intensity further shows that it is non-volatile (Fig. 8d). The modified HCD ion source is capable of detecting many explosives at trace levels. As a result, the improved HCD ion source has been found to be capable of concurrently detecting explosives of several types at trace levels.

\subsection{Explosives analysis in real time using HCD at $\sim 0.8-1.0$ Torr}

At lower ionization pressures, real-time explosive analysis has also been performed ( $\sim .8$ 1.0 Torr). Among the explosives, only TNT and RDX showed molecular and fragment ions in the negative ion mode, as illustrated in Figures 11(a) and (b), respectively. Even when the quantities were increased to $5 \mathrm{ng}$, neither NG nor PETN showed any discernible peaks at the reduced ion source pressure. Because the low ion source pressure causes ordinary dc-glow discharge, the explosives' spectral pattern differed from that observed at higher ion source pressures ( 28.0-30.0 Torr) [7,23,31,139]. TNT exhibited a strong molecular ion, ([TNT] $]^{-}, \mathrm{m} / \mathrm{z}$ 227), with very weak ions such as ([TNT-OH] $\left.]^{-}, m / z, 210\right)$ and ([TNT-NO $]^{-}, m / z$ 197) (Fig. 11a) whereas RDX exhibited only fragment ions with strong ion intensities, for example, ([RDX$\left.\mathrm{NO}_{2}-\mathrm{HNO}_{2}\right]^{-}, m / z$ 129) and ([RDX- $\left.\left(\mathrm{NO}_{2}\right)_{2}-\mathrm{NCH}_{2}\right]^{-}, m / z$ 102) (Fig. 11b) [23,30,31]. At air pressures between 0.8 and 1.0 Torr, no adduct ion evidence for RDX were seen. The TIC of the mixed explosives is shown in Figure 11(c), while the EICs for the ions of $m / z 227$ (TNT) and 129 (RDX) are shown in the insets of Figure 11(a) and (b), respectively. TNT has a vapor pressure of $\sim 10^{-4}$ Torr $\left(20^{\circ} \mathrm{C}\right)$, whereas RDX only has a vapor pressure of $\sim 10^{-9}$ Torr $\left(20{ }^{\circ} \mathrm{C}\right)$, hence TNT evaporates faster than RDX molecules. The EIC for $m / z$ 227, [TNT]', displays a rapid peak and decrease pattern (inset in Fig. 11a). RDX, on the other hand, has a rapid rising EIC signal but a delayed fall with a large tailing (inset in Fig. 11b) [31]. The signal of RDX's EIC tails due to its non-volatility. Because the EIC for $m / z, 227$ (TNT) is 0.46 min and the EIC for $129(\mathrm{RDX})$ is $0.49 \mathrm{~min}$, no ion signal from RDX was recorded (Fig. 11a). TNT, on the other hand, gave strong molecular ion signal at $m / z, 227$ in the RDX's EIC (Fig. 11b). At the reduced 
ion source pressure, no ion signals were recorded from NG and PETN, as previously stated $[23,31]$. The results reveal that the fragments generated by NG and/or PETN in the glow discharge plasma may not be stable at lower ion source pressures ( 0.8-1.0 Torr) or that TNT and RDX in the dc-plasma undergo electron attachment and/or capture ionization [23,30,31].

RDX provides only fragment ions of $\mathrm{m} / \mathrm{z}, 102,129$, and 176 utilizing a dc-glow discharge ion source at 0.8 Torr of air pressure, according to McLuckey et al. (1996) [7]. Using a lowtemperature DBD plasma, Garcia-Reyes et al. (2011) detected the molecular ion of TNT, ([TNT] $\left.]^{-}, m / z, 227\right)$ [16]. Using ac-APCI with an insulating tube, TNT gave molecular ion of TNT as a major ion $\left(\left[\mathrm{TNT}^{-}, m / z 227\right) \text {, whereas the formation of [TNT] }\right]^{-}$ion was significantly suppressed by the fragment ion, [TNT-H]-, $m / z$ 226), using dc-APCI [18]. Under ambient conditions, Usmanov et al. (2013) reported the formation of fragment ion from TNT, ([TNT$\mathrm{H}^{-}, m / z$ 226) utilizing He-DBDI [135]. The plasma exhibits normal glow discharge at lower ion source pressures ( 0.80-1.0 Torr), and the generation of $\mathrm{NO}_{3}{ }^{-}$and/or $\mathrm{NO}_{2}{ }^{-}$is greatly reduced, hence the fragment ion for TNT, ([TNT-H] $]^{-}, m / z$ 226), was not observed $[23,30,31]$. Because $\mathrm{NO}_{3}{ }^{-}$and/or $\mathrm{NO}_{2}{ }^{-}$ions in the plasma extract protons from TNT molecules, the equation $\mathrm{TNT}+\mathrm{NO}_{3}{ }^{-} / \mathrm{NO}_{2}{ }^{-} \longrightarrow\left[\mathrm{TNT}-\mathrm{H}^{-}{ }^{-}+\mathrm{HNO}_{3} / \mathrm{HNO}_{2}\right.$ is used.

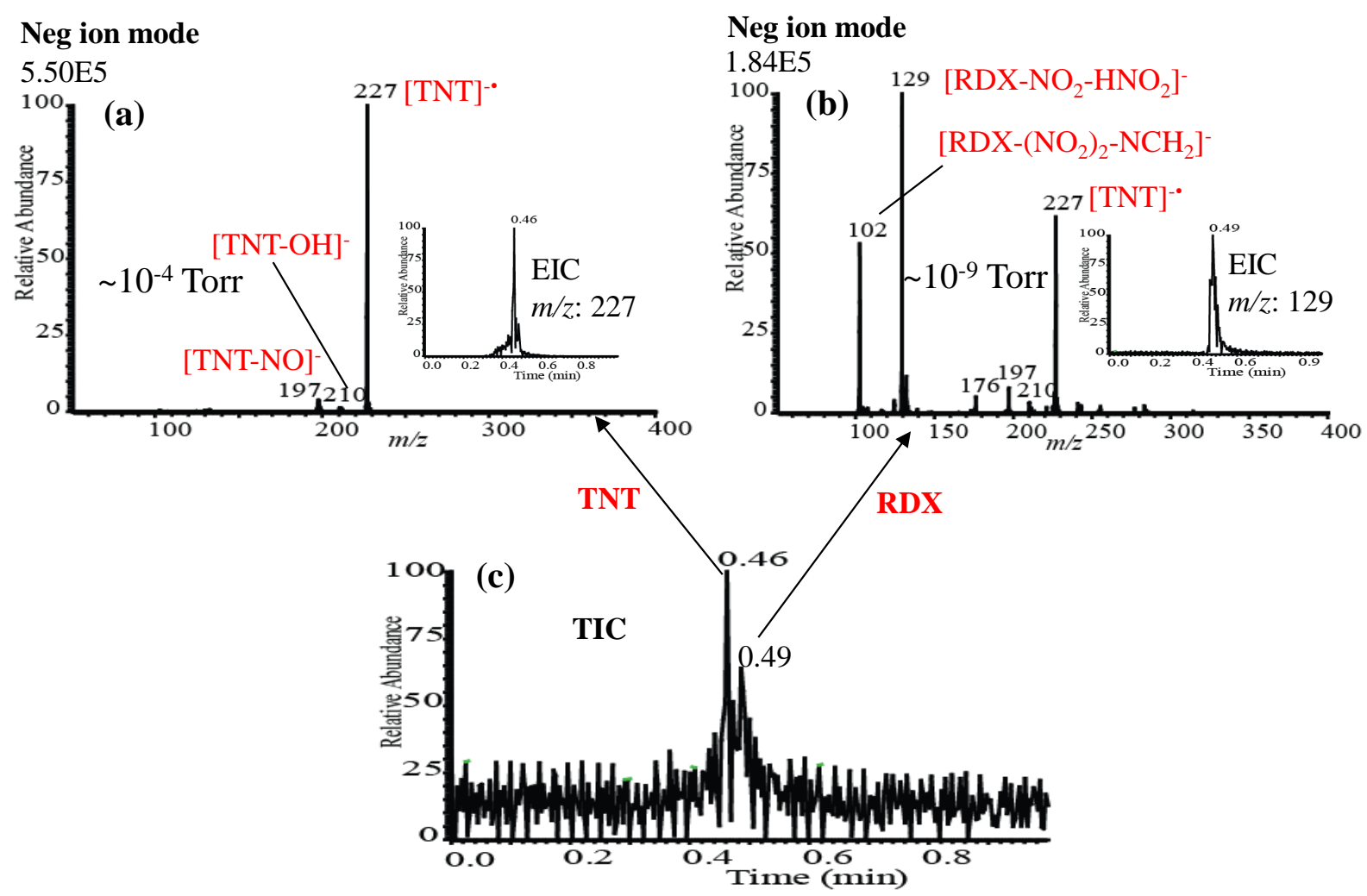

Figure 11. Negative mass spectra of the mixed explosives of (a) $1 \mathrm{ng}$ TNT and (b) $1 \mathrm{ng}$ RDX using the dual pressure HCD ion source where (c) stands for TIC. The EIC of each explosive is represented in the insets. This reprint has been approved by Elsevier [31]. 
Because of the positive electron affinity of TNT molecules, the high electron density in the HCD plasma leads to the formation of a molecular ion, ([TNT $\left.]^{-*}, m / z, 227\right)$, via an electron attachment reaction $[23,30-32,130]$. As a result, it is reasonable to conclude that the modified HCD ion source may detect and quantify explosives from mixtures at trace and/or ultra-trace levels.

At lower ion source pressures (0.8-1.0 Torr), TNT showed a better LOD value (1.00 \pm 0.03 $\mathrm{pg}$ ). The electron attachment reaction of TNT molecules (EA: $2.5 \mathrm{eV}$ ) is facilitated by the glow discharge-like plasma at lower ion source pressures, resulting in the formation of the molecular ion ([TNT] $]^{-}, m / z$ 227) $[23,30-32]$. Because of the low pressure, only a little amount of $\mathrm{NO}_{\mathrm{x}}$ was formed, hence TNT molecules were mostly involved in the electron attachment reaction, despite the electron affinity of $\mathrm{NO}_{3}$ being $3.92 \mathrm{eV}[23,29-31,130]$. For RDX, the $m / z 129$, [M$\left.\mathrm{NO}_{2}-\mathrm{HNO}_{2}\right]^{-}$, a fragment ion of RDX, had a better LOD value $(10.33 \pm 0.45 \mathrm{pg})$, but the $\left(\left[\mathrm{RDX}+\mathrm{NO}_{3}\right]^{-}, m / z, 284\right)$ had a greater LOD value $(30.75 \pm 0.95 \mathrm{pg})$ [31]. Using a glow discharge ion source operating at 0.80 Torr of air pressure, McLuckey et al. (1996) found improved sensitivity for RDX with a few pg [7].

\subsection{Pressure dependent negative HCD mass spectra of TNT and TNB}

The negative mass spectra of TNT and TNB measured by HCDI-MS system are shown in Figure 12(a) and (b), respectively. At lower ion source pressures (1 Torr), TNT and TNB both

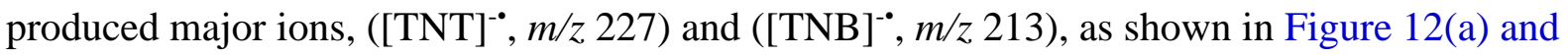
(b), but TNT produced two fragment ions, ([TNT-OH] $\left.]^{-}, m / z 210\right)$ and ([TNT-NO $]^{-}, m / z$ 197), whereas TNB produced only the fragment ion, ([TNB-NO] $]^{-}, m / z$ 183) [23,31,32]. The formation of the ([TNT-OH] $\left.]^{-}, m / z, 210\right)$ ion is due to the presence of a methyl $\left(-\mathrm{CH}_{3}\right)$ group in TNT molecules. The methyl hydrogen should be more acidic than the ring hydrogen, and the oxygen atom of the neighboring $-\mathrm{NO}_{2}$ group (ortho to the $-\mathrm{CH}_{3}$ group) causes the methyl proton to be abstracted, resulting in the formation of the ([TNT-OH $\left.]^{-}, m / z 210\right)$ ion from the TNT molecules.

In contrast, when the ion source pressures increase, the intensities of the molecular ions for both TNT and TNB drop (Fig. 12a,b). At 5 Torr, the [M-H] $]^{-}$ion developed into major ions such ([TNT-H] $\left.]^{-}, m / z 226\right)$ and ([TNB-H] $\left.]^{-}, m / z, 212\right)$, although their molecular ions remained small. When the ion source pressure was increased to 30 Torr, the molecular ions for TNT and TNB vanished completely, and their respective adduct ions, ([TNT $\left.\left.+\mathrm{NO}_{3}-\mathrm{HNO}_{2}\right]^{-}, m / z, 242\right)$ and $\left(\left[\mathrm{TNB}+\mathrm{NO}_{3}-\mathrm{HNO}_{2}\right]^{-}, m / z\right.$ 228), appeared as major ions (Fig. 12a,b). 
The ratio of $\mathrm{NO}_{\mathrm{x}}$ such as $\mathrm{NO}_{2}$ and $\mathrm{NO}_{3}$ in air-excited plasma increases as the ion source pressure rises. The $\mathrm{NO}_{2}{ }^{-}$and $\mathrm{NO}_{3}{ }^{-}$ions generated in the $\mathrm{HCD}$ plasma then took part in proton abstraction processes, as described in Equs. 1 and 2 [23,30-32,139]:

$$
\begin{aligned}
& \mathrm{TNT}+\mathrm{NO}_{3}{ }^{-} / \mathrm{NO}_{2}{ }^{-} \longrightarrow[\mathrm{TNT}-\mathrm{H}]^{-}(m / z, 226)+\mathrm{HNO}_{3} / \mathrm{HNO}_{2} \\
& \mathrm{TNB}+\mathrm{NO}_{3}{ }^{-} / \mathrm{NO}_{2}{ }^{-} \longrightarrow[\mathrm{TNB}-\mathrm{H}]^{-}(m / z, 212)+\mathrm{HNO}_{3} / \mathrm{HNO}_{2}
\end{aligned}
$$

At higher ion source pressures (5-30 Torr), NG, PETN, and RDX produce adduct ions with the $\mathrm{NO}_{3}^{-}$ion, however TNT and TNB did not generate any adduct ions with the $\mathrm{NO}_{3}{ }^{-}$, $\left(\left[\mathrm{TNT}+\mathrm{NO}_{3}\right]^{-}, m / z, 289\right)$ and $\left(\left[\mathrm{TNB}+\mathrm{NO}_{3}\right]^{-}, m / z, 228\right)$, respectively $[23,30-32,139]$. Usmanov et al. (2015) used density functional theory (DFT) calculations to study the anomalous mass spectrum of TNT [139]. Because of the negative energy of activation $(E=-21.4 \mathrm{kcal} / \mathrm{mol})$, the $\mathrm{NO}_{3}{ }^{-}$ion is tightly attached to two carbon atoms of the benzene ring of TNT molecules, according to DFT calculations. Deprotonation occurs at the transition state by cleaving the C$\mathrm{H}$ bond, resulting in the formation of $[\mathrm{M}-\mathrm{H}]^{-}$ions such as $\left([\mathrm{TNT}-\mathrm{H}]^{-}, m / z 226\right),\left([\mathrm{TNB}-\mathrm{H}]^{-}, m / z\right.$ $212)$ etc. The DFT calculation revealed a minimal activation energy of $+9.8(=-11.6-21.4)$ $\mathrm{kcal} / \mathrm{mol}$ for proton abstraction from the benzene ring. This shows that the formation of the $[\mathrm{M}-\mathrm{H}]^{-}$ion would be kinetically favorable [139]. The dc-corona APCI ambient ion source was used to study proton transfer processes in aliphatic and aromatic compounds with various functional groups $[133,139,140]$. TNT was analyzed using an ambient ac-corona APCI, which identified the molecular ion, $\left([\mathrm{TNT}]^{-\bullet}, m / z 227\right)$, as the predominant ion, with ([TNT-H $]^{-\bullet}, m / z$ 226) and ([TNT-NO $\left.]^{-}, m / z, 197\right)$ as minor ions $[18,30]$. Minor ions $[\text { TNT }]^{-}, m / z$ 27) and ([TNT$\mathrm{H}]^{-}, m / z$ 226) were also found in the dc corona APCI, whereas the fragment ion ([TNT-NO]', $m / z$ 197) was found as a major ion $[18,30]$. TNB also produced a major ion, ([TNB $]^{-\bullet}, m / z, 213$ ),

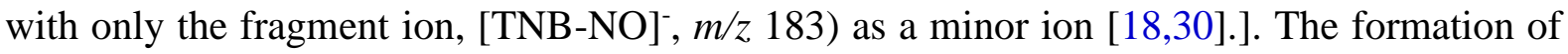
the $[\mathrm{TNT}-\mathrm{OH}]^{-}, m / z, 210$ ) as a major ion was confirmed by the MS/MS mode (CID 25\%) for the precursor ion, $\left(\left[\mathrm{TNT}^{-}, \mathrm{m} / \mathrm{z} 227\right)[23,30] \text {. Minor ions were ([TNT-NO] }\right]^{-}, \mathrm{m} / z$ 197), ([TNT$\left.2 \mathrm{NO}^{-}, m / z, 167\right)$ and ([TNT-3NO] $]^{-}, m / z$ 137). These findings are also consistent with those of other investigations $[8,11,16,23,30-32,123,126,129]$. TNT produced ions with $m / z, 212,213$, and 214 with intensity ratios of 5:4:3 at both 5 and 30 Torr, but TNB produced minor ions with intensity ratios of 15:3:2 at 5 Torr (Fig. 12a,b). TNB is thought to be responsible for the development of ions with $m / z 212,213$, and even 214 in the HCD plasma, as a result of TNT photodegradation processes. 

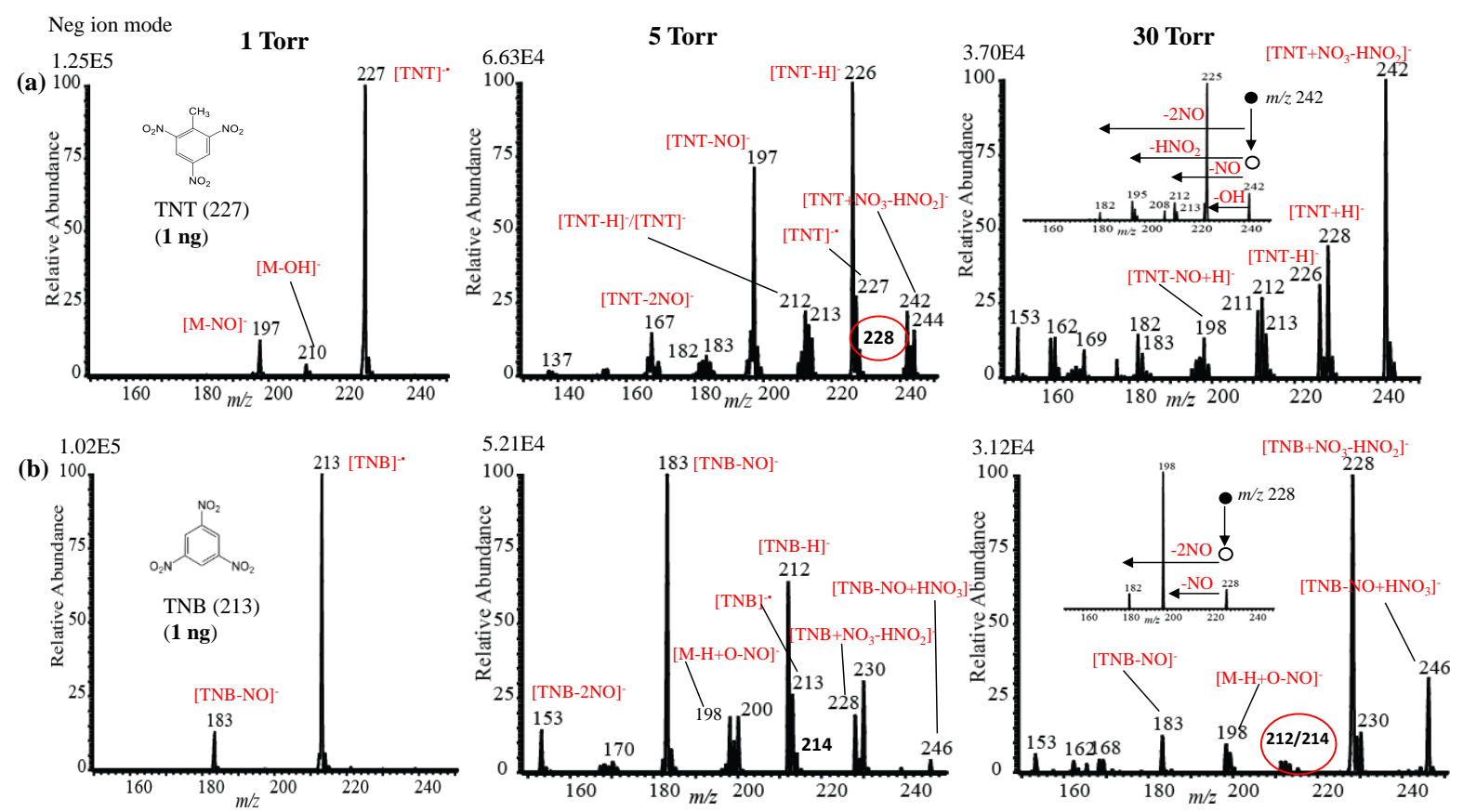

Figure 12. HCD mass spectra of (a) TNT and (b) TNB at 1, 5 and 30 Torr in negative ion mode. Inset in 2(a) indicates the MS/MS spectrum for $m / z, 242\left(\left[\mathrm{TNT}+\mathrm{NO}_{3}-\mathrm{HNO}_{2}\right]^{-}\right)$and that in Fig. 2(b) stands for MS/MS spectrum of $m / 2228\left(\left[\mathrm{TNB}+\mathrm{NO}_{3}-\mathrm{HNO}_{2}\right]^{-}\right)(\mathrm{CID}: 25 \%)$. This reprint has been approved by Elsevier [32].

However, the generation of $m / z, 212$ and 213 ions was seen in the MS/MS spectra for the precursor ion with $m / z$ 242. (inset in Fig. 12a) [32]. Furthermore, when utilizing MS/MS mode, the intensity ratios for the $m / z, 212,213$, and 214 ions derived from the $\mathrm{m} / \mathrm{z}, 242$ ion are completely different from those formed from TNB (Fig. 12a,b). As a result, the peaks in the TNT mass spectra at $m / z 212$ and 213 are thought to be from the ([TNT+NO $\left.\left.3-\mathrm{HNO}_{2}\right]^{-}, m / z, 242\right)$ ion [32].

At 30 Torr, TNT produced a new peak at $m / z$ 228. (Fig. 12a). The hydride-adduct ion of TNT, $[\mathrm{TNT}+\mathrm{H}]^{-}$, has been ascribed to the peak at $m / z$ 228. TNB also produced the hydrideadduct ion ([TNB+H] $\left.]^{-}, m / z 214\right)$, which included the minor ion ([TNB-H] $]^{-}, m / z$ 212) (Fig. 12b). The MS/MS spectra for the precursor ions $m / z, 242$ and 228are shown in the insets in Fig. 12(a) and (b) (CID 25\%), respectively [23,31,32]. At the higher ion source pressure of 30 Torr, TNT and TNB both produced adduct ions such as $\left(\left[\mathrm{TNT}+\mathrm{NO}_{3}-\mathrm{HNO}_{2}\right]^{-}, \mathrm{m} / z, 242\right)$ and $\left(\left[\mathrm{TNB}+\mathrm{NO}_{3}-\right.\right.$ $\left.\mathrm{HNO}_{2}\right]^{-}, m / z$ 228) as major ions. The MS/MS system has designated the ions that appear in the lower $m / z$ area (see insets in Fig. 12). The MS/MS spectrum for the $m / z, 242$, [TNT+NO $\left.\mathrm{HNO}_{2}\right]^{-}$, ion showed that the ions at $m / z, 212 / 213,195$, and 182 originated from TNT; however, the MS/MS peak for $m / z 225$ did not appear in the TNT mass spectrum at 30 Torr (Fig. 12a) 
[32].At higher ion source pressures, the absence of the $m / z, 228$ ion in the MS/MS spectrum for the $m / z, 242$ ion rather exposes the formation of the TNT hydride-adduct ion, [TNT $+\mathrm{H}^{-}$(see inset in Fig. 12a). TNT molecules participated in both gas phase and surface-assisted processes at the same time, yielding the $\left(\left[\mathrm{TNT}+\mathrm{NO}_{3}-\mathrm{HNO}_{2}\right]^{-}, \mathrm{m} / z, 242\right)$ ion and the hydride-adduct ion, $\left([\mathrm{TNT}+\mathrm{H}]^{-}, m / z, 228\right)$, respectively $[31,32]$.
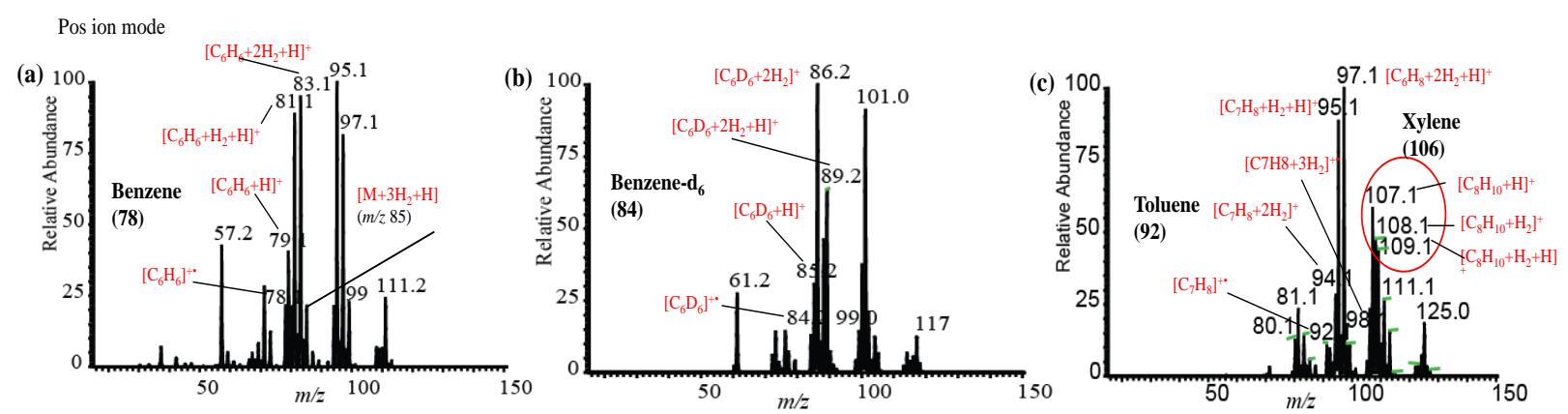

Figure 13. Positive HCD mass spectra of (a) benzene, (b) deuterated benzene and (c) toluene using headspace method. Molar mass of each organic compound in the parentheses. This reprint has been approved by Elsevier [32].

Even at 5 Torr (red circle) (Fig. 12a for 5 Torr), the hydride-adduct ion of TNT, $\left([\mathrm{TNT}+\mathrm{H}]^{-}\right.$ ,$m / z 228$ ), appears as minor ions, but its intensity increases as the ion source pressure increases [32]. It should be mentioned that practically all metal surfaces can adsorb hydrogen gas, with palladium metal adsorbing/absorbing hydrogen gas in a large way. The cathode in this work is stainless steel, therefore in the presence of high electron density, metastable species, and photons in the HCD plasma, the inner surface becomes reactive, assisting surface reactions. To explore the Birch type reduction processes of the nitroaromatic explosives in the HCD ion source, benzene, deuterated benzene, and toluene were used as model organic compounds shown in Figures 13(a), (b) and (c) [32,137,138]. At higher ion source pressures (5 and 30 Torr), the mass spectra of these organic compounds confirmed the generation of hydride-adduct ions of TNT and its precursors (Fig. 13). The ions with the $m / z, 198$ and 182 (inset in Fig. 12b) were found in the MS/MS spectra for $m / z 228$ (CID 25\%), whereas TNB revealed the ions with the $m / z$ 198, 192, 168, 153, including $m / z, 212$ and 214. The removal of NO (30) from the $m / z$ 228 ion, $\left[\mathrm{TNB}+\mathrm{NO}_{3}-\mathrm{HNO}_{2}\right]^{-}$, results in the formation of the $\mathrm{m} / z, 198$ ion in the TNB mass spectrum (Fig. 12b). The strong $\mathrm{m} / \mathrm{z} 183$ ion originating from TNB molecules may suppress the $\mathrm{m} / \mathrm{z} 182$ ion in the MS/MS spectrum for the precursor ion $\mathrm{m} / \mathrm{z} 228$ by the removal of NO from the molecular ioni.e., ([TNB $\left.]^{-}, m / z, 213\right) \stackrel{-N O}{\longrightarrow}\left([T N B-N O]^{-}, m / z, 183\right)$ (Fig. 12b) [32]. 
In the negative ion mode, the existing $\mathrm{HCD}$ ion source produced $\mathrm{NO}_{2}{ }^{-}(\mathrm{m} / \mathrm{z} 46), \mathrm{NO}_{3}{ }^{-}(\mathrm{m} / \mathrm{z}$ $62)$, and $\mathrm{CO}_{3}{ }^{-}(\mathrm{m} / \mathrm{z}, 60)$, while $\mathrm{O}_{3}$ is one of the neutral products in the air-assisted plasma and should appear at $\mathrm{m} / \mathrm{z}, 48,\left[\mathrm{O}_{3}\right]^{-}$, but did not appear in the back ground mass spectrum (Fig. 2) $[23,30,31]$. Because the electron affinities of the $\mathrm{NO}_{2}(2.3 \mathrm{eV})$ and $\mathrm{NO}_{3}(3.9 \mathrm{eV})$ species are substantially higher than those of $\mathrm{O}_{3}(2.1 \mathrm{eV})$, the $\mathrm{NO}_{2}{ }^{-}$and $\mathrm{NO}_{3}{ }^{-}$ions must prevent the formation of $\mathrm{O}_{3}{ }^{-}[23,30-32,141]$. The $\mathrm{O}_{3}{ }^{-}(\mathrm{m} / \mathrm{z}, 48)$ ion has been infrequently detected in airexcited plasma [77,133]. At higher ion source pressures, both TNT and TNB molecules produced $\left[\mathrm{M}+\mathrm{NO}_{3}-\mathrm{HNO}_{2}\right]^{-}$adduct ions, which became major ions as the ion source pressure was increased from 5 to 30 Torr. In the HCD ion source, the ion formation mechanism of TNT and TNB is pressure dependent. The lower ion source pressure (1 Torr) produced molecular

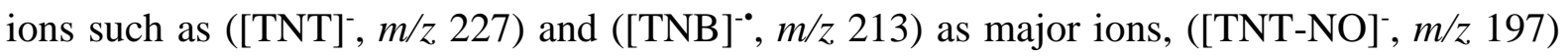
and ([TNT-NO $\left.]^{-}, m / z, 183\right)$ as minor ions, and no fragment ions such as ([TNT-H] $\left.]^{-}, m / z 226\right)$ and $\left([\mathrm{TNB}-\mathrm{H}]^{-}, m / z 212\right)$ were observed.

When the ion source pressure is increased from 1 to 30 Torr, however, the mass spectral pattern changes dramatically (Figs. 12a,b). At 5 Torr, TNT produced the fragment ion ([TNT$\mathrm{H}]^{-}, m / z$ 226) as a major ion along with ([TNT-NO $]^{-}, m / z$ 197) as a minor ion. At 5 Torr, TNB gave the fragment ion ([TNB-NO $\left.]^{-}, m / z 183\right)$ as a major ion and $\left([\mathrm{TNB}-\mathrm{H}]^{-}, m / z 212\right)$ as a minor ion. At the higher ion source pressure of 30 Torr, however, both TNT and TNB showed their respective adduct ions such as $\left(\left[\mathrm{TNT}+\mathrm{NO}_{3}-\mathrm{HNO}_{2}\right]^{-}, m / z, 242\right)$ and $\left(\left[\mathrm{TNB}+\mathrm{NO}_{3}-\mathrm{HNO}_{2}\right]^{-}, m / z\right.$ 228) as major ions [32].

The LOD values of TNT were $1.02 \pm 0.02,10.20 \pm 0.35$, and $30.32 \pm 1.03 \mathrm{pg}$ at 1,5 , and 30 Torr, respectively, using the modified variable pressure HCD ion source. For 1, 5 and 30 Torr, the LOD values for TNB were $2.10 \pm 0.06,12.08 \pm 0.41$, and $30.25 \pm 1.25 \mathrm{pg}$, respectively [32]. TNT was also analyzed using a previous version of the HCD ion source, which yielded 2, 50 and $70 \mathrm{pg}$ at 1,5 and 30 Torr, respectively $[23,30]$. TNT was detected using ambient ac-APCI and dc-APCI, with LOD values of 30 and $50 \mathrm{pg}$, respectively. Using the ac/plastic and dc/plastic APCI ion sources, TNB had greater LOD values than TNT [18,30].

The dc-corona APCI was also fabricated and used to analyze TNT using a counter-flow introduction sampling technique, and the formation of TNT molecular ions ([TNT $]^{-}, m / z 227$ ) was reported [134]. Because the air pressure is reduced by the counter-flow introduction sampling method, the presence of $\mathrm{NO}_{\mathrm{x}}$ is reduced to a minimum, preventing the proton abstract reaction from the TNT molecules. Because of TNT's strong electron affinity $(2.5 \mathrm{eV})$, the electron attachment reaction takes precedence and the molecular ion emerges as a major ion $[23,30-32,140,141]$. Formation of TNT molecular ion, $\left([\mathrm{TNT}]^{-*}, m / z\right.$ 227) was also observed 
by using the direct analysis in real time (DART) ion source [77,79]. This is because helium plasma in the DART holds high electron density rather than $\mathrm{NO}_{\mathrm{x}}$ that facilitates the electron attachment reaction. Electrospray-based techniques have also been used and found the molecular ion, ([TNT] $\left.]^{*}, m / z 227\right)$ is the major ion $[8,125,129]$. The DBD ion source, on the other hand, produced $\left([\mathrm{TNT}-\mathrm{H}]^{-}, m / z, 226\right)$ as a major ion and $\left([\mathrm{TNT}]^{-}, m / z 227\right)$ as a minor ion $[11,14,135]$. As a result, it is argued that air-excited plasma produces ([TNT-H]', $m / z$ 226) and/or ([TNB-H $\left.]^{-}, m / z, 212\right)$ ions, whereas solely helium plasma promotes electron attachment processes that produce the molecular ion. To put it another way, as the plasma gas is contaminated by air, the relative intensity of $[\mathrm{M}-\mathrm{H}]^{-}$rises $[11,14,135]$.

\subsection{Pressure dependent negative HCD mass spectra of 2,3-DNT, 2,4-DNT and 2,6-DNT}

Because the dinitrotoluene (DNT) isomers are precursors to TNT, they have been utilized to make TNT, despite the fact that they can be used as explosives directly. Therefore, it is quite likely that DNT isomers will be detected at trace levels. Because they are homologues, the spectrum patterns of the DNT isomers and TNT are identical. The DNT isomers can also be found in the environment as degradation products of TNT and other precursors like 2A-DNT and 4A-DNT. From the standpoints of public security/safety and environmental monitoring, analysis of TNT and its homologues/precursors is required. The gas phase ion-molecule reactions of the DNT isomers were also investigated using the newly fabricated variable pressure HCD ion source.

The pressure dependence negative HCD mass spectra of 2,3-DNT, 2,4-DNT, and 2,6-DNT are shown in Figures 14(a), (b), and (c), respectively. At 1 Torr, all DNT isomers produced the molecular ion $\left([\mathrm{DNT}]^{-\bullet}, \mathrm{m} / \mathrm{z}, 182\right)$ as the primary ion, with a very low intensity fragment ion $\left([\mathrm{DNT}]^{-\bullet}, \mathrm{m} / \mathrm{z}, 152\right)$ as a minor ion. However, as the ion source pressures rise from 1 to 30 Torr, the spectral pattern changes dramatically (Fig. 14a,b,c). As the ion source pressures increase, the intensity of the ion signals decreases. At 5 Torr, 2,3-DNT produced the adduct ion $\left(\left[\mathrm{DNT}+\mathrm{NO}_{3}-\mathrm{HNO}_{2}\right]^{-}, \mathrm{m} / \mathrm{z}, 197\right)$, the fragment ion $\left([\mathrm{DNT}-\mathrm{NO}]^{-}, \mathrm{m} / \mathrm{z}, 152\right)$ as the second highest peak, and ([DNT-H $\left.]^{-}, m / z, 181\right)$ and $\left([\mathrm{DNT}]^{-}, m / z, 182\right)$ as the third highest peaks. The adduct ion, ([DNT+ $\left.\left.\mathrm{NO}_{3}-\mathrm{HNO}_{2}\right]^{-}, m / z, 197\right)$, emerged as the second highest peak in the 2,4-DNT and 2,6-DNT isomers, with ([DNT-H $]^{-}, m / z$ 181) being the main ion (Fig. 14a,b,c).

At 5 Torr, the DNT isomers, like TNT and TNB, produced the molecular ion ([DNT] $]^{\circ}, \mathrm{m} / \mathrm{z}$ 182), fragment ion ([DNT-H] $\left.]^{-}, m / z, 181\right)$, and hydride-adduct ion ([DNT+H]',$\left.m / z 183\right)$. The DNT isomers, however, have distinct ratios of ion intensities for these three ions. 

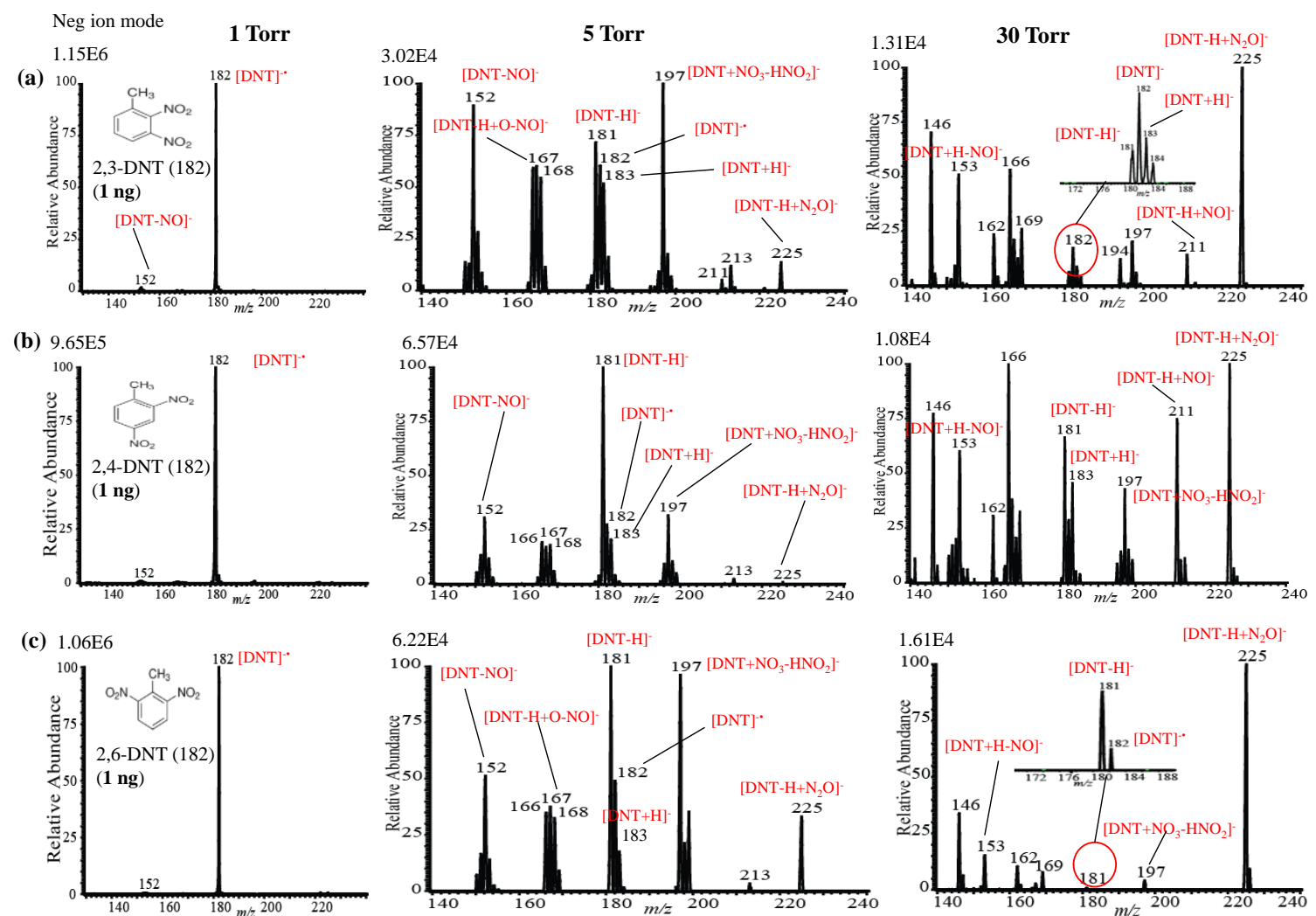

Figure 14. Negative HCD mass spectra of DNT isomers of (a) 2,3-DNT, (b) 2,4-DNT and (c) 2,6-DNT at 1, 5 and 30 Torr. This reprint has been approved by Elsevier [32].

The ion intensities ratios of these three ions, $[\mathrm{DNT}-\mathrm{H}]^{-} /[\mathrm{DNT}]^{-*} /[\mathrm{DNT}+\mathrm{H}]^{-}=1.2 / 1.1 / 1.0$, 5.0/1.3/1.0, and 6.7/3.0/1.0 for 2,3-DNT, 2,4-DNT, and 2,6-DNT, respectively. Because of their differing structures, it is logical to expect this variation in the DNT isomers. The positions of the nitro $\left(-\mathrm{NO}_{2}\right)$ group enhance the benzene ring's reactivity since the methyl $\left(-\mathrm{CH}_{3}\right)$ group is an electron releasing group. The ortho- $\mathrm{NO}_{2}$ (2-position) group enhances the $-\mathrm{CH}_{3}$ group's electron releasing capability for 2,3-DNT, whereas the ortho (2-position) and para (4-position) $-\mathrm{NO}_{2}$ groups activate the $-\mathrm{CH}_{3}$ group for 2,4-DNT, and the two ortho (2- and 6-positions) $-\mathrm{NO}_{2}$ groups activate the $-\mathrm{CH}_{3}$ group for 2,6-DNT. As a result, the fragment ion ([DNT-H] $]^{-}, \mathrm{m} / z$ 181) was identified as a major ion for both the 2,4-DNT and 2,6-DNT isomers (Fig. 14b,c for 5 Torr). Because the para $-\mathrm{NO}_{2}$ group is thought to activate the $-\mathrm{CH}_{3}$ group more than the ortho $-\mathrm{NO}_{2}$ group, the 2,4-DNT produced a strong peak of the fragment ion, ([DNT-H] $]^{-}, \mathrm{m} / \mathrm{z} 181$ ) [32]. The 2,3-DNT and 2,6-DNT isomers, on the other hand, produced strong ion signals for the adduct ion $\left(\left[\mathrm{DNT}+\mathrm{NO}_{3}-\mathrm{HNO}_{2}\right]^{-}, m / z\right.$ 197), whereas 2,4-DNT produced a weak ion signal. Because the main ion in the 2,4-DNT isomer was ([DNT-H] $\left.]^{-}, m / z 181\right)$, it was expected that the abundance of the fragment ion, $\left([\mathrm{DNT}-\mathrm{H}]^{-}, \mathrm{m} / \mathrm{z}, 181\right)$ would allow the formation of a large amount of the adduct ion, ([DNT-H+O $\left.]^{-}, \mathrm{m} / \mathrm{z}, 197\right)$ at 5 Torr [32]. 
The $\left[\mathrm{DNT}-\mathrm{H}+\mathrm{N}_{2} \mathrm{O}\right]^{-}$ion occurred at $\mathrm{m} / z, 225$ as minor ions at 5 Torr, and the ion became the base peak as the ion source pressure was increased from 5 to 30 Torr, resulting in a new peak for the DNT isomers. Unlike TNT and TNB, which have ([TNT+NO $\left.\left.3-\mathrm{HNO}_{2}\right]^{-}, m / z, 242\right)$ and $\left(\left[\mathrm{TNB}+\mathrm{NO}_{3}-\mathrm{HNO}_{2}\right]^{-}, \mathrm{m} / z, 228\right)$ as base peaks at 30 Torr, the DNT isomers produced novel adduct ions, [DNT-H $\left.+\mathrm{N}_{2} \mathrm{O}\right]^{-}$, as major ions at $\mathrm{m} / \mathrm{z}$ 225. Furthermore, 2,3-DNT and 2,4-DNT produced a new peak at $m / z, 211$, which has been designated as [DNT-H+NO] whereas 2,6DNT did not produce any ion signal (Figs. 14a,b,c at 30 Torr). The expanded mass spectrum for the $m / z, 282,281$ and 283 ions is shown in the inset in Fig. 14(a) at 30 Torr. At 30 Torr, the molecular ion ([DNT $]^{-\bullet}, \mathrm{m} / \mathrm{z}$ 182) is still dominant for the 2,3-DNT isomer, although other DNT isomers, including TNT and TNB, are unlikely. The results show that the 2,3-DNT isomer's methyl hydrogen is less acidic than that of the 2,4-DNT and/or 2,6-DNT isomers [32]. The LOD values of the DNT isomers were determined using analytical calibration curves. The LOD values for the 2,3-DNT, 2,4-DNT, and 2,6-DNT were 3.03 $\pm 0.07,3.02 \pm 0.05$ and 3.02 $\pm 0.03 \mathrm{pg}$ for 1 Torr, $15.22 \pm 0.62,8.12 \pm 0.33$, and $8.25 \pm 0.27 \mathrm{pg}$ for 5 Torr, and $50.4 \pm 02.25,40.33 \pm 1.92$, and $40.62 \pm 1.85 \mathrm{pg}$ for 30 Torr, according to the calibration curves [32].

\subsection{Pressure dependent negative HCD mass spectra of 2A-4,6-DNT and 4A-2,6-DNT}

The nitroaromatic compounds 2ADNT and 4ADNT are also used as explosives. The HCD ion source was also used to look into pressure-dependent ion-molecule reactions in the gas phase. The negative HCD mass spectra of 2ADNT and 4ADNT at various ion source pressures are shown in Figures 15(a) and (b). Only 4ADNT, like TNT and TNB, produced a strong molecular ion, [4ADNT] $]^{\bullet}$, which appeared at $\mathrm{m} / z$ 197, but 2ADNT produced the fragment ion, ([2ADNT-H] $]^{-}, m / z$ 196), as a major ion with the molecular ion, ([2ADNT] $\left.{ }^{-*}, m / z, 197\right)$, as a minor ion with an intensity of $47 \%$ (Fig. 15a,b) [32]. The spectral pattern difference between the 2ADNT and 4ADNT is reasonable. This is because the acidic character of the methyl ($\mathrm{CH}_{3}$ ) hydrogen in the 2ADNT and 4ADNT is obviously different, resulting in the formation of the fragment ion ([ADNT-H] $]^{-}, m / z$ 196) in the ADNT with the high acidic character hydrogen. The acidic property of the methyl hydrogen is enhanced by the nitro group $\left(-\mathrm{NO}_{2}\right)$ at position4 (para) in relation to the $-\mathrm{CH}_{3}$ group. Because the amino group at position 2 is basic in nature in comparison to the methyl group, abstracting protons from the $-\mathrm{CH}_{3}$ group and converting the amino group to a quaternary nitrogen cation is facilitated. The quaternary nitrogen cation must be unstable in the HCD plasma severe conditions, therefore a trace amount of $\mathrm{NO}_{3}{ }^{-}$and/or $\mathrm{NO}_{2}{ }^{-}$ions generated at 1 Torr of air pressure leads to the formation of the ([2ADNT-H] $]^{-}, \mathrm{m} / \mathrm{z}$ 196) ion (Fig. 15a) [32]. 
At 5 Torr, both the 2ADNT and 4ADNT amino nitroaromatic compounds produced minor ions with $m / z 227$ and 228 while the ([ADNT-H] $]^{-} m / z$ 196) ion produced major ions. For

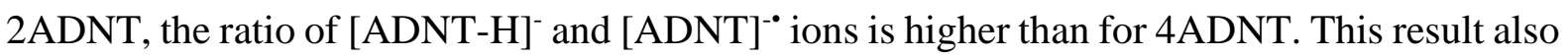
implies that the simple abstraction of protons from the $-\mathrm{CH}_{3}$ group is due to the $-\mathrm{NO}_{2}$ group at para position. TNT was responsible for the emergence of ions with $\mathrm{m} / \mathrm{z} 227$ and 228. At the higher ion source pressure of 30 Torr, both amino nitro aromatic compounds produced ions of $m / z$ 226, 228 and 242 (Fig. 15a,b). At higher ion source pressures, the occurrence of the $\mathrm{m} / \mathrm{z}$ 242 ion from 2ADNT and 4ADNT nitroaromatic compounds is highly fascinating. TNT produced ions of $m / z$ 226, 228 and 242 at 30 Torr, as shown in Figure 12(a). Furthermore, the MS/MS spectra (CID 25\%) for the $m / z 242$ precursor ion yielded ions of $m / z, 212 / 213,182$, 225, and 195 (inset in Fig. 12a). According to these findings, both the 2ADNT and 4ADNT compounds participated in oxidation processes in the HCD harsh plasma, resulting in the formation of TNT molecules in situ. TNT molecules produced in situ then participated in ionmolecule reactions in the ion source. TNB, which could emerge from amino nitroaromatic compounds via photodegradation process, is thought to be responsible for the appearance of the $m / z, 212,213,211$ ions (Fig. 15a,b).
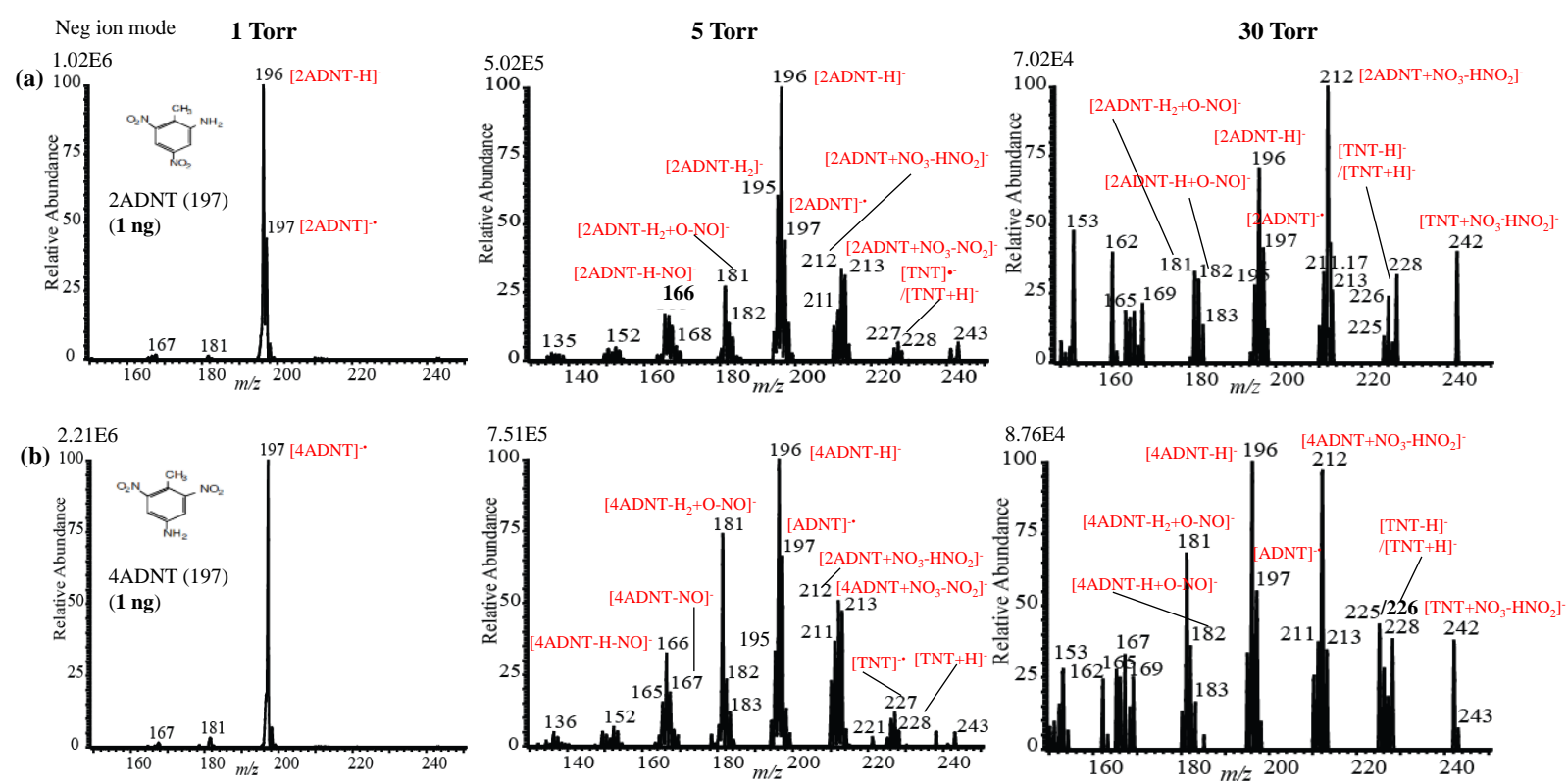

Figure 15. Negative HCD mass spectra of ADNT of (a) 2A-4,6-DNT and (b) 4A-2,6-DNT at 1, 5 and 30 Torr. This reprint has been approved by Elsevier [32].

When the mass spectra of TNB and 2ADNT/4ADNT molecules are compared at 5 and 30 Torr, the spectral pattern for the $m / z 212,213,214$ ions is clearly different. The reason for this is that TNB and 2ADNT/4ADNT have different ratios of 212, 213, and 214.TNB produces [TNB-H] ${ }^{-}$ 
, [TNB] $]^{\bullet}$, and [TNB+H] $]^{-}$, which have $m / z 212,213$, and 214, respectively (Fig. 12b). The ions with the $m / z 212,213$, on the other hand, came from the $m / z 242$ ion as fragment ions, as indicated in the inset in Fig. 12(a) [32]. TNT ions with $m / z$ 212, 211, and 213 appeared as minor ions (Fig. 12a), whereas 2ADNT and 4ADNT ions appeared as major ions (Fig. 15a,b). The formation of adduct ions of the 2ADNT and/or 4ADNT is thought to be responsible for the $\mathrm{m} / \mathrm{z}$ 212 ion, which has been designated as $\left[\mathrm{ADNT}+\mathrm{NO}_{3}-\mathrm{HNO}_{2}\right]^{-}, \mathrm{m} / z, 212$ ).

Both TNT and TNB produced identical adduct ions, ([TNT+NO $\left.\left.3-\mathrm{HNO}_{2}\right]^{-}, m / z, 242\right)$ and $\left(\left[\mathrm{TNB}+\mathrm{NO}_{3}-\mathrm{HNO}_{2}\right]^{-}, m / z, 228\right)$, respectively, as described in the preceding section, and these two adduct ions appeared as major ions at 30 Torr (Fig. 12a,b). At 5 and 30 Torr, 2ADNT and 4ADNT produced the ([ADNT+NO $\left.\left.3-\mathrm{HNO}_{2}\right]-, m / z, 212\right)$ as main ions, similar to TNT and TNB (Fig. 15a,b). Because TNT is the oxidation product of 2ADNT and 4ADNT in the HCD ion source and produces the adduct ion ([TNT $\left.\left.+\mathrm{NO}_{3}-\mathrm{HNO}_{2}\right]^{-}, \mathrm{m} / z, 242\right)$, it must contribute to the ion intensity of the $\mathrm{m} / \mathrm{z} 212$ ion for both amino nitroaromatic compounds, 2ADNT and 4ADNT, by fragmentation. At 30 Torr, the ([ADNT+ $\left.\left.\mathrm{NO}_{3}-\mathrm{HNO}_{2}\right]^{-}, \mathrm{m} / \mathrm{z} 212\right)$ appears as a major ion for 2ADNT (Fig. 15a), but as the second major ion for 4ADNT (Fig. 15b). This is because the 2ADNT offers more ([2ADNT-H] $\left.]^{-}, m / z, 196\right)$ ions than the 4ADNT, making it easier for the 2ADNT to generate more ([ADNT+NO $\left.3-\mathrm{HNO}_{2}\right]^{-}, \mathrm{m} / z$ 212) ions (Fig. 15a for 30 Torr).

The LOD values for $2 \mathrm{ADNT}$ were $4.03 \pm 0.06,10.03 \pm 0.37$, and $50.03 \pm 2.07 \mathrm{pg}$ at 1,5 and 30 Torr [32]. For 4ADNT, the LOD values were $3.03 \pm 0.04,10.03 \pm 0.35$, and $50.03 \pm 2.02 \mathrm{pg}$ at 1, 5 and 30 Torr, respectively. The somewhat higher LOD for 2ADNT (4.03 $\pm 0.06 \mathrm{pg})$ than for 4ADNT $(3.03 \pm 0.04 \mathrm{pg})$ is reasonable. The formation of trace levels of $\mathrm{NO}_{\mathrm{x}}$, which are the principal reactive species in the ion-molecule reactions for the formation of the ([2ADNT-H]', $m / z$ 196) through proton abstraction from the $-\mathrm{CH}_{3}$ group, is caused by the low ion source air pressure (1 Torr). The MALDI-ToF was used to estimate the LOD of ADNT, which was found to be $0.25 \mathrm{ng} / \mathrm{L}[142]$.

\subsection{Negative DBDI mass spectra of TNT and related compounds using headspace method}

To compare the ion-molecule reactions that occur in the DBD and HCD ion sources, DNT isomers were subjected to a homemade helium dielectric barrier discharge (DBD) ion source. Through the headspace approach, gaseous DNT isomers, including TNT, were injected into the DBD ion source. Figure 16 depicts the helium DBD ion source [32]. 
(a)

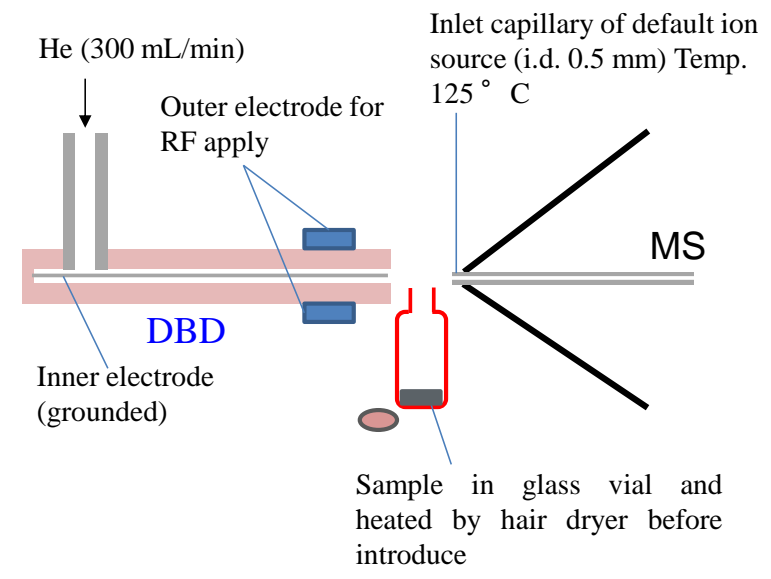

(b)

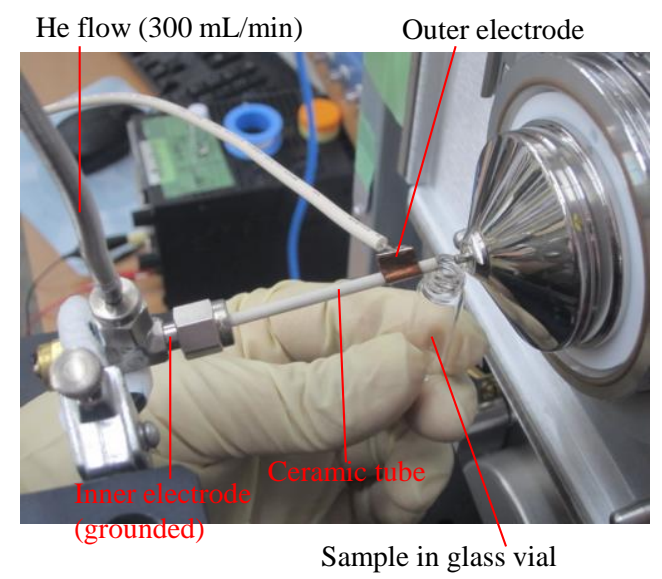

Figure 16. (a) Schematic diagram and (b) Photograph of an experimental setup of a DBD ion source. TNT and its precursors were evaporated from their solution using the headspace method, which involved gently heating the solution with a hair drier. This reprint has been approved by Elsevier [32].

The negative DBDI background mass spectra for lower and higher $m / z$ regions are shown in Figures 17 (a) and (b), respectively. The ion signals for $\mathrm{NO}_{2}^{-}(\mathrm{m} / z 46), \mathrm{CO}_{3}^{-}\left(\mathrm{m} / \mathrm{z}\right.$ 60), $\mathrm{HCO}_{3}{ }^{-}$ $(\mathrm{m} / \mathrm{z} 61)$, and $\mathrm{NO}_{3}{ }^{-}(\mathrm{m} / \mathrm{z}, 62)$ ions are dominant in the lower $\mathrm{m} / \mathrm{z}$ region (Fig. 17a), but only $\mathrm{NO}_{3}{ }^{-}$ $(\mathrm{m} / \mathrm{z}$ 62) appears in the upper $\mathrm{m} / \mathrm{z}$ region (Fig. 17b). In both the lower and upper $\mathrm{m} / \mathrm{z}$ regions, a background ion signal with the $m / z 93$ appeared, along with other ion signals that have yet to be identified [32].

Neg ion mode
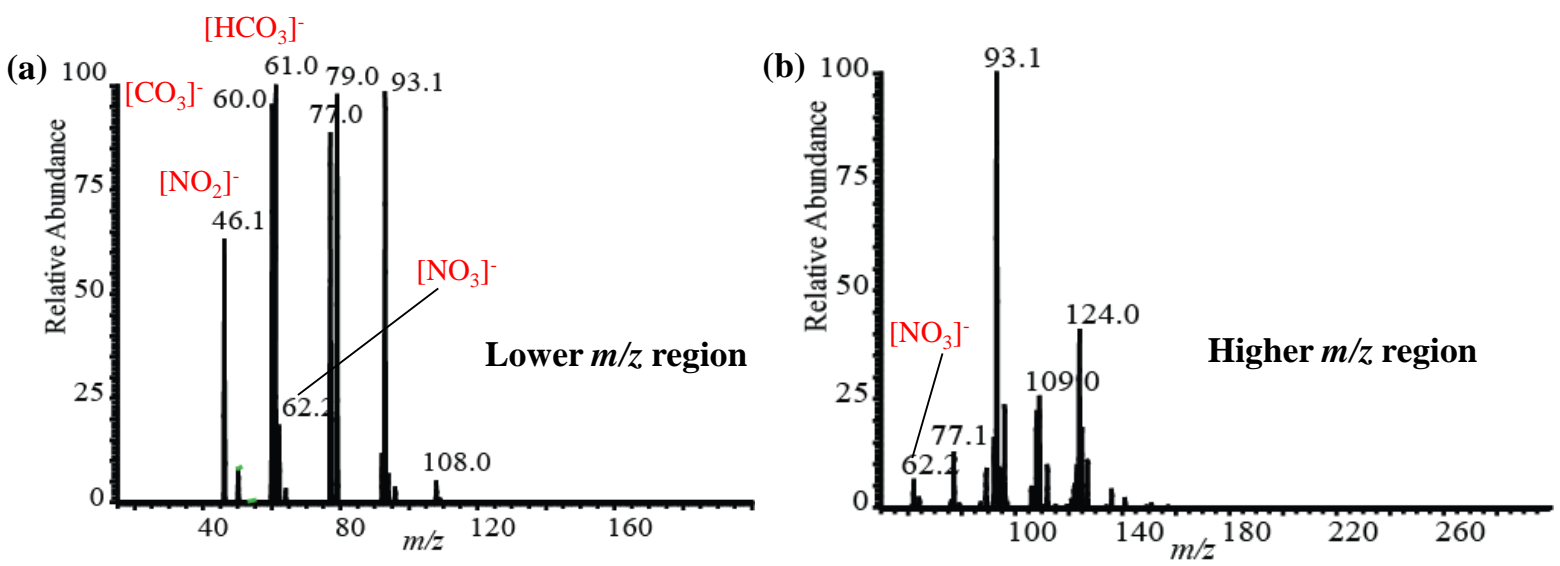

Figure 17. Negative DBDI background mass spectra of (a) lower $\mathrm{m} / \mathrm{z}$ region and (b) upper $\mathrm{m} / \mathrm{z}$ region. This reprint has been approved by Elsevier [32]. 
To investigate the ion formation mechanism of the DNT isomers utilizing DBD as an ion source, 2,3-DNT, 2,4-DNT, 3,4-DNT, and 2,6-DNT including TNT were used as model compounds. Negative DBDI mass spectra of 2,3-DNT, 2,4-DNT, 3,4-DNT, 2,6-DNT, and TNT are shown in Figures 18(a)-(e), respectively. Only 2,4-DNT formed the fragment ion ([DNT$\left.\mathrm{H}]^{-}, m / z, 181\right)$ as a major ion, while the other isomers produced the molecular ion ([DNT] $]^{\bullet}, m / z$ 182) as major ions (Fig. 18a-d). When compared to the molecular ion ([TNT] $]^{-}, m / z 227$ ), the fragment ion ([TNT-H $\left.]^{-}, m / z, 226\right)$ of TNT also appeared as a prominent ion (Fig. 18e). As a result of the DBD ion source producing $\mathrm{NO}_{2}{ }^{-}$and $\mathrm{NO}_{3}{ }^{-}$as reagent ions, these ions must participate in gas phase ion-molecule reactions, abstracting protons from the $-\mathrm{CH}_{3}$ group of TNT, DNT isomers, and 2ADNT/4ADNT and/or the benzene ring, as in TNB. Furthermore, utilizing the helium DBD ion source, no fragment ions were produced by the DNT isomers or TNT. In the investigation of TNT and its precursors, the results reveal that the DBD ion source is substantially softer than the HCD ion source. Finally, it is concluded that the para (4-position) $-\mathrm{NO}_{2}$ group is more effective than the ortho (2- or 6-position) in increasing the acidity of the $\mathrm{CH}_{3}$ hydrogen, whilst the meta (3- or 5-position) may not contribute to the acidity of the $-\mathrm{CH}_{3}$ hydrogen.
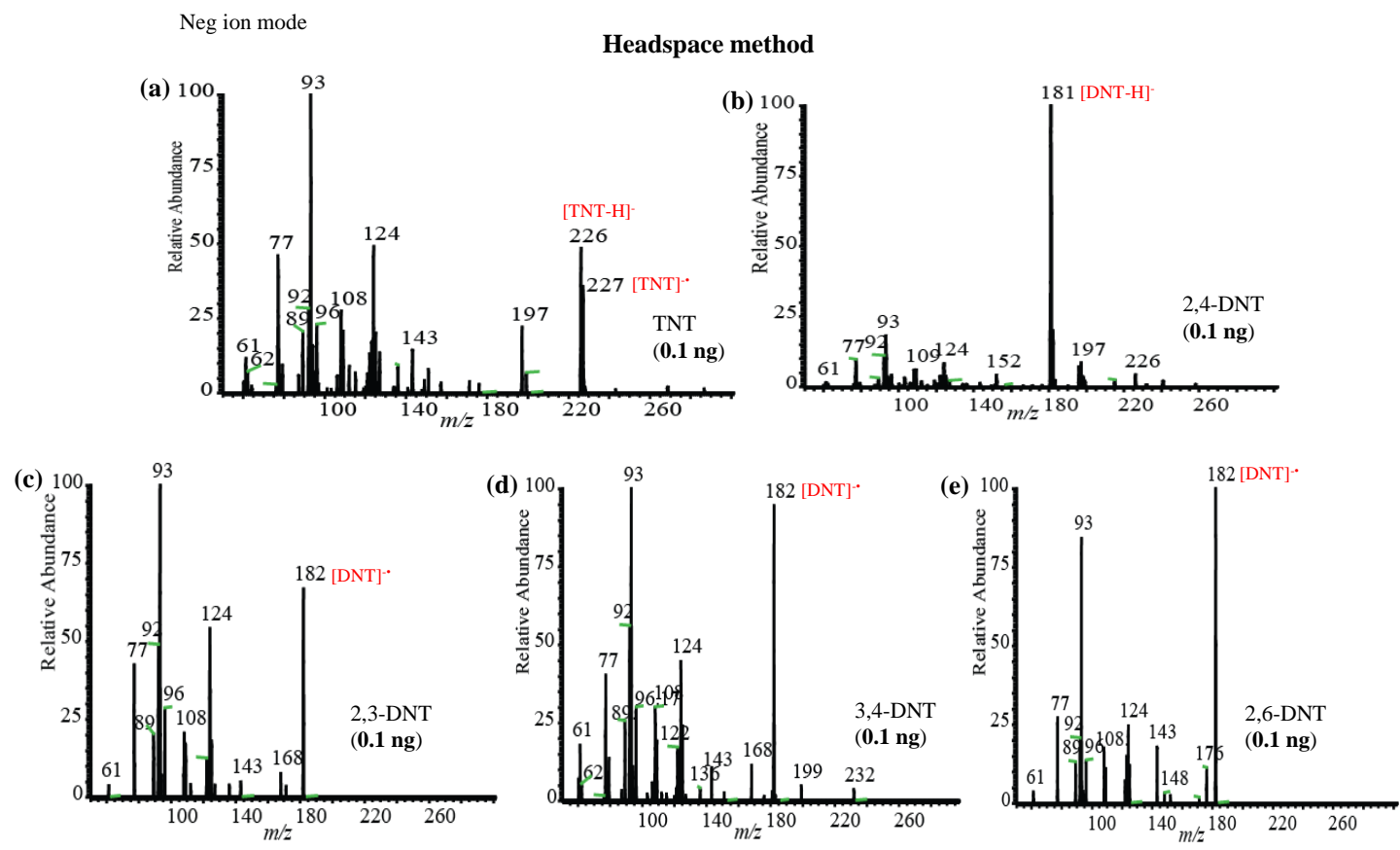

Figure 18. DBDI mass spectra of (a) TNT, (b) 2,4-DNT, (c) 2,3-DNT, (d) 3,4-DNT and (e) 2,6-DNT using headspace method in negative ion mode. This reprint has been approved by Elsevier [32]. 
With the exception of 2ADNT, which produced fragment ions ([2ADNT-H]', $m / z$ 196) as the major ion at 1 Torr, TNT, TNB, 2,3-DNT, 2,4-DNT, 2,6-DNT, and 4ADNT all produced molecular ions, $[\mathrm{M}]^{-\bullet}$, as the major ion. At 5 Torr, TNT, TNB, 2,4-DNT, 2,6-DNT, 2ADNT, and 4ADNT all gave the major ion, [M-H]-, but only 2,3-DNT gave the adduct ions $\left(\left[\mathrm{DNT}+\mathrm{NO}_{3}-\mathrm{HNO}_{2}\right]^{-}, \mathrm{m} / z, 197\right)$. The spectral pattern changed dramatically as the ion source pressure was increased from 5 to 30 Torr. In TNT, TNB, 2ADNT, and 4ADNT, the adduct ions, $\left[\mathrm{M}+\mathrm{NO}_{3}-\mathrm{HNO}_{2}\right]^{-}$, were found to be the major ions, however in the DNT isomers, a new adduct ion $\left(\left[\mathrm{M}-\mathrm{H}+\mathrm{N}_{2} \mathrm{O}\right]^{-}, \mathrm{m} / z\right.$ 225) was detected. The nitroaromatic explosive compounds produced hydride-adduct ions, $[\mathrm{M}+\mathrm{H}]^{-}$, at 5 and 30 Torr. The harsh plasma in the HCD ion source facilitates the formation of hydride-adduct ions by surface-assisted Birch type reduction processes. The LOD values of the nitroaromatic explosive compounds ranged from 1 to $50 \mathrm{pg}$ depending on the ion source pressures. The lower the ion source pressure provided the better the LODs, while the poorer LODs were obtained at the higher the ion source pressure. An airassisted glow discharge can produce a wide range of spectral patterns, which could be beneficial for detecting TNT and TNT-related explosives. As a result, the proposed variable ion source pressure HCD can be used in the real world to detect and quantify nitroaromatic explosives at trace-to ultra-trace levels in combination with an ion trap mass spectrometer using air as a carrier gas.

\section{Conclusion and future outlooks}

The hollow cathode effect has been exploited in the manufacture of hollow cathode lamps for AAS/AES since Friedrich Paschen discovered it in 1916. Lindinger and colleagues used the HCD as an ion source in proton transfer reaction mass spectrometry for the first time. The purpose of this review is to conduct a literature review on the fabrication of a variable-pressure HCD ion source for MS in detection, quantification and investigation of gas phase ionmolecule reactions of explosives and related compounds. The use of air as a carrier gas in the HCD ion source eliminates the need to change reagent gases like He or Ar on a regular basis, making the ion source more practical for MS applications. The HCD ion source has been designed in such a way that it can accurately and simultaneously detect explosives and related substances at trace to ultra-trace levels. The HCD performs well at high ion source pressures (28.0-30.0 Torr), whereas the conventional GD appears at low ion source pressures (0.8-1.0 Torr). At 28-30 Torr, the explosive and related compounds produced ions in both positive and negative modes; however, at 1 Torr, electron attachment/electron capture processes produced exclusively negative ions. In the positive ion mode, HMTD and TATP produced ions 
exclusively at higher ion source pressures (5.0-30.0 Torr), but the ion intensities rose when the ion source pressure was increased from 5.0 to 30.0 Torr. As a result, the fabricated variablepressure HCD ion source can be used in combination with an ion trap mass spectrometer that uses air as a carrier gas to detect and quantify explosives and related compounds at trace-toultra-trace quantities in the real world.

In the future, the developed air-based quasi-ambient HCD ion source could be combined with an ion trap MS to provide a miniature-MS system for detecting illicit chemicals such as explosives, drugs of abuse, and pesticides/herbicides in real-world applications.

\section{Author contributions}

$\mathrm{HH}$ : conceptualization, writing original draft-review, $\mathrm{AH}$ : conceptualization, writing original draft-review, and final review \& editing, LB: conceptualization and funding acquisition. DSQ: final review \& editing, LW: conceptualization, supervision, final review \&editing, and funding acquisition. The published version of the manuscript has been read and approved by all authors.

\section{Funding}

The authors acknowledge the financial support for this work by the National Key Research and Development Program of China (Grant No. 2018YFC0807404), the Yunnan Provincial Key Research and Development Program of China (Grant No. 2018BC011), the Innovative Teams Fund of "3315 Plan" in Ningbo of China (2020A-17-C), the Entrepreneurial and Innovative Leading Team of Panyu District of Guangzhou of China (Grant No. 2017-R01-5) and the K.C. Wong Magna Fund in Ningbo University.

\section{Declaration of competing interest}

There are no competing financial interests declared by the authors.

\section{Acknowledgement}

AH expresses his gratitude to Prof. Kenzo Hiraoka of the University of Yamanashi, Japan for hiring as a postdoctoral fellow for the development of new ion sources for mass spectrometry (2011-2013). This is a brief note to thank specific colleagues, institutions, or agencies for their assistance in the authors' work. 


\section{References}

[1] H. Budzikiewicz, C. Djerassi, D. H. Williams, Structure Elucidation of Natural Products by Mass Spectrometry. Band 1: Alkaloids, Angew. Chem.77 (1965) 392. https://doi.org/10.1002/ange.19650770834.

[2] H. Budzikiewicz, C. Djerassi, D. H. Williams, Structure Elucidation of Natural Products by Mass Spectrometry: Steroids, terpenoids, sugars, and miscellaneous classes,Angew. Chem. 78 (1966) 124. https://doi.org/10.1002/ange.19660780131.

[3] H. Budzikiewicz, C. Djerassi, D. H. Williams, Mass spectrometry of organic compounds, J. Mass Spectrom. 1 (1968) 739-740. https://doi.org/10.1002/oms.1210010512.

[4] W. F.Bryant, T. H.Kinstle, Mass spectroscopy of organic mercury compounds, J. Organomet. Chem. 24 (1970) 573-587. https://doi.org/10.1016/S0022-328X(00)84486-1.

[5] K. Biemann, Structure Determination of Natural Products by Mass Spectrometry, Annu. Rev. Anal. Chem. 8 (2015) 1-19. doi: 10.1146/annurev-anchem-071114-040110.

[6] J. Prichystal, K. A. Schug, K. Lemr, J. Novak, V. Havlicek, Structure analysis of natural $\begin{array}{lllll}\text { products, } & \text { Anal. } & \text { Chem. } & 88 & \text { (2016) }\end{array}$ https://doi.org/10.1021/acs.analchem.6b02386.

[7] S.A. McLuckey, D.E. Goeringer, K.G. Asano, G. Vaidyanathan Jr, J.L. Stephenson, High explosives vapor detection by glow discharge ion trap mass spectrometry, Rapid Commun. Mass Spectrom. $10 \quad$ (1996) 287-298. https://doi.org/10.1002/(SICI)10970231(199602)10:3<287::AID-RCM429>3.0.CO;2-H.

[8] Z. Takáts, I. Cotte-Rodriguez, N. Talaty, H. Chen, R.G. Cooks, Direct, trace level detection of explosives on ambient surfaces by desorption electrospray ionization mass spectrometry, Chem. Commun. (2005) 1950-1952. https://doi.org/10.1039/B418697D.

[9] Y. Song, R.G. Cooks, Atmospheric pressure ion/molecule reactions for the selective detection of nitroaromatic explosives using acetonitrile and air as reagents, Rapid Commun. Mass Spectrom. 20 (2006) 3130-3138. DOI: 10.1002/rcm.2714.

[10] N. Na, M. Zhao, S. Zhang, C. Yang, X. Zhang, Development of a dielectric barrier discharge ion source for ambient mass spectrometry, J. Am. Soc. Mass Spectrom. 18 (2007a) 1859-1862. https://doi.org/10.1016/j.jasms.2007.07.027. 
[11] N. Na, C. Zhang, M. Zhao, S. Zhang, C. Yang, X. Fang, X. Zhang, Direct detection of explosives on solid surfaces by mass spectrometry with an ambient ion source based on dielectric barrier discharge, J. Mass Spectrom. 42 (2007b) 1079-1085. DOI: 10.1002/jms.1243. [12] I. Cotte-Rodríguez, H. Hernandez-Soto, H. Chen, R.G. Cooks, In situ trace detection of peroxide explosives by desorption electrospray ionization and desorption atmospheric pressure chemical ionization, Anal Chem. 80 (2008) 1512-1519. doi:10.1021/ac7020085.

[13] J.D. Harper, N.A. Charipar, C.C. Mulligan, X. Zhang, R.G. Cooks, Z. Ouyang, Lowtemperature plasma probe for ambient desorption ionization, Anal Chem. 80 (2008) 90979104. doi:10.1021/ac801641a.

[14] Y. Zhang, X. Ma, S. Zhang, C. Yang, Z. Ouyang, X. Zhang, Direct detection of explosives on solid surfaces by low temperature plasma desorption mass spectrometry, Analyst 134 (2009) 176-181. http://DOI: 10.1039/B816230A.

[15] J.M. Nilles, T.R. Connell, S.T. Stokes, H.D. Durst, Explosive detection using direct analysis in real time (DART) mass spectrometry, Propellants, Explosives, Pyrotechniques. 35 (2010) 446-451. DOI: 10.1002/prep.200900084.

[16] J.F. Garcia-Reyes, J.D. Harper, G.A. Salazar, N.A. Charipar, Z. Ouyang, R.G. Cooks, Detection of explosives and related compounds by low-temperature plasma ambient ionization mass spectrometry, Anal. Chem. 83 (2011) 1084-1092. doi:10.1021/ac1029117.

[17] Y. Takada, H. Nagano, Y. Suzuki, M. Sugiyama, E. Nakajima, Y. Hashimoto, M. Sakairi, High-throughput walkthrough detection portal for counter terrorism: Detection of triacetone triperoxide (TATP) vapor by atmospheric-pressure chemical ionization ion trap mass spectrometry, Rapid Commun. Mass Spectrom. 25 (2011) 2448-2452. DOI: 10.1002/rcm.5147. [18] A. Habib, D.T. Usmanov, S. Ninomiya, L.C. Chen, K. Hiraoka, Alternative current corona discharge/atmospheric pressure chemical ionization (APCI) for mass spectrometry, Rapid Commu. Mass Spectrom. 27 (2013) 2760-2766. https://doi.org/10.1002/rcm.6744.

[19] R. Sekar, S.K. Kailasa, H.N. Abdelhamid, Y.-C. Chen, H.-F. Wu, Electrospray ionization tandem mass spectrometric studies of copper and iron complexes with tobramycin, Inter. J. Mass Spectrom. 338 (2013) 23-29. https://doi.org/10.1016/j.ijms.2012.12.001.

[20] Y. Su, H. Wanga, J. Liu, P. Wei, R.G. Cooks, O. Zheng, Quantitative Paper Spray Mass Spectrometry Analysis of Drugs of Abuse, Analyst. 138 (2013) 4443-4447. DOI: 10.1039/c3an00934c.

[21] A. Habib, S. Ninomiya, L.C. Chen, D.T. Usmanov, K. Hiraoka, Desorption Mass Spectrometry for Nonvolatile Compounds Using an Ultrasonic Cutter, J. Am. Soc. Mass Spectrom. 25 (2014) 1177-1180: https://doi.org/10.1007/s13361-014-0899-7. 
[22] G. Groeneveld, M. de Puit, S. Bleay, R. Bradshaw, S. Francese, Detection and mapping of illicit drugs and their metabolites in fingermarks by MALDI MS and compatibility with forensic techniques, Sci. Reports 5 (2015) 11716. DOi: 10.1038/srep11716.

[23] A. Habib, L.C. Chen, D.T. Usmanov, Z. Yu, K. Hiraoka, Detection of explosives using a hollow cathode discharge ion source, Rapid Commu. Mass Spectrom. 29 (2015) 601-610. https://doi.org/10.1002/rcm.7142.

[24] Y.-C., Chen, H.N. Abdelhamid, H.-F. Wu, Simple and direct quantitative analysis for quinidine drug in fish tissues, Mass Spectrom. Lett. 8 (2017) 8-13. DOI: 10.5478/MSL.2017.8.1.8.

[25] S. Kumano, H. Nagano, Y. Takada, M. Sugiyama, H. Mizuno, T. Ito, T. Nojiri, Y. Hashimoto, M. Namai, J. Nakamura, Development of evaluation method for explosives trace detection with non-contact sampling, Sci. Tech. Energetic Materials, 79 (2018) 124-130. https://iss.ndl.go.jp/books/R000000004-I029207003-00.

[26] D.T. Usmanov, M.K. Mandal, K. Hiraoka, S. Ninomiya, H. Wada, M. Matsumura, S. Sanada-Morimura, H. Nonami, S. Yamabe, Dipping probe electrospray ionization/mass spectrometry for direct on-site and low-invasive food analysis, Food Chem. 260 (2018) 53-60. doi:10.1016/j.foodchem.2018.04.003.

[27] T.-T. Ng, P.-K. So, B. Hu, Z.-P. Yao, Rapid detection and quantitation of drugs-of-abuse by wooden-tip electrospray ionization mass spectrometry, J. Food Drug Anal. 27 (2019) 428438. https://doi.org/10.1016/j.jfda.2018.09.002.

[28] A. Habib, A. Nargis, L. Bi, P. Zhao, L. Wen, Analysis of amphetaminic drug compounds in urine by headspace- dielectric barrier discharge ionization-mass spectrometry, Arab. J. Chem. 13 (2020) 2162-2170. https://doi.org/10.1016/j.arabjc.2018.04.001.

[29] L. Bi, A. Habib, L. Chen, L. Xu, L. Wen, Ultra-trace level detection of nonvolatile compounds studied by ultrasonic cutter blade coupled with dielectric barrier discharge $\begin{array}{lllll}\text { ionization-mass } & \text { spectrometry, } & \text { Talanta } & 222 & \text { (2021) }\end{array}$ https://doi.org/10.1016/j.talanta.2020.121673

[30] A. Habib, L. Bi, H. Hong, L. Wen, Challenges and Strategies of Chemical Analysis of Drugs of Abuse and Explosives by Mass Spectrometry, Front. Chem. 8 (2021a) 598487. DOI: 10.3389/fchem.2020.598487.

[31] A. Habib, L. Bi, L. Wen, Simultaneous detection and quantification of explosives by a modified hollow cathode discharge ion source, Talanta 233 (2021b) 122596. 10.1016/j.talanta.2021.122596. 
[32] H. Hong, A. Habib, L. Bi, L. Wen, Gas phase ion-molecule reactions of nitroaromatic explosive compounds studied by mass spectrometry, Talanta 236 (2022) 122834. https://doi.org/10.1016/j.talanta.2021.122834.

[33] I. Dalmazio, A. P. F. M. de Urzedo, T. M. A. Alves, R. R. Catharino, M. N. Eberlin, C. C. Nascentes, R. Augusti, Electrospray ionization mass spectrometry monitoring of indigo carmine degradation by advanced oxidative processes, J. Mass Spectrom. 42 (2007) 12731278. DOI: $10.1002 / \mathrm{jms} .1159$.

[34] Z. Han, X. Gu, S. Wang, L. Liu, Y. Wang, Z. Zhao, Z. Yu, Time-resolved in situ monitoring of photocatalytic reactions byprobe electrospray ionization mass spectrometry, Analyst145 (2020) 3313-3319. https://doi.org/10.1039/D0AN00305K.

[35] R. Aebersold, M. Mann, Mass spectrometry-based proteomics, Nature 422 (2003) 198207. https://doi.org/10.1038/nature01511

[36] X. Han, A. Aslanian, J. R. Yates,Mass Spectrometry for Proteomics, Curr. Opin. Chem. Biol. 12 (2008) 483-490.doi: 10.1016/j.cbpa.2008.07.024.

[37] W. J. Griffiths, Y. Wang, Mass spectrometry: from proteomics to metabolomics and lipidomics, Chem. Soc. Rev. 38 (2009)1882-96. doi: 10.1039/b618553n.

[38] C. R. Ferreira, E. G. Lo Turco, S. A. Saraiva et al., Proteomics, Metabolomics and Lipidomics in Reproductive Biotechnologies: The MS Solutions, Acta Sci. Vet. 38 (2010) s591-s603.

[39] Z. Lei, D. V. Huhman, L. W. Sumner, Mass Spectrometry Strategies in Metabolomics, J. Biol. Chem. 286 (2011) 25435-25442. DOI:https://doi.org/10.1074/jbc.R111.238691.

[40] H. C. Köfeler, A. Fauland, G. N. Rechberger, M. Trötzmüller, Mass Spectrometry Based Lipidomics: An Overview of Technological Platforms, Metabolites 2 (2012) 19-38.doi: 10.3390/metabo2010019.

[41] R. Smith, A.D. Mathis, D. Ventura, J.T. Prince, Proteomics, lipidomics, metabolomics: a mass spectrometry tutorial from a computer scientist's point of view, BMC Bioinformatics 15 (2014) S9. http://www.biomedcentral.com/1471-2105/15/S7/S9.

[42] C. L. Feider, A. Krieger, R. J. DeHoog, L. S. Eberlin, Ambient ionization Mass Spectrometry: Recent Developments and Applications, Anal. Chem. 91 (2019) 4266-4290.doi: 10.1021/acs.analchem.9b00807.

[43] D. Raftery, Mass Spectrometry in Metabolomics: Methods and Protocols, Springer, 2014.

[44] S. Alseekh, A., Aharoni, Y. Brotman et al., Mass spectrometry-based metabolomics: a guide for annotation, quantification and best reporting practices. Nat. Methods 18 (2021) 747756. https://doi.org/10.1038/s41592-021-01197-1. 
[45] J. Cai, M. Zheng, C.-Q. Yan, H.-Y. Fu, Y.-J. Zhang, M. Li, Z. Zhou, Y. -H. Zhang, Application and Progress of Single Particle Aerosol Time-of-Flight Mass Spectrometry in Fine Particulate Matter Research, Chin. J. Anal. Sci. 43 (2015) 765-774. https://doi.org/10.1016/S1872-2040(15)60825-8.

[46] L. Ma, M. Li, Z. Huang, L. Li, W. Gao, H. Nian, L. Zou, Z. Fu, J. Gao, F. Chai, Z. Zhou, Real time analysis of lead-containing atmospheric particles in Beijing during springtime by single particle aerosol mass spectrometry, Chemosphere 154 (2016) 454-462. https://doi.org/10.1016/j.chemosphere.2016.04.001.

[47] M. Shariatgorji, P. Svenningsson, P. Andrén, Mass Spectrometry Imaging, an Emerging Technology in Neuropsychopharmacology, Neuropsychopharmacol. 39 (2014) 34-49. https://doi.org/10.1038/npp.2013.215

[48] A. R. Buchberger, K. DeLaney, J. Johnson, L. Li, Mass Spectrometry Imaging: A Review of Emerging Advancements and Future Insights, Anal. Chem. 90 (2018) 240-265.doi: 10.1021/acs.analchem.7b04733.

[49] B. Fan, J. Wang, Y. Xu, J. Chen, Single-Cell Protein Assays: A Review, Methods Mol. Biol. 1754 (2018) 293-309. doi: 10.1007/978-1-4939-7717-8_17.

[50] L. M. Heaney, Advancements in mass spectrometry as a tool for clinical analysis: part II. Clin. Chem. Lab. Med. 58 (2020) 855-857. doi: 10.1515/cclm-2020-0259.

[51] S. Robert, Space Sciences (Mass Spectroscopy applications) In: Mass Spectrometry: Instrumentation, Interpretation, and Applications. 2008, pp. 253-266. DOI: 10.1002/9780470395813.ch11.

[52] C.R. Arkin, T.P. Griffin, J.H. Hoffman, T. Limero, Space Applications of Mass Spectrometry. 2010, Ch. 31, 3-5. https://ntrs.nasa.gov/citations/20100039433.

[53] NASA, Final Report of the International Space Station Independent Safety Task Force, Washington DC, 2007, USA.

[54] A.J. Dempster, Positive Ray Analysis of Lithium and Magnesium, Phy. Rev. 18 (1921) 415-422. doi:10.1103/PhysRev.18.415.

[55] H.M. Fales, G.W. Milne, J.J. Pisano, H.B. Brewer, M.S. Blum, J.G. MacConnell, J. Brand, N. Law, Biological applications of electron ionization and chemical ionization mass spectrometry, Recent Prog. Horm. Res. 28 (1972) 591-626. https://pubmed.ncbi.nlm.nih.gov/4569234/.

[56] H.M. Fales, G.W. Milne, J.J. Pisano, H.B. Brewer, M.S. Blum, J.G. MacConnell, J. Brand, N. Law, Biological applications of electron ionization and chemical ionization mass 
spectrometry, Recent Prog. Horm. Res. $28 \quad$ (1972) 591-626. https://pubmed.ncbi.nlm.nih.gov/4569234/.

[57] A.G. Harrison, Chemical Ionization Mass Spectrometry, Second Edition. CRC Press, 1992.

[58] F.H. Field, Chemical ionization mass spectrometry, Accounts Chem. Res. 1 (2002) 42-49. doi:10.1021/ar50002a002.

[59] M. Barber, R.S. Bordoli, R.D. Sedgwick, A.N. Tyler, Fast atom bombardment of solids as an ion source in mass spectrometry, Nature 293 (1981a) 270-275. doi:10.1038/293270a0.

[60] M. Barber, R.S. Bordoli, R.D. Sedgewick, A.N. Tyler A. N. (1981b). Fast atom bombardment of solids (F.A.B.): a new ion source for mass spectrometry, J. Chem. Soc., Chem. Commun. (1981b) 325-327. doi:10.1039/C39810000325.

[61] M. Barber, R.S. Bordoli, G.J. Elliott, R.D. Sedgwick, A.N. Tyler, Fast Atom Bombardment Mass Spectrometry, Anal. Chem. 54 (1982) 645A-657A. doi:10.1021/ac00241a817.

[62] F.M. Penning, Über Ionisation durch metastabile Atome (On the ionization of metastable atoms), Die Naturwissenschaften (in German). 15 (1927) 818. DOI:10.1007/bf01505431.

[63] C.A. Arango, M. Shapiro, P. Brumer, Cold atomic collisions: coherent control of penning and associative ionization, Phys. Rev. Lett. $97 \quad$ (2006) 193202. doi:10.1103/PhysRevLett.97.193202.

[64] K. Hiraoka, H. Furuya, S. Kambara, S. Suzuki, Y. Hashimoto, A. Takamizawa, Atmospheric-pressure Penning ionization of aliphatic hydrocarbons, Rapid Commun. Mass Spectrom. 20 (2006) 3213-22. doi:10.1002/rcm.2706.

[65] C.K. Meng, M. Mann, J.B. Fenn, Of protons or proteins. Z Phys D - Atoms, Molecules and Clusters 10 (1988) 361-368. https://doi.org/10.1007/BF01384871.

[66] R.D. Smith, C.J. Barinaga, H.R. Udseth, Improved electrospray ionization interface for capillary zone electrophoresis-mass spectrometry. Anal. Chem. 60 (1988) 1948-1952. https://doi.org/10.1021/ac00169a022.

[67] J.B. Fenn, M. Mann, C.K. Meng, S.F. Wong, C.M. Whitehouse, Electrospray ionization for mass spectrometry of large biomolecules, Science 246 (1989) 64-71. DOI: $10.1126 /$ science. 2675315 .

[68] D.C. Gale, R.D. Smith, Small volume and low flow-rate electrospray lonization mass spectrometry of aqueous samples, Rapid Commun. Mass Spectrom. 7 (1993) 1017-1021. DOI: $10.1002 / \mathrm{rcm} .1290071111$. 
[69] Z. Takáts, I. Cotte-Rodriguez, N. Talaty, H. Chen, R.G. Cooks, Direct, trace level detection of explosives on ambient surfaces by desorption electrospray ionization mass spectrometry, Chem. Commun. (2005) 1950-1952. https://doi.org/10.1039/B418697D.

[70] D.R. Justes, N. Talaty, I. Cotte-Rodriguez, R.G. Cooks, Detection of explosives on skin using ambient ionization mass spectrometry, Chem. Commun. 21 (2007) 2142-2144. https://doi.org/10.1039/B703655H.

[71] K. Hiraoka, K. Nishidate, K. Mori, D. Asakawa, S. Suzuki, Development of probe electrospray using a solid needle, Rapid Commu. Mass Spectrom. 21 (2007) 3139-3144. doi:10.1002/rcm.3201.

[72] D.T. Usmanova, S. Saha, L.C. Chen, S. Ninomiya, M.K. Mandal, K. Hiraoka, Probe electrospray ionization (PESI) mass spectrometry with discontinuous atmospheric pressure interface (DAPI), Eur. J. Mass Spectrom. 21 (2015) 327-334. doi:10.1255/ejms.1309.

[73] D.T. Usmanov, M.K. Mandal, K. Hiraoka, S. Ninomiya, H. Wada, M. Matsumura, S. SanadaMorimura, H. Nonami, S. Yamabe, Dipping probe electrospray ionization/mass spectrometry for direct on-site and low-invasive food analysis, Food Chem. 260 (2018) 53-60. doi:10.1016/j.foodchem.2018.04.003.

[74] E.C. Horning, M.G. Horning, D.I. Carroll, I. Dzidic, R.N. Stillwell, New picogram detection system based on a mass spectrometer with an external ionization source at atmospheric pressure, Anal. Chem. 45 (1973) 936-943. DOI:10.1021/ac60328a035.

[75] D.I. Carroll, I. Dzidic, R.N. Stillwell, K.D. Haegele, E.C. Horning, Atmospheric pressure ionization mass spectrometry. Corona discharge ion source for use in a liquid chromatographmass spectrometer-computer analytical system, Anal. Chem. 47 (1975) 2369-2373. doi:10.1021/ac60364a031.

[76] W.C. Byrdwell, Atmospheric pressure chemical ionization mass spectrometry for analysis of lipids, Lipids. 36 (2001) 327-346. DOI:10.1007/s11745-001-0725-5.

[77] R.B. Cody, J.A. Laramee, H.D. Durst, Versatile new ion source for the analysis of materials in open air under ambient conditions, Anal. Chem. 77 (2005) 2297-302. doi: 10.1021/ac050162j.

[78] S. D. Maleknia, T. M. Vail, R. B. Cody, D.O. Sparkman, T. L. Bell, M.A. Adams, Temperature-dependent release of volatile organic compounds of eucalypts by direct analysis in real time (DART) mass spectrometry, Rapid Commu. Mass Spectrom. 23 (2009) 22412246. doi:10.1002/rcm.4133. 
[79] J.M. Nilles, T.R. Connell, S.T. Stokes, H.D. Durst, Explosive detection using direct analysis in real time (DART) mass spectrometry, Propellants, Explosives, Pyrotechniques. 35 (2010) 446-451. DOI: 10.1002/prep.200900084.

[80] M. Karas, D. Bachmann, F. Hillenkamp, Influence of the Wavelength in High-Irradiance Ultraviolet Laser Desorption Mass Spectrometry of Organic Molecules, Anal. Chem. 57 (85) 2935-2939. doi:10.1021/ac00291a042.

[81] M. Karas, D. Bachmann, U. Bahr, F. Hillenkamp, Matrix-Assisted Ultraviolet Laser Desorption of Non-Volatile Compounds, Inter. J. Mass Spectrom. Ion Proc. 78 (1987) 53-68. doi:10.1016/0168-1176(87)87041-6.

[82] M. Karas, U. Bahr, Laser Desorption Ionization Mass Spectrometry of Large Biomolecules, Trends Anal. Chem. 9 (1990) 321-325. doi:10.1016/0165-9936(90)85065-F.

[83] H.N. Abdelhamid, H.-F. Wu, A method to detect metal-drug complexes and their interactions with pathogenic bacteria via graphene nanosheet assist laser desorption/ionization mass spectrometry and biosensors, Anal. Chim. Acta 751 (2012) 94-104. https://doi.org/10.1016/j.aca.2012.09.012.

[84] H.N. Abdelhamid, H.-F. Wu, Furoic and mefenamic acids as new matrices for matrix assisted laser desorption/ionization-(MALDI)-mass spectrometry, Talanta 115, 442-450. https://doi.org/10.1016/j.talanta.2013.05.050.

[85] H.N. Abdelhamid, H.-F. Wu, Gold nanoparticles assisted laser desorption/ionization mass spectrometry and applications: from simple molecules to intact cells, Anal. Bioanal. Chem. 408 (2016) 4485-4502. https://doi.org/10.1007/s00216-016-9374-6.

[86] H.N. Abdelhamid, Z.Y. Chen, H.F. Wu, Surface tuning laser desorption/ionization mass spectrometry (STLDI-MS) for the analysis of small molecules using quantum dots, Anal. Bioanal. Chem. 409 (2017) 4943-4950. https://doi.org/10.1007/s00216-017-0433-4.

[87] H.N. Abdelhamid, Nanoparticle-based surface assisted laser desorption ionization mass spectrometry: a review, Microchim Acta 186 (2019) 682. https://doi.org/10.1007/s00604-019$3770-5$.

[88] Z. Takáts, J.M. Wiseman, B. Gologan, R.G. Cooks, Mass Spectrometry Sampling Under Ambient Conditions with Desorption Electrospray Ionization, Science 306 (2004) 471-473. DOI:10.1126/science.1104404.

[89] I. Cotte-Rodríguez, H. Hernandez-Soto, H. Chen, R.G. Cooks, In situ trace detection of peroxide explosives by desorption electrospray ionization and desorption atmospheric pressure chemical ionization, Anal Chem. 80 (2008) 1512-1519. doi:10.1021/ac7020085. 
[90] D.R. Ifa, C. Wu, Z. Ouyang, R.G. Cooks, Desorption electrospray ionization and other ambient ionization methods: current progress and preview, Analyst 135 (2010) 669-81. doi: 10.1039/b925257f.

[91] R. Javanshad, A.R. Venter, Ambient ionization mass spectrometry: real-time, proximal sample processing and ionization, Anal. Methods 9 (2017) 4896-4907. doi:10.1039/C7AY00948.

[92] J. Shiea, M.-Z. Huang, H.-J. Hsu, C.-Y. Lee, C.-H. Yuan, I. Beech, J. Sunner, Electrospray-assisted laser desorption/ionization mass spectrometry for direct ambient analysis of solids, Rapid Commu. Mass Spectrom. 19 (2005) 3701-3704. doi: 10.1002/rcm.2243.

[93] N. Na, M. Zhao, S. Zhang, C. Yang, X. Zhang, Development of a dielectric barrier discharge ion source for ambient mass spectrometry, J. Am. Soc. Mass Spectrom. 18 (2007a) 1859-1862. https://doi.org/10.1016/j.jasms.2007.07.027.59.

[94] N. Na, C. Zhang, M. Zhao, S. Zhang, C. Yang, X. Fang, X. Zhang, Direct detection of explosives on solid surfaces by mass spectrometry with an ambient ion source based on dielectric barrier discharge, J. Mass Spectrom. 42 (2007b) 1079-1085. DOI: 10.1002/jms.1243. [95] J.D. Harper, N.A. Charipar, C.C. Mulligan, X. Zhang, R.G. Cooks, Z. Ouyang, Low temperature plasma probe for ambient desorption ionization, Anal Chem. 80 (2008) 9097 9104. doi:10.1021/ac801641a.

[96] Y. Zhang, X. Ma, S. Zhang, C. Yang, Z. Ouyang, X. Zhang, Direct detection of explosives on solid surfaces by low temperature plasma desorption mass spectrometry, Analyst 134 (2009) 176-181. http://DOI: 10.1039/B816230A.

[97] L.C. Chen, Z. Yu, H. Furuya, Y. Hashimoto, K. Takekawa, H. Suzuki, O. Ariyada, K. Hiraoka, Development of ambient sampling chemi/chemical ion source with dielectric barrier discharge, J. Mass Spectrom. 45 (2010) 861-869. https://doi.org/10.1002/jms.1772.

[98] J.F. Garcia-Reyes, J.D. Harper, G.A. Salazar, N.A. Charipar, Z. Ouyang, R.G. Cooks, Detection of explosives and related compounds by low-temperature plasma ambient ionization mass spectrometry, Anal. Chem. 83 (2011) 1084-1092. doi:10.1021/ac1029117.

[99] B. Gilbert-López, F.J. Lara-Ortega, J. Robles-Molina, S. Brandt, A. Schütz, D. MorenoGonzález, J.F. García-Reyes, A. Molina-Díaz, J. Franzke, Detection of multiclass explosives and related compounds in soil and water by liquid chromatography-dielectric barrier discharge ionization-mass spectrometry, Anal. Bioanal. Chem. 411 (2019) 4785-4796. doi:10.1007/s00216-019-01627-2.

[100] A.A. Ganeev, M.A. Kuz'menkov, V.A. Lyubimtsev, S.V. Potapov, A.I. Drobyshev, S.S. Potemin, M.V. Voronov, Pulsed discharge in a hollow cathode with the detection of ions in a 
time-of-flight mass spectrometer: Analytical capabilities in the analysis of solid samples, J. Anal. Chem. 62 (2007) 444-453. https://doi.org/10.1134/S1061934807050097.

[101] F. Paschen, Bohr's helium lines, Ann. Phys. 50 (1916) 901. https://doi.org/10.1002/andp.19163551603

[102] P.F. Little, A. von Engel, The hollow-cathode effect and the theory of glow discharges, Proceedings of the Royal Society A 224 (1954). https://doi.org/10.1098/rspa.1954.0152.

[103] H. Helm, Experimental Evidence of the Existence of the Pendel Effect1 in a Low Pressure Hollow Cathode Discharge in Argon, Z. Naturforsch, 27a (1972) 1812-1820. https://doi.org/10.1515/zna-1972-1218

[104] H. Pak, M.J., Kushncr, Simulation of the switching performance of an optically triggered pseudo-spark thyratron, J. Appl. Phys. 66 (1989) 2325-2331. https://doi.org/10.1063/1.344291. [105] G. Schaefer, K.H. Schoenbach, In: Physics and Applications of Pseudosparks, Eds. A. Gundersen, M.A., Schaefer, G., Plenum, New York, 1990, p. 55.

[106] H. Pak, M.J. Kushner, Breakdown characteristics in nonplanar geometries and hollow cathode pseudospark switches, J. Appl. Phys. 71 (1992) 94-100. https://doi.org/10.1063/1.350653.

[107] H. Eichhorn, K.H. Schoenbach, T. Tessnow, Paschen's law for a hollow cathode discharge, Appl. Phys. Lett. 63 (1993) 2481-2483. https://doi.org/10.1063/1.110455.

[108] R.K. Marcus, Glow Discharge Spectroscopies, Plenum Press, New York, 1993.

[109] A. Hansel, A. Jordan, R. Holzinger, P. Prazeller, W. Vogel, W. Lindinger, Proton transfer reaction mass spectrometry: on-line trace gas analysis at the ppb level, Int. J. Mass Spectrom. Ion Processes., 149/150 (1995) 609-619. https://doi.org/10.1016/0168-1176(95)04294-U.

[110] W. Lindinger, A. Hansel, A. Jordan, On-line monitoring of volatile organic compounds at pptv levels by means of proton-transfer-reaction mass spectrometry (PTR-MS). Medical applications, food control and environment research, Int. J. Mass Spectrom. Ion Processes. 173 (1998) 191-241. https://doi.org/10.1016/S0168-1176(97)00281-4.

[111] C.L. Yang, W.W. Harrison, Investigation of a novel hollow cathode configuration for Grimm-type glow discharge emission, Spectrochim. Acta Part B: At. Spectros. 56 (2001) 11951208. https://doi.org/10.1016/S0584-8547(01)00181-1.

[112] D. Zhechev, V.I. Zhemenik, S. Tileva, G.V. Mishinsky, N. Pyrvanova, A hollow cathode discharge modification as a source of sputtered atoms and their ions, Nucl. Instrum. Meth. Phys. Res. Sec. B: Beam Interac. Mater. Atoms 204 (2003) 387-391. https://doi.org/10.1016/S0168-583X(02)01996-1. 
[113] R. Pessoa, B.N. Sismanoglu, J. Amorim, H.S. Maciel, Hollow cathode discharges: low and high-pressure operation. In: Gas Discharges - Fundamentals \& applications (Eds., Amorin, J.), Kerala, Transworld Research Network, 2007.

[114] R.S. Blake, P.S. Monks, A.W. Ellis, Proton-transfer reaction mass spectrometry, Chem. Rev., 109 (2009) 861-896. https://doi.org/10.1021/cr800364q.

[115] T. Gusarova, V.-D. Hodoroaba, R. Matschat, H. Kipphardt, U. Panne, Exploitation of the hollow cathode effect for sensitivity enhancement of Grimm-type DC glow discharge optical emission spectroscopy, J. Anal. At. Spectrom. 24 (2009) 680-684. https://doi.org/10.1039/B814977A.

[116] R. Mavrodineanu, Hollow Cathode Discharges-Analytical applications, J. Res. Nation. Bureau Stand. 89 (2009) 143-185. DOI:10.6028/JRES.089.009.

[117] V. Weinstein, E.B.M. Steers, P. Šmíd, J.C. Pickering, S. Mushtaq, A detailed comparison of spectral line intensities with plane and hollow cathodes in a Grimm type glow discharge source, J. Anal. At. Spectrom., 25 (2010) 1283-1289. https://doi.org/10.1039/C003457F.

[118] D. Ishikawa, S. Hasegawa, Development of Removable Hollow Cathode Discharge Apparatus for Sputtering Solid Metals, J. Spectros. (2019) 7491671. https://doi.org/10.1155/2019/7491671.

[119] J.J. Thomson, G.P. Thomson, Conduction of electricity in gases, Cambridge University Press, 1933.

[120] H. Costa, Via the subsequent delivery electrons through a photoelectric effect in a dependent hydrogen discharge, Z. Phys. 113 (1939) 531-546.

[121] D.A. Skoog, F.J. Holler, S.R. Crouch, Principles of Instrumental Analysis (6th edition), 2006.

[122] A.A. Ganeev, A.I. Drobyshev, A.R. Gubal, N.D. Solovyev, V.A. Chuchina, N.B. Ivanenko, A.S. Kononov, A.D. Titova, I.S. Gorbunov, Hollow Cathode and New Related Analytical Methods, J. Anal. Chem., $74 \quad$ (2019) 975-981. https://doi.org/10.1134/S1061934819100046.

[123] K. Sekimoto, M. Takayama, Negative ion formation and evolution in atmospheric pressure corona discharges between point-to-plane electrodes with arbitrary needle angle, Eur. Phys. J. D 60 (2010) 589-599. https://doi.org/10.1140/epjd/e2010-10449-7.

[124] Y. Takada, Y. Kawaguchi, H. Nagano, Y. Suzuki, Evaluation of false alarm rates of a walkthrough detection portal designed for detecting triacetone triperoxide (TATP) vapour from field test results and receiver operating characteristic (ROC) curves, Int. J. Safety Secur. Eng., 2 (2012) 25-264. DOI: 10.2495/SAFE-V2-N3-256-264. 
[125] H. Chen, B. Hu, Y. Hu, Y. Huan, Z. Zhou, X. Qiao. Neutral desorption using a sealed enclosure to sample explosives on human skin for rapid detection by EESI-MS, J. Am. Soc. Mass Spectrom. 20 (2009) 719-722. https://doi.org/10.1016/j.jasms.2008.12.011.

[126] M. E. Sigman, C.D. Clark, R. Fidler, C.L. Geiger, C.A. Clausen, Analysis of triacetone triperoxide by gas chromatography/mass spectrometry by electron and chemical ionization, Rapid Commun. Mass Spectrom. 20 (2006) 2851-2857. DOI: 10.1002/rcm.2678.

[127] K. Hiraoka, L.C. Chen, T. Iwama, M.K. Mandal, S. Ninomiya, H. Suzuki, O. Ariyada, H. Furuya, K. Takekawa, Development of a remote-from-plasma dielectric barrier discharge ion source and its application to explosives, J. Mass Spectrom. Jpn. 58 (2010) 215-220. https://doi.org/10.5702/massspec.58.215.

[128] K. Hiraoka, Gas-phase ion/molecule reactions, in: K. Hiraoka (Eds.), Fundamentals of Mass Spectrometry, Springer, 2013, chap. 7.

[129] J. Yinon, J. E. McClellan, R. A. Yost, Electrospray ionization tandem mass spectrometry collision-induced dissociation study of explosives in an ion trap mass spectrometry, Rapid Commun. Mass Spectrom. 11 (1997) 1961-1970. https://doi.org/10.1002/(SICI)10970231(199712)11:18<1961::AID-RCM99>3.0.CO;2-K.

[130] E.C. M. Chen, E.S. Chen, The calculation of electron affinities and bond dissociation energies of pesticides and explosives analyzed in negative ion mobility spectrometry, Int. J. Ion Mobility Spectrom. 3 (2002) 11.

[131] J. Cooper, C. D. Grant, J. Zhang, An initio calculation of ionization potential and electron affinity of six common explosive compounds, Rep. Theoret. Chem. 1 (2012) 11-19. DOI https://doi.org/10.2147/RTC.S36686.

[132] K. Nagato, Y. Matsui, T. Miyama, T. Yamauchi, An analysis of the evolution of negative ions produced by a corona ionizer in air, Int. J. Mass Spectrom. 248 (2006) 142-147. https://doi.org/10.1016/j.ijms.2005.12.001.

[133] K. Sekimoto, M. Sakai, M. Takayama, Specific interaction between negative atmospheric ions and organic compounds in atmospheric pressure corona discharge ionization mass spectrometry, J. Am. Soc. Mass Spectrom. 23 (2012) 1109-1119. DOI: 10.1007/s13361-0120363-5.

[134] Y. Takada, H. Nagano, M. Suga, Y. Hashimoto, M. Yamada, M. Sakairi, K. Kusumoto, T. Ohta, J. Nakamura, Detection of military explosives by atmospheric pressure chemical ionization mass spectrometry with counter-flow introduction, Propellants, Explosives, $\begin{array}{lllll}\text { Pyrotechniques. } & 27 & \text { (2002) } & 224-228 . & \text { https://doi.org/10.1002/1521- }\end{array}$ 4087(200209)27:4<224::AID-PREP224>3.0.CO;2-V. 
[135] D.T. Usmanov, S. Ninomiya, K. Hiraoka, Flash desorption/mass spectrometry for the analysis of less- and nonvolatile samples using a linearly driven heated metal filament, J. Am. Soc. Mass Spectrom. 24 (2013) 1727-1735. https://doi.org/10.1007/s13361-013-0711-0.

[136] M. Batley, L. Lyons, Electron Affinities of Organic Molecules. Nature 196 (1962) 573574. https://doi.org/10.1038/196573a0.

[137] A.J. Birch, Reduction by dissolving metals. Part I, J. Chem. Soc. (1944) 430-436. https://doi.org/10.1039/JR9440000430.

[138] A.J. Birch, Reduction by Dissolving Metals, Nature 158 (1946) 585. https://doi.org/10.1038/158585c0.

[139] D.T. Usmanov, L.C. Chen, Z. Yu, S. Yamabe, S. Sakaki, K. Hiraoka, Atmospheric pressure chemical ionization of explosives using alternating current corona discharge ion source, J. Mass Spectrom. 50 (2015) 651-61. doi: 10.1002/jms.3552.

[1140] K. Sekimoto, M. Takayama, Collision-induced dissociation analysis of negative atmospheric ion adducts in atmospheric pressure corona discharge ionization mass spectrometry, J. Am. Soc. Mass Spectrom. 24 (2013) 780-788. DOI: 10.1007/s13361-0130576-2.

[141] B.M. Smirnov, Negative Ions, McGraw-Hill Inc., New York, 1982.

[142] S.L. Kober, H. Hollert, M. Frohme, Quantification of nitroaromatic explosives in contaminated soil using MALDI-TOF mass spectrometry, Anal. Bioanal. Chem. 411 (2019) 5993-6003. https://doi.org/10.1007/s00216-019-01976-y. 